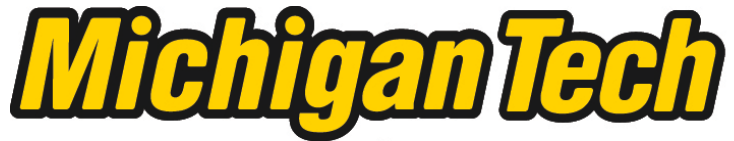 \\ Michigan Technological University Create the Future Digital Commons @ Michigan Tech
}

\section{Evaluating northern hardwood management using retrospective analysis and diameter distributions}

Nan C. Pond

Michigan Technological University

Follow this and additional works at: https://digitalcommons.mtu.edu/etds

Part of the Forest Sciences Commons

Copyright 2012 Nan C. Pond

\section{Recommended Citation}

Pond, Nan C., "Evaluating northern hardwood management using retrospective analysis and diameter distributions", Dissertation, Michigan Technological University, 2012.

https://doi.org/10.37099/mtu.dc.etds/134

Follow this and additional works at: https://digitalcommons.mtu.edu/etds

8 Part of the Forest Sciences Commons 
EVALUATING NORTHERN HARDWOOD MANAGEMENT USING RETROSPECTIVE ANALYSIS AND DIAMETER DISTRIBUTIONS

\author{
By \\ Nan C. Pond
}

\begin{abstract}
A DISSERTATION
Submitted in partial fulfillment of the requirements for the degree of DOCTOR OF PHILOSOPHY

(Forest Science)
\end{abstract}

MICHIGAN TECHNOLOGICAL UNIVERSITY

2012

(c) 2012 Nan C. Pond 
This dissertation, "Evaluating Northern Hardwood Management using Retrospective Analysis and Diameter Distributions," is hereby approved in partial fulfillment of the requirements for the Degree of DOCTOR OF PHILOSOPHY IN FOREST SCIENCE.

School of Forest Resources and Environmental Science

Signatures:

Dissertation Advisor

Dr. Robert E. Froese

Committee Member

Dr. Linda M. Nagel

Committee Member

Dr. David D. Reed

Committee Member

Dr. Gary A. Campbell

Dean

Dr. Terry L. Sharik

Date 
PSALM 111:2 Great are the works of the Lord, studied by all who delight in them.

I dedicate my words and work to the Eternal God, the Creator who made the beautiful hardwoods of Michigan and gave me the capacity to enjoy His work and my own. 


\section{Contents}

List of Figures $\ldots \ldots \ldots \ldots \ldots \ldots \ldots \ldots \ldots \ldots \ldots$ viii

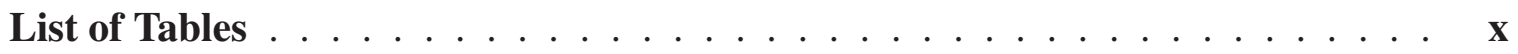

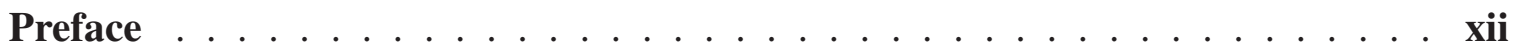

Acknowledgments $\ldots \ldots \ldots \ldots \ldots \ldots \ldots \ldots \ldots \ldots \ldots \ldots \ldots \ldots$ xiii

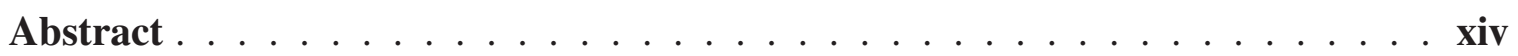

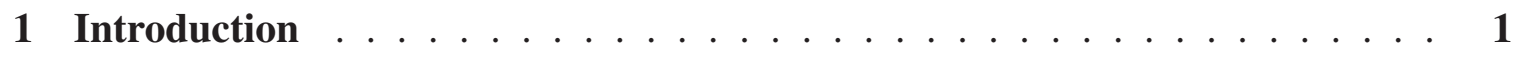

2 Forensic imputation of breast height information . . . . . . . . . 5

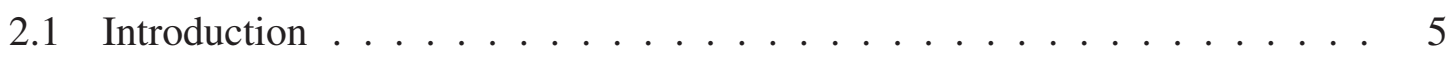

2.1.1 Prediction equations $\ldots \ldots \ldots \ldots \ldots \ldots$

2.2 Methods . . . . . . . . . . . . . . . . . . 10

2.3 Results . . . . . . . . . . . . . . . . . . . . . . . . . 14

2.3.1 Model validation and recalibration . . . . . . . . . . . . 14

2.3.2 Stand-level comparisons . . . . . . . . . . . . . . . . . . . . 19

2.3.3 In cases of timber trespass $\ldots \ldots \ldots \ldots \ldots . \ldots \ldots$

2.4 Discussion . . . . . . . . . . . . . . . . . . . . . . . 22

2.4.1 Models with one predictor . . . . . . . . . . . . 22

2.4.2 Gains from the inclusion of stump height $\ldots \ldots \ldots . \ldots 23$

2.4.3 Tests of equivalence . . . . . . . . . . . . . . . . . 24

2.4.4 Recommendations . . . . . . . . . . . . . . 26 
2.4.5 Whole tree taper equations as an alternative . . . . . . . . . 27

2.5 Conclusions . . . . . . . . . . . . . . . . 27

3 Sustainability of the selection system in northern hardwood forests . . . . . . 29

3.1 Introduction . . . . . . . . . . . . . . . . . 29

3.1.1 Northern hardwood management . . . . . . . . . . . . . 30

3.1.2 Northern hardwood ownership . . . . . . . . . . . . . . 32

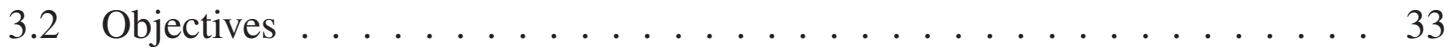

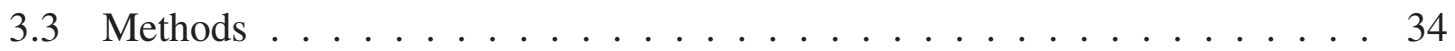

3.3.1 Stand Selection . . . . . . . . . . . . . . . . . 34

3.3.2 Field measurements . . . . . . . . . . . . . . 35

3.3.3 Analytical methods .................. 36

3.3.3.1 Stand management guidelines . . . . . . . . 36

3.4 Results . . . . . . . . . . . . . . . . . 38

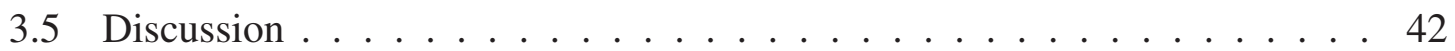

3.5.1 Idealized northern hardwood silviculture . . . . . . . . . . . . . 42

3.5.2 Northern hardwood silviculture in practice . . . . . . . . . . . . . . 44

3.5.3 The relevance of management guidelines . . . . . . . . . . . . 46

3.6 Conclusions . . . . . . . . . . . . . . . . . . . . 48

4 An appraisal of a managed northern hardwood forest landscape with a harvest taxonomy $\ldots \ldots \ldots \ldots \ldots$

4.1 Introduction . . . . . . . . . . . . . . . . . 49

4.1.1 Classification systems . . . . . . . . . . . 51

4.1.2 Description of harvest classifications . . . . . . . . . . . . 54

4.1.2.1 Type 1: Maximized short-term profit, low potential for continued yield (MPLY) . . . . . . . . . . 55

4.1.2.2 Type 2: Maximized short-term profit, some potential for continued yield (MPCY) . . . . . . . . . . 56 
4.1.2.3 Type 3: Maximized sustainable yield (MRSY) . . . . . 57

4.1.2.4 Type 4: Highly selective cut . . . . . . . . . . 58

4.1.2.5 Type 5: High residual, sustainable yield (HRSY) . . . . 58

4.1.2.6 Type 6: Late-successional structural characteristics (LSSC) 59

4.1.2.7 Sanitation cuts (Sub-category) . . . . . . . . . . . 60

4.2 Study Objectives . . . . . . . . . . . . . . . . . . . 61

4.3 Methodology ......................... 61

4.3.1 Field Methodology . . . . . . . . . . . . . . 61

4.3.2 Analytical methodology . . . . . . . . . . . . 62

4.4 Results ........................... 63

4.5 Discussion ............................ 67

4.5.1 Harvest classifications by ownership . . . . . . . . . . . . 67

4.5.2 Future implications . . . . . . . . . . . . . . 69

4.5.3 Influence of plot size on classifications . . . . . . . . . . 71

4.6 Conclusions . . . . . . . . . . . . . . . . . 73

5 Describing northern hardwood stand structure using kernel density estimation and data-driven binning methods $\ldots \ldots \ldots$

5.1 Introduction . . . . . . . . . . . . . . 75

5.1.1 Past use in research and management . . . . . . . . . . 76

5.1.2 Data-driven binning methods . . . . . . . . . . . . . 82

5.2 Goal and objectives . . . . . . . . . . . . . . . . 85

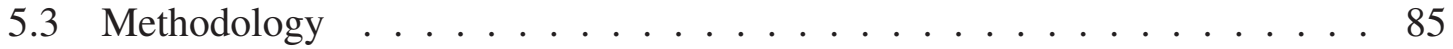

5.4 Results . . . . . . . . . . . . . . . . . . 88

5.4.1 Comparison of binning algorithms . . . . . . . . . . 88

5.4 .2 Kernel Density Estimation . . . . . . . . . . . . 95

5.5 Discussion . . . . . . . . . . . . . . . . . . . . 99

5.5.1 Comparison of binning algorithms . . . . . . . . . . . . . 99 
5.5.2 Application of the polynomial regression-based classification system to histograms constructed with binning algorithms . . . . 100

5.5.3 Kernel density estimation . . . . . . . . . . . . . . 103

5.5.4 Integration and comparison of the regression-based classification and kernel density estimation approaches . . . . . . . . . . 104

5.5.5 Application and limitations of findings . . . . . . . . . . . . 107

5.6 Conclusions . . . . . . . . . . . . . . . . . 108

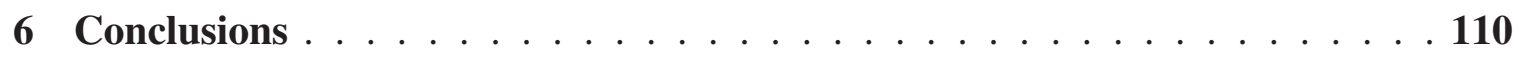

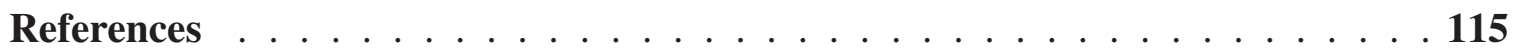

Appendix A Stand locations . . . . . . . . . . . . . 126

Appendix B Fruchterman-Reingold layout . . . . . . . . . . . . . . 128

Appendix C Curve shape classifications by bin width and plot size . . . . . . 129

Appendix D Letters of Permission . . . . . . . . . . . . . . . . . . 136 


\section{List of Figures}

2.1 Results of equivalence tests between measured dbh and predictions from published equations, and between basal area predictions using those

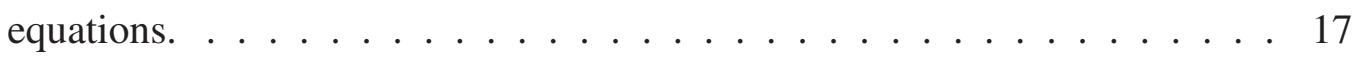

2.2 Results of equivalence tests between dbh predictions from localized equations on all stumps. . . . . . . . . . . . . . . . . 18

2.3 Results of regression-based equivalence tests of all predicted stand level basal area removals. . . . . . . . . . . . . . . . . 20

2.4 Difference in value of removed timber estimated using eight prediction equations at medium site indices, compared to McClure's localized equation form. Positive values indicate estimates larger than the estimates using McClure's form. . . . . . . . . . . . . . . . . 22

3.1 Comparison of pre- and post-harvest levels by ownership . . . . . . . . . . 39

3.2 Pre- and post-harvest stocking in all stands by size class . . . . . . . . . . 40

4.1 Graphical representation of harvest taxonomy . . . . . . . . . . . 53

4.2 Graphical representation of harvest taxonomy, and results, from 96 stands measured in 2010 with $100 \mathrm{~m}^{2}$ plots. . . . . . . . . . . . . . 64

4.3 Harvest classifications by percentage . . . . . . . . . . . . . 65

5.1 Best-fitting curves and one histogram fit to a stand using pre-harvest data from $400 \mathrm{~m}^{2}$ plots . . . . . . . . . . . . . . . . . . 91

5.2 Kernel density estimate of distribution of diameters in one stand, based on pre-harvest data from $400 \mathrm{~m}^{2}$ plots. . . . . . . . . . . . . . . . 92 
5.3 Pre-harvest curve shapes for each stand assigned to histograms of varying binwidth from each binning algorithm, using 2011 data, $400 \mathrm{~m}^{2}$ plots. . . . 94

5.4 Generalized trends in polynomial regression-based classification by binwidth 95

5.5 Network diagram showing pairs of kernel density estimates of pre-harvest stand structures that were not different using 2011 data, $400 \mathrm{~m}^{2}$ plots. . . . 97

5.6 Network diagram showing pairs of stands classified as IQ using the polynomial regression procedure for which kernel density estimates were not different using 2011 data, $400 \mathrm{~m}^{2}$ plots. . . . . . . . . . . . . . 98 


\section{List of Tables}

2.1 Common forms of published stump to breast height prediction equations . . 7

2.2 Common forms of published stump to breast height prediction equations, continued. ........................ 8

2.3 Published northern hardwoods equations used in this study . . . . . . . . 12

2.5 Coefficients for use with McClure's (1968) equation form . . . . . . . . . . 15

$2.4 \mathrm{R}^{2}$ and root mean square error calculated using each equation for each species group. . . . . . . . . . . . . . . . 16

3.1 Target stand structure according to Arbogast (1957) . . . . . . . . . . 37

3.2 Pre-harvest conditions of northern hardwood stands, after Arbogast (1957) . 41

3.3 Post-harvest assessments relative to Arbogast's (1957) marking guide . . . 42

4.1 Abbreviations used for postulated harvest types . . . . . . . . . . 54

4.2 Assessment of published structures using harvest taxonomy . . . . . . . . 63

4.3 Aggregate harvest classifications in 2010 and 2011 . . . . . . . . . 66

4.4 Contingency table of 2010 and 2011 classifications . . . . . . . . . 66

5.1 Method using signs of coefficients in polynomial regression models to determine diameter distribution shape in northern hardwood stands. From Janowiak et al. (2008). . . . . . . . . . . . . . . . . 81

5.2 Optimal binwidths $(\mathrm{cm})$ calculated using each algorithm averaged by algorithm, plot size, and across the dataset. . . . . . . . . . . . . . 89

5.3 Pre-harvest binwidth $(\mathrm{cm})$ summaries by plot size . . . . . . . . . . . . . 89

5.4 Mode number of bins calculated using each binning algorithm . . . . . . . 90 
5.5 Percentage of pre-harvest categorical classification similarity between different algorithms with similar binwidths, $400 \mathrm{~m}^{2}$ plots. . . . . . . . . 93

5.6 Cliques and relationships from network analysis of pre- and post-harvest kernel density estimates using $400 \mathrm{~m}^{2}$ plot data . . . . . . . . . . . . 96

5.7 Percentage of edges connecting vertices with the same named classifications. 99 


\section{Preface}

Chapters within this work include the text of multi-authored journal articles in various stages of preparation, submission, and review. At the time of this writing, no material has been accepted for publication and thus is no chapter is under other copyright. Authorship for the chapters as articles is as follows:

Chapter 2, Forensic imputation of breast height information- all analysis, all figures and tables, and bulk of writing, performed by Nan Pond. Some ideas, direction, and editing contributed by Robert Froese.

Chapter 3, Sustainability of the selection system in northern hardwood forests-all analysis, all figures and tables, and bulk of writing, performed by Nan Pond. Editing and revisions contributed by Robert Froese and Linda Nagel.

Chapter 4, An appraisal of a managed northern hardwood forest landscape with a harvest taxonomy-all analysis, all figures and tables, and bulk of writing, performed by Nan Pond. Editing and revisions contributed by Robert Froese and Linda Nagel.

Chapter 5, Describing northern hardwood stand structure using kernel density estimation and data-driven binning methods -all analysis, all figures and tables, and bulk of writing, performed by Nan Pond. Code for equivalence tests, direction, editing and revisions contributed by Robert Froese. 


\section{Acknowledgments}

With utmost appreciation I thank my advisor, Robert Froese, for your encouragement, flexibility, and support along every step of this process. Thank you also to Linda Nagel, David Reed, and Gary Campbell, for challenging and aiding me throughout this process.

For my husband, Travis Pond, I have nothing but thanks and gratitude for your loving encouragement, gentle insistence on much-needed study breaks, and for always being my terra firma. I love you.

Thank you also to Bryan and Sarah Murray, without whose hospitality and friendship this work would have been a completely impractical dream, and Brian Danielak, for a decade of friendship and three years of invaluable education in the making of ever-better figures (and forgiving me for my code).

Finally, I joyfully acknowledge the absurd cross-disciplinary thinktank that is my family- thank you to Will for always being online; Nora, for answering my random questions and the generous gift of a day of proofreading; Jamie, for teaching me about adjacency matrices; and Russ, Mat, Kirsten and our wonderful parents, for encouragement and welcome distractions. 


\section{Abstract}

Northern hardwood management was assessed throughout the state of Michigan using data collected on recently harvested stands in 2010 and 2011. Methods of forensic estimation of diameter at breast height were compared and an ideal, localized equation form was selected for use in reconstructing pre-harvest stand structures. Comparisons showed differences in predictive ability among available equation forms which led to substantial financial differences when used to estimate the value of removed timber. Management on all stands was then compared among state, private, and corporate landowners. Comparisons of harvest intensities against a liberal interpretation of a well-established management guideline showed that approximately one third of harvests were conducted in a manner which may imply that the guideline was followed. One third showed higher levels of removals than recommended, and one third of harvests were less intensive than recommended. Multiple management guidelines and postulated objectives were then synthesized into a novel system of harvest taxonomy, against which all harvests were compared. This further comparison showed approximately the same proportions of harvests, while distinguishing sanitation cuts and the future productive potential of harvests cut more intensely than suggested by guidelines. Stand structures are commonly represented using diameter distributions. Parametric and nonparametric techniques for describing diameter distributions were employed on pre-harvest and post-harvest data. A common polynomial regression procedure was found to be highly sensitive to the method of histogram construction which provides the data points for the regression. The discriminative ability of kernel density estimation was substantially different from that of the polynomial regression technique. 


\section{Chapter 1}

\section{Introduction}

This work utilizes biometric and silvicultural analyses to describe and appraise northern hardwood harvesting practices in Michigan, and in doing so contributes to a broader understanding of current management practices and the future of managed forests in the Great Lakes region. The northern hardwood forest type is among the most harvested forest type in the Great Lakes region and throughout its range, which includes the northeastern United States and the Acadia and St. Lawrence regions in Canada. Dominant tree species include sugar maple (Acer saccharum), red maple (Acer rubrum), yellow birch (Betula allegheniensis), American basswood (Tilia americana), and American beech (Fagus grandifolia). Much of the area is privately owned by landowners with a wide variety of ownership and management objectives (FIA, 2011). These privately owned tracts are increasingly fragmented (Haines et al., 2011). State landholdings also remain significant in many areas, and corporate management of large areas continues in some regions.

Silviculture in this forest type has been studied throughout its range. Harvesting alters forest structures in ways that have been studied for decades; selection system management, for example, has been the subject of numerous short- and long-term studies (Nyland, 2005; 
Bohn and Nyland, 2006; Erickson et al., 1990). With the average private landholding diminishing, corporate ownership trending away from traditional vertically integrated timber companies, and overall an increasing diversity of landowners and management objectives, identifying stand-level management trends is crucial to understanding the managed forest landscape. Analytical systems to reflect stand structural changes and the impacts of various management approaches are therefore increasingly important (Oliver et al., 1990).

In an assessment of management, post-harvest measurements can be analyzed retrospectively so that one set of measurements represents two points- before and after a harvest. The selection of a stump-to-breast height prediction equation is a critical part of this reconstructive methodology, as misapplication of analytical and statistical techniques hinders precise and accurate description of stands and harvests. The specific quantitative techniques used to fit diameter distribution curves also influence the representation of stand structure. Parametric and nonparametric methods may be used to represent the frequency distribution of diameters within a stand; this attribute of stand structure can be compared to established curve shapes and stand trajectories to approximate the future growth of the stand and its stability over time (Gove et al., 2008; Janowiak et al., 2008; Leak, 1996; Garcia, 1991; Cao and Burkhart, 1984). Diameter distributions are used to represent stand structure quantitatively, as representative of attributes of structural sustainability, and as indicators of old-growth, equilibrium structures (Diaci et al., 2011; Goodburn and Lorimer, 1999; Lorimer and Frelich, 1984). Proper interpretation of the curves requires an accurate understanding of the limitations of and alternatives to historic approaches; reliance on a sensitive or fallible method therefore may result in incorrect conclusions about old-growth stand dynamics and the development of old-growth-like structures through active management.

Quantitative descriptions of stand structure can serve as a springboard for qualitative analyses of the same. Harvests can be compared to published management guidelines 
using reconstructed pre-harvest stand structures to determine removal levels. Published guidelines written to maximize timber production represent only one of numerous possible management objectives, however. A synthesis of other possible management objectives and the characteristics of harvests intended to meet those objectives provides an alternative metric against which to compare managed stands. Together these two qualitative assessments show the differences and similarities among landowners and managers in the region, as well as providing additional insight into the sustainability of future timber production and ecosystem services.

The four parts of this work include a critical assessment of equations that are used to estimate pre-harvest structure from post-harvest stands, assessments of management sustainability against conventional metrics and theorized objectives, comparisons of the differences in management among state, industrial, and nonindustrial private landowners, and a test of parametric and nonparametric curves used to describe stand structure.

Motivating research questions stimulated exploration of these various attributes of the managed landscape in Michigan, in the broader context of silviculture of the northern hardwood forest type. Specific hypotheses were that there would be financial differences between volume and value estimates generated using available equations with published and localized coefficients. In the construction of histograms to represent stand structure, it was expected that data-driven binning methods would produce varied results and smaller bin widths than the $5 \mathrm{~cm}$ ( 2 inch) bins most commonly used. Testing of a common parametric procedure used to differentiate and name the shapes of diameter distributions curves was expected to show that it was sensitive to the binwidth of the histogram underlying the procedure. Furthermore, it was expected that the discrimination among curves using that procedure would differ from tests for differences between kernel density estimates for each stand.

The silvicultural analyses were conducted to determine whether the majority of stands 
were harvested in a manner reflecting the ubiquitous and respected management guideline published by Arbogast (1957) from the work of Eyre and Zillgitt (1953), as is widely assumed to be the case (Nyland, 2003; Goodburn and Lorimer, 1999; Niese and Strong, 1992; Tubbs, 1977). It was expected that most harvests would resemble the recommended management, with minor differences in management among state, private industrial, and nonindustrial private owner types. It was postulated that likely differences would include that private industrial ownerships harvest more intensely, nonindustrial private management varyies widely, and state lands are managed for sustainable production of sawtimber. However, because Arbogast (1957) reflects management solely for the production of sawtimber, a system of harvest taxonomy was developed; this was hypothesized to be an accurate representation of probable objectives. Management for alternate objectives was further tested through the use of this tool. The same differences in management by owner type were expected to be found through the use of this more detailed metric. 


\section{Chapter 2}

\section{Forensic imputation of breast height information}

\subsection{Introduction}

Selection of an accurate model to estimate tree diameter from stump diameter is crucial for the reconstruction of pre-harvest stems and stand structure from post-harvest data. Small differences in diameter predictions are likely magnified into substantial differences in basal area, volume, and value. In instances of timber trespass, when a harvest deliberately or accidentally crosses ownership boundaries, inaccurate dbh estimation will impact the prediction of the volume of removed timber and the assigned dollar value of the cut trees (Bylin, 1982; Westfall, 2010). Similarly, measurements of trees and stumps can be used to recreate pre-disturbance or historic conditions, where errors in diameter predictions result in an inaccurate reconstruction of stand history (Oliver and Stephens, 1977; Naficy et al., 2010). The multiplicative relationship between $\mathrm{dbh}$ and volume is such that a minimal bias in dbh leads to a larger bias in volume- for example, a $10 \%$ difference in dbh prediction 
can become a $20 \%$ difference or more in an estimate of volume.

A survey of the literature shows that numerous equations have been developed, most for specific regions of North America, though also for species and regions of other continents. There are often multiple equations of different forms available for a given region, raising the questions of how the ideal prediction equation is selected and what the ramifications of choosing a given equation may be. I present a summary of the forms of published prediction equations, describing the historical development of such equations and the relationship between breast height prediction and prediction of merchantable volume. I further discuss the similarities between describing the taper of the stump of a tree and the taper of the entire stem of a tree.

\subsubsection{Prediction equations}

Most published prediction equations were specifically developed for species or species groups in a certain country or region (Table 2.1). Equations range in complexity, with the general trend being that the more recent equations are more complex. The most simplistic include calculation of ratios for diameter classes (Horn and Keller, 1957) and simple linear regression (Bones, 1960). 


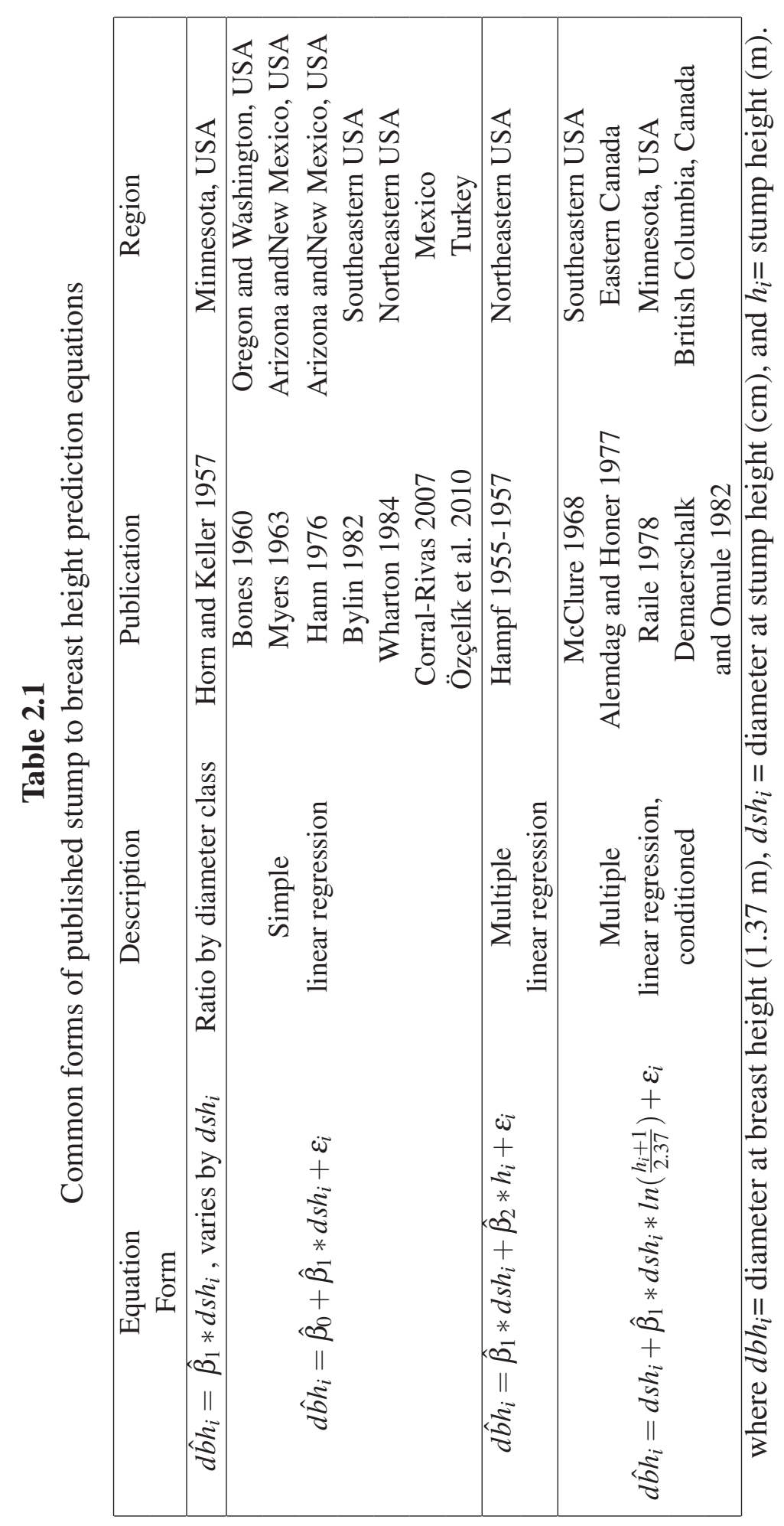




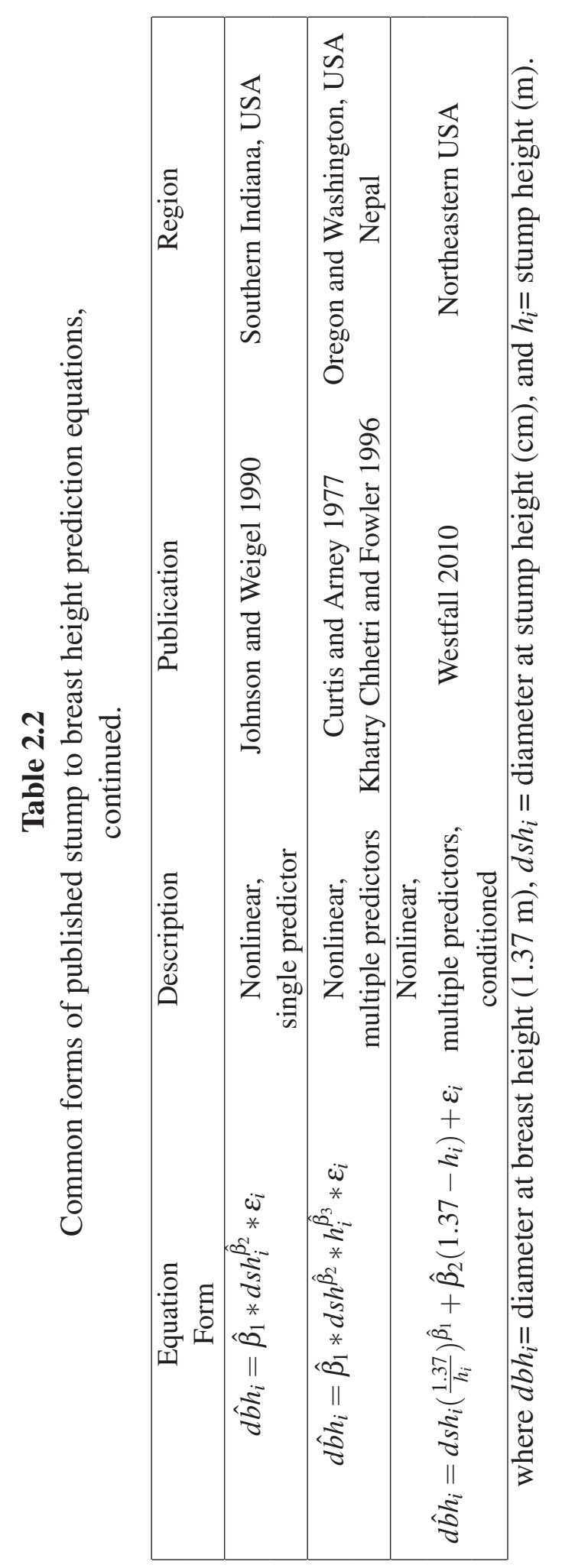


Multiple linear regressions include both diameter at stump height (dsh) and stump height as predictors. McClure (1968), Wiant and Williams (1987), and Raile (1978) published related multiple linear regression equations for different regions of the United States. With the exception of Hampf's (1955) series of equations, all multiple linear regression equations in Table 2.1 included logarithmic transformations of stump height. Raile's equation is inexplicably conditioned to overpredict diameter when stump height equals breast height. His published equation form is a variation of an equation for prediction of dbh of southeastern US tree species (McClure, 1968), which is properly conditioned so that predicted diameter equals stump diameter when stump height equals breast height.

Published nonlinear equations include those with single variables, such as Johnson and Weigel (1990), and multivariate equations, such as those developed by Khatry Chhetri and Fowler (1996) and Westfall (2010). In most equations the variables are the bases raised to the power of a coefficient, and are linearizable by transformation. Westfall's (2010) equation includes both absolute and relative stump height, as well as dsh, as predictors. This equation, like those of Demaerschalk and Omule (1982), McClure (1968), and Alemdag and Honer (1977), effectively conditions the model such that dbh equals dsh when stump height equals breast height. Westfall's equation also includes an error variance formulation to correct for an observed heteroscedasticity in the errors, with variance increasing with increasing $\mathrm{dsh}$, and includes a mixed-effects model to account for within-tree correlation specific to his calibration data.

The inclusion of stump height is a key difference between available models. Corral-Rivas et al. (2007) suggest that when stump height is constant, as it was in their data, it is not necessary to include in the model. Where stump height is varied, however, the height at which a stump is measured may be important in estimating the amount of taper between that point and breast height.

Stump to breast height modelling shares strong similarities with tree taper modelling. In 
both cases an unknown diameter is predicted from a known diameter; the main difference is that in the case of a taper equation tree height is known. This provides an additional data point; at the top height of a tree, the diameter is equal to zero. Studies of tree taper have found that the butt portion of a tree can be best approximated as the frustrum of a neiloid (Max and Burkhart, 1976: Walters et al., 1986; Sharma and Burkhart, 2003). Prediction of the diameter at any height of a neiloid requires two known diameters and heights (Walters et al., 1986). The shape of a neiloid clearly shows the curvalinear relationship between diameter and height.

The goals of this work were first, to compare the predictive accuracy of published stump to breast height predictive models, to estimate accuracy and precision; second, to test through recalibration the contribution of stump height as a predictor and the effect of model conditioning; and third, to determine predictive similarities between equation forms at the stem and stand level using equivalence testing. The final goal was to demonstrate practical differences among equation forms and localizations through a comparison of the volume removal and dollar value of hypothetical timber trespass estimated from different diameter predictions.

\subsection{Methods}

We used an extensive data set from recently harvested northern hardwood stands that were measured during the summer of 2010. Northern hardwood (maple-beech-birch) forests are a valuable natural resource in the northeastern and Great Lakes regions of the United States, providing both high-quality timber and important non-timber ecosystem services. These forests are dominated by tree species including sugar maple (Acer saccharum), red maple (Acer rubrum), American basswood (Tilia americana), yellow birch (Betula allegheniensis) and American beech (Fagus grandifolia). Forests of this type are not 
only significant land cover, but also the source of much of Michigan's harvested timber (FIA, 2011). Stands were sampled from among the holdings of the three largest corporate landowners in the state of Michigan, non-industrial private landowners identified by consulting foresters, and open state timber sales. Ninety-six stands harvested within the past six years were identified throughout the state, which has a wide latitudinal and longitudinal range (see Appendix A for stand locations). The sampled area therefore includes a substantial range of growing conditions for each species.

In each stand, ten circular $100 \mathrm{~m}^{2}$ (0.0247 acre) plots were randomly located. Species and dbh were measured for all trees over $10 \mathrm{~cm}$ (3.94 in) dbh. Stump diameter and height were measured and recorded for trees selected so that the number and species of stump diameters measured on standing trees matched or exceeded the number of stumps of each species measured in a plot, whenever possible. All stumps appearing to have been cut in the most recent harvest were also measured (decay classes 1-3, after Thomas, 1979). Species, diameter of the cut surface (the average of two perpendicular diameters), and stump height were recorded for each stump. This resulted in a fitting dataset comprised of standing trees on which stump height, dsh, and dbh were measured, and a predictive dataset of stumps on which dsh and stump height were measured.

In our literature review, we identified five published equations that were calibrated for this region and forest type (Table 2.3). These included a model of ratios by size class (Horn and Keller, 1957), a simple linear regression equation (Wharton, 1984), a conditioned multiple linear regression (Raile, 1978), and a nonlinear multiple regression conditioned so that dbh equals dsh when stump height is 4.5 feet (Westfall, 2010). All equations had species-specific coefficients for most of the species in our dataset, and provided "generic" coefficients for other species. Raile's (1978) equation form was used as published with published coefficients, and also with proper conditioning after McClure (1968). For the sake of clarity the properly conditioned form will be referred to as McClure's. 
Table 2.3

Published northern hardwoods equations used in this study

\begin{tabular}{|ll|}
\hline Equation form & Publication \\
\hline$d \hat{b} h_{i}=\hat{\beta}_{0} * d s h_{i}, \beta_{0}$ varies with $d s h_{i}$ & Horn and Keller \\
& 1957 \\
\hline$d \hat{b} h_{i}=\hat{\beta}_{0}+\hat{\beta}_{1} * d s h_{i}+\varepsilon_{i}$ & Wharton 1984 \\
\hline$d \hat{b} h_{i}=d s h_{i}\left(\hat{\beta}_{1}+\hat{\beta}_{2}\left(\log \left(h_{i}+1\right)-\log (2.37)\right)+\right.$ & McClure $1968^{*}$ \\
$\left.\hat{\beta}_{3}\left(h_{i}-1.37\right)\left(d s h_{i}\right)\right)+\varepsilon_{i}$ & \\
$\hat{\beta}_{1}=1$ & Raile $1978^{\dagger}$ \\
$d \hat{b} h_{i}=d s h_{i}\left(\hat{\beta}_{1}+\hat{\beta}_{2}\left(\log \left(h_{i}+1\right)-\log (2.37)\right)+\right.$ & \\
$\left.\hat{\beta}_{3}\left(h_{i}-1.37\right)\left(d s h_{i}\right)\right)+\varepsilon_{i}$ & \\
$\hat{\beta}_{1} \neq 1$ & Westfall 2010 \\
\hline$d \hat{b} h_{i}=d s h_{i}\left(\frac{1.37}{h_{i}}\right)^{\hat{\beta}_{0}}+\hat{\beta}_{1}\left(1.37-h_{i}\right)+\varepsilon_{i}$ & \\
\hline
\end{tabular}

*Correct conditioning of Raile's published variant of McClure's equation form $\dagger$ Raile's variant of McClure's equation form, as published

To validate existing models, predictions were made using the species groupings used by each author. For use of Wharton's equation with published coefficients, diameter outside bark was converted to diameter inside bark using bark factor equations from the Forest Vegetation Simulator Lake States Variant (Dixon and Keyser, 2008). For recalibration, species groups were assigned following Scott (1981); these are the groups used in the U.S. Forest Inventory and Analysis National Program and the composition of the species groups fit well with the distribution of species in our dataset. Equations were re-fit for all species groups representing $2 \%$ or greater of the fitting data set, a total of seven species groups.

Ratios of dbh as a percentage of dsh were developed for each $2.54 \mathrm{~cm}$ stump diameter class, following the methodology of Horn and Keller (1957). The equations from Wharton, Raile, and McClure were refit to the local data using linear regression techniques in $\mathrm{R}$, using the same predictors and transformations as the published equation forms. For those species not falling into the seven species groups most common to our fitting dataset, generic coefficients were calculated for use with McClure's (1968) conditioning of the equation 
form.

Westfall's equation was re-fit with a nonlinear generalized least squares approach, using the nlme package of R (Pinheiro et al., 2010). Coefficients provided by Westfall (2010) were used as starting values. Increasing variance with increasing dbh was accounted for using weights, in keeping with Westfall's approach. Mixed-effects modelling was not used, because the strong within-tree grouping in Westfall's (2010) study was not present in my dataset. Patterns of residuals, descriptive statistics, and inherent characteristics of the models were used to compare the best-fitting prediction equation for the dataset. Descriptive statistics calculated for each equation and species group included mean residual (bias), absolute mean residual, $\mathrm{I}^{2}$ (equivalent to $\mathrm{R}^{2}$ for local coefficients), and root mean square error (RMSE). Basal area $\left(\mathrm{m}^{2} \mathrm{ha}^{-1}\right)$ removal for all species in the 96 stands was also calculated using each of the nine equations.

Regression-based equivalence testing was conducted to assess the overall predictive ability of two models, or a model against fitting data (tests of the intercept), and to test the variability of individual point predictions against a threshold of allowable variation (tests of the slope). This approach uses a null hypothesis of dissimilarity rather than similarity between models, with the test indicating whether two sets of predictions are similar. Robinson et al. (2005) describe the framework for testing the slope and intercept of a linear regression of one set of model predictions on another (see also Robinson and Froese, 2004 and Wellek, 2010 for further detail). We utilized the two-one-sided test (Wellek's "double one-sided testing procedure"), in which two one-sided confidence intervals are constructed around the slope and intercept of the model. This interval is compared to a previously established region of indifference; if the confidence intervals about the metric from the model are contained within the region of indifference, the null hypothesis is rejected. For the test of the intercept, an indifference interval of $\pm 0.25 \mathrm{~cm}$ was used, corresponding to the acceptable error tolerance for diameter measurements in US FIA data collection. For tests of the slope, a $10 \%$ error tolerance $( \pm 0.1)$ was estimated to be an "acceptable" level 
of error for field foresters. Equivalence tests performed included measured dbh against predicted dbh, localized predictions of dbh against one another, and stand level basal area removals calculated with each equation against one other, to determine the relative impact of small differences in dbh prediction on the calculation of basal area.

Four stands were selected to test the application of prediction equations to hypothetical cases of timber trespass. Two stands were chosen that had above average pre-harvest sugar maple importance values, and two that had lower sugar maple importance and more harvested species. Estimates were made following the protocol described by Simpson and Wiant (1992) and Avery and Burkhart (2002). This protocol requires that prediction equations be used to estimate dbh from dsh, volume equations be used to estimate volumes from diameters, and then stumpage prices be used to determine the value of removed timber. Volumes of sawtimber and pulpwood were estimated using equations developed by Raile et al. (1982) for each species. Value estimates came from publicly available stumpage price reports (Michigan Department of Natural Resources, 2011). Because all harvests were completed by 2010 , the average sale price for each species and product for the 12-month span of October 2008-September 2009 was used.

\subsection{Results}

\subsubsection{Model validation and recalibration}

The best-fitting equation forms for most species groups were McClure (1968) and Raile (1978) (Table 2.4). For American beech and birch species, predictions from Westfall's (2010) equation resulted in a higher $\mathrm{I}^{2}$ and lower RMSE. The two equation forms without stump height as a predictor had lower $\mathrm{I}^{2}$ values, though still over 0.95 for most species 
groups. The localization of Raile's (1978) equation and McClure's equation form had the highest, and in most cases identical, $\mathrm{R}^{2}$ for all species except red maple; the lowest RMSE varied between Raile's and McClure's equation forms. The coefficients from fitting McClure's equation for the most common species groups are provided in Table 2.5.

Table 2.5

Coefficients for use with McClure's (1968) equation form

\begin{tabular}{|ccccc|}
\hline \multicolumn{5}{c|}{ Equation form } \\
$d \hat{b} h_{i}=d s h_{i}\left(\hat{\beta}_{1}+\hat{\beta}_{2}\left(\log \left(h_{i}+1\right)-\log (2.37)\right)+\hat{\beta}_{3}\left(h_{i}-1.37\right)\left(d s h_{i}\right)\right.$ \\
\hline Species Group & $b_{1}$ & $b_{2}$ & $b_{3}$ & $\mathrm{n}$ \\
\hline balsam fir & 1 & 0.1390609 & -0.0002686 & 135 \\
sugar maple & 1 & 0.0999197 & 0.0001411 & 2768 \\
poplars, ashes & 1 & 0.128442 & -0.0000055 & 112 \\
birches & 1 & 0.1127746 & 0.0002942 & 129 \\
Am. beech & 1 & 0.1292612 & -0.0001483 & 223 \\
Am. basswood & 1 & 0.0847785 & 0.0001932 & 111 \\
red maple & 1 & 0.0936072 & 0.0001396 & 361 \\
generic coefficients & 1 & 0.1003032 & 0.0001827 & 4384 \\
\hline
\end{tabular}

The distributions of stump heights in the fitting and predictive datasets were tested using a two-sample Kolmogorov-Smirnov test and found to be differ $(\mathrm{D}=0.0993, \mathrm{p}<0.001)$. A visual comparison of the distributions showed that the predictive dataset includes more stumps measured at higher stump heights (data not shown). Equivalence testing showed that in the tests of the intercepts, the null hypothesis of dissimilarity was not rejected for all comparisons of equations using published coefficients, and for almost all equations using localized coefficients (Figures 2.1, 2.2). The null hypothesis was rejected for comparison of the intercepts of McClure's equation to Westfall's localized equation. Tests of the intercept represent tests in the overall predictive differences of the models; tests of the slopes compare individual point predictions. In all cases, the null hypothesis of dissimilarity in slopes was rejected. 


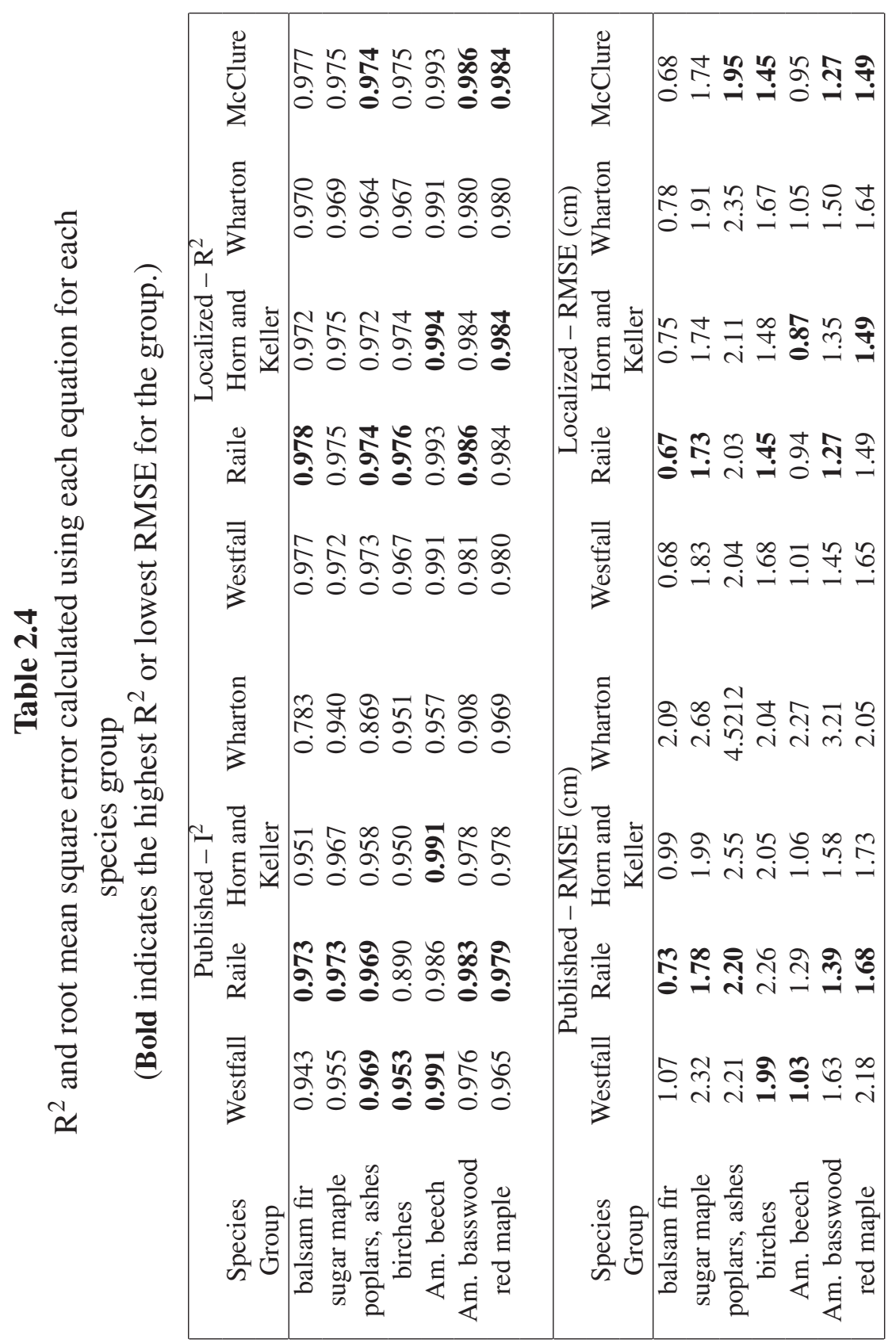



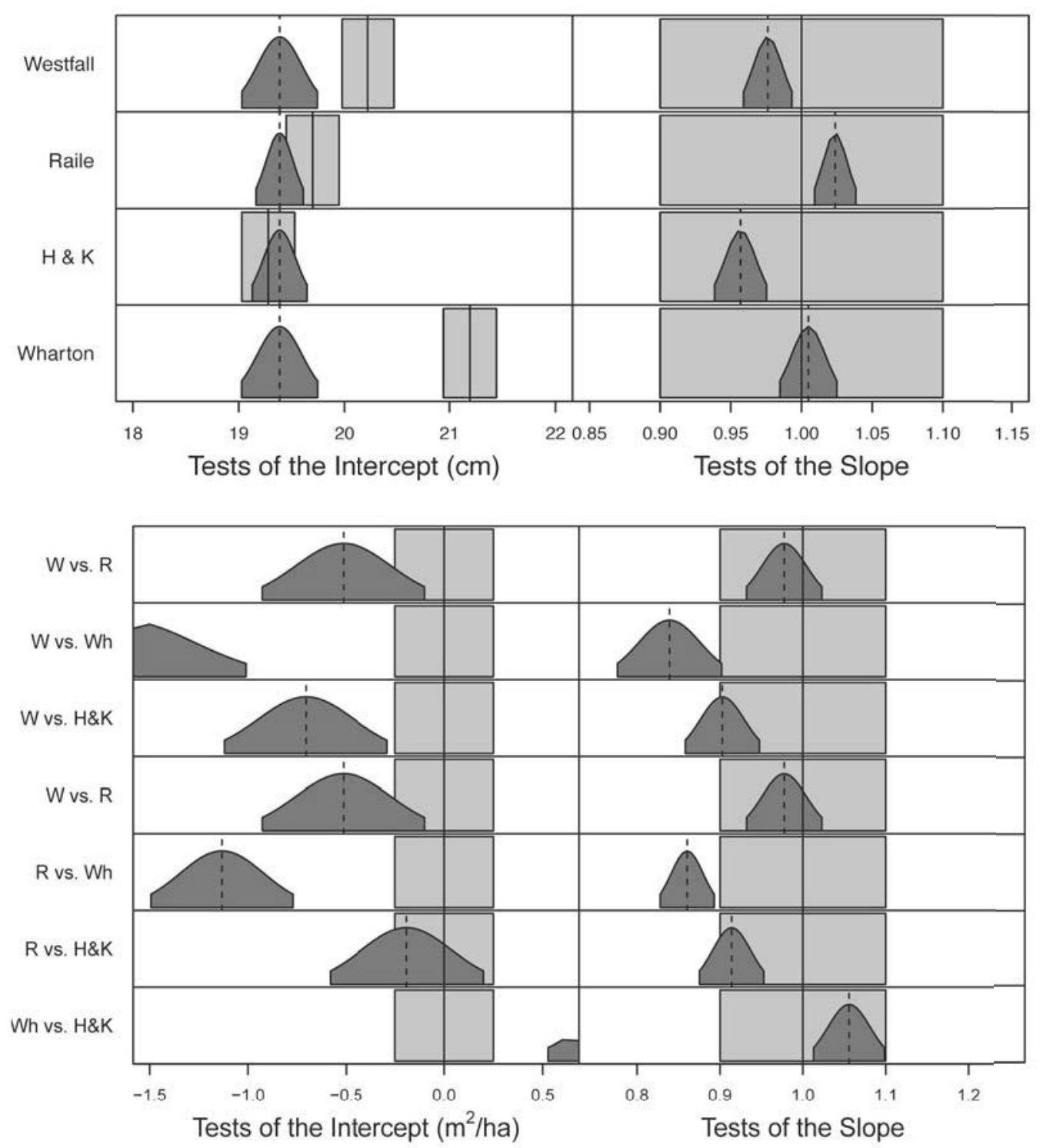

Figure 2.1: Results of equivalence tests between measured dbh and predictions from published equations, and between basal area predictions using those equations. Light grey bars represent the indifference intervals and dark grey distributions represent the two-one-sided confidence intervals. The null hypothesis is rejected where the dark grey distributions are completely within the light grey indifference intervals (after Pokharel and Froese, (2008). W=Westfall, R=Raile, Wh=Wharton, H\&K= Horn and Keller, Mc=McClure. 


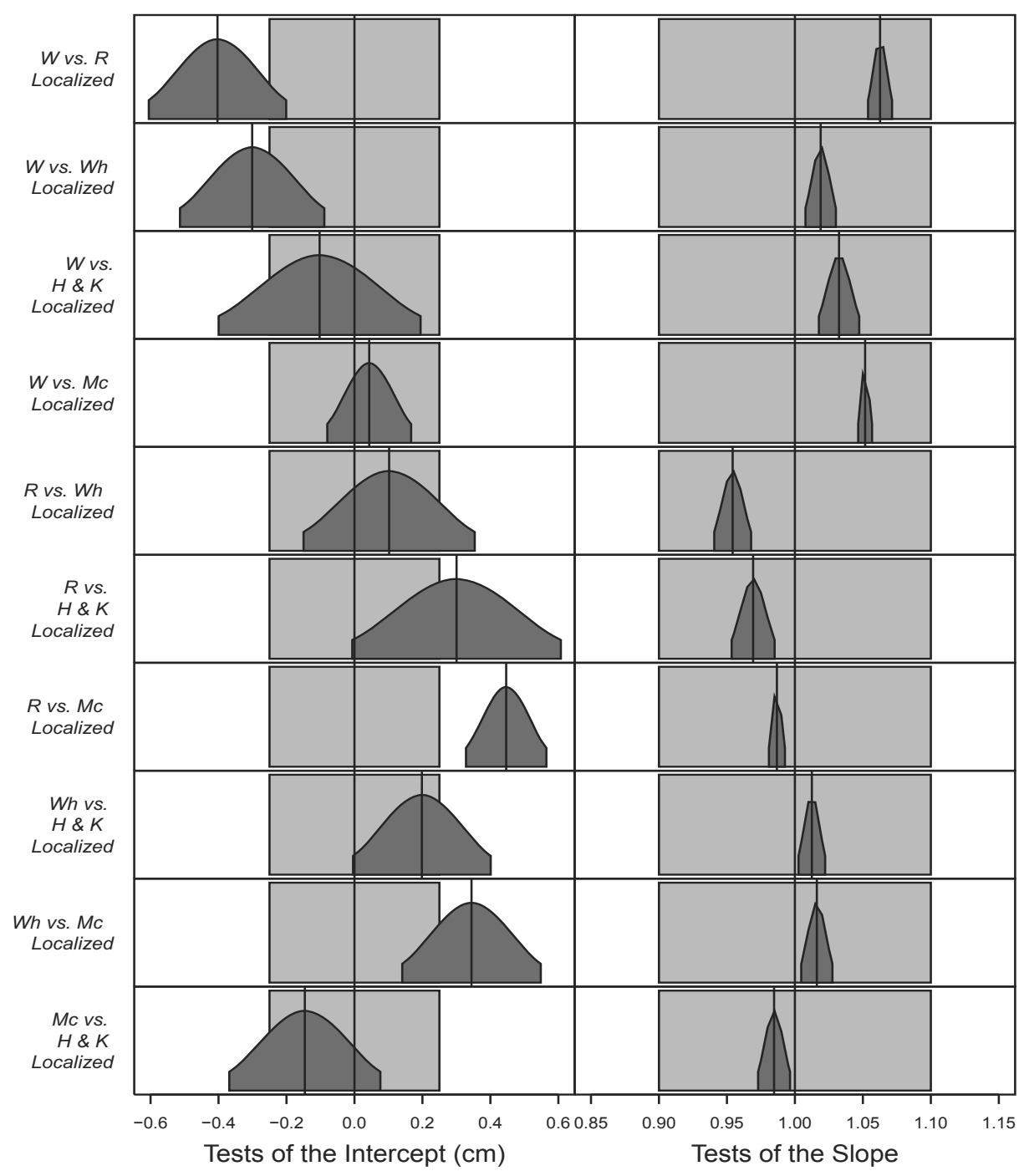

Figure 2.2: Results of equivalence tests between dbh predictions from localized equations on all stumps. Light grey bars represent the indifference intervals and dark grey distributions represent the two-one-sided confidence intervals. The null hypothesis is rejected where the dark grey distributions are completely within the light grey indifference intervals (after Pohkarel and Froese, 2008). W=Westfall, R=Raile, Wh=Wharton, H\&K= Horn and Keller, Mc=McClure. 


\subsubsection{Stand-level comparisons}

Nine different estimates of removals were made for each of the 96 harvested stands. Estimates were made using the four published northern hardwood prediction equations and five equation forms with locally generated coefficients. The equivalence tests on stand-level basal area removal levels resulted in the failure to reject the null hypothesis for all combinations of predictions using published coefficients, as well as rejection of the null for all tests of the intercept using localized coefficients (Figure 2.3). Tests of the slope for all but one pair of localized equations resulted in a rejection of the null hypothesis using localized coefficients, reflecting minimal variability among predictions for individual stands (Figure 2.3). 


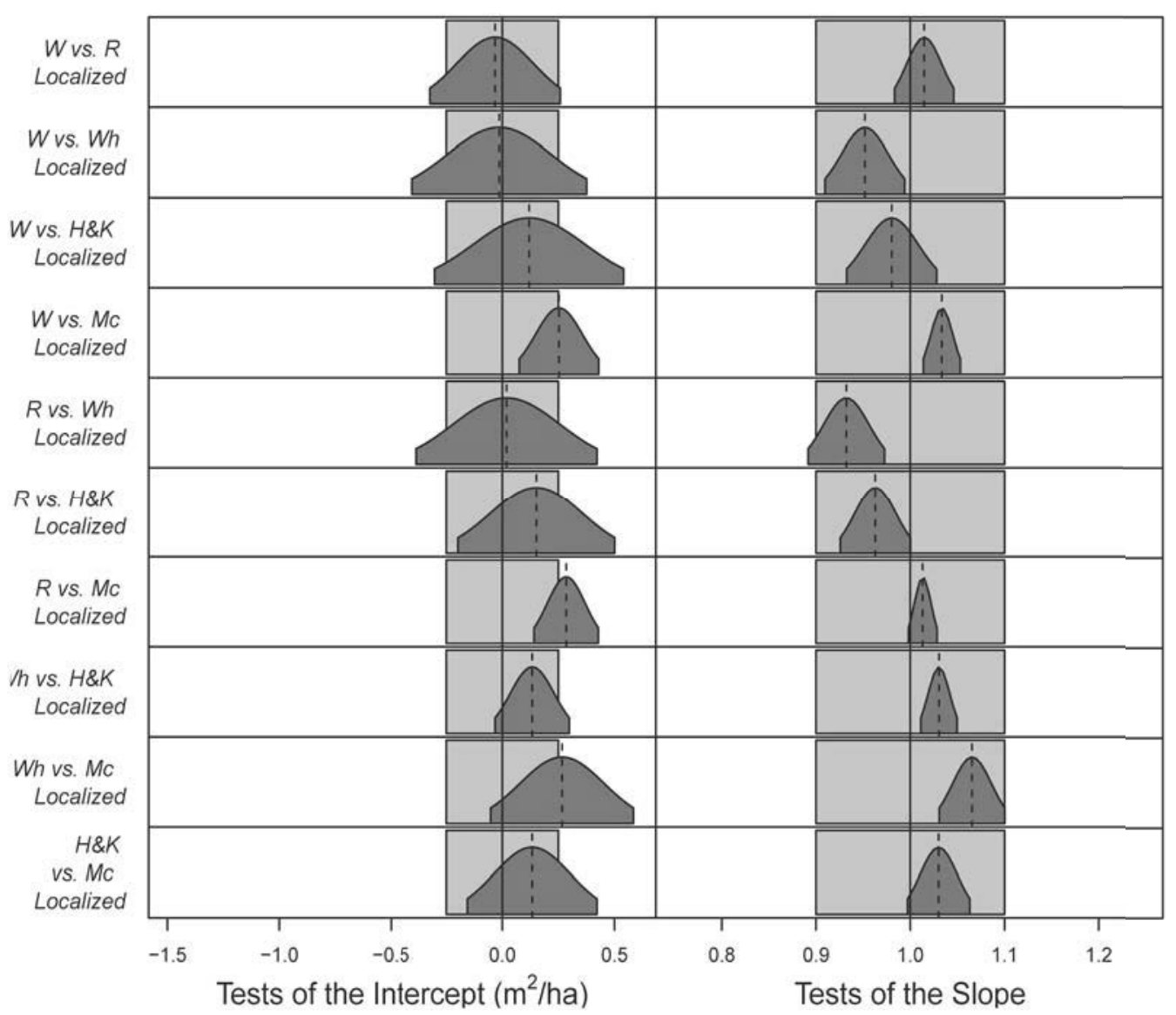

Figure 2.3: Results of regression-based equivalence tests of all predicted stand level basal area removals. Light grey bars represent the indifference intervals and dark grey distributions represent the two-one-sided confidence intervals. The null hypothesis is rejected where the dark grey distributions are completely within the light grey indifference intervals (after Pohkarel and Froese, 2008). W=Westfall, R=Raile, Wh=Wharton, H\&K= Horn and Keller, Mc=McClure.

The average removal was calculated to be $10.3 \mathrm{~m}^{2}$ ha ${ }^{-1}$ using Westfall's equation form, $10.8 \mathrm{~m}^{2} \mathrm{ha}^{-1}$ using Raile's form, $11 \mathrm{~m}^{2} \mathrm{ha}^{-1}$ using Horn and Keller's form, and 11.9 $\mathrm{m}^{2} \mathrm{ha}^{-1}$ using Wharton's form. For some stands differences in removal predictions were greater than $8 \mathrm{~m}^{2} \mathrm{ha}^{-1}$. Once locally fit, the means for all equations were closer, within $0.4 \mathrm{~m}^{2} \mathrm{ha}^{-1}$ of each other, but outside the region of indifference used in the equivalence test. The average removal was around $10.8 \mathrm{~m}^{2} \mathrm{ha}^{-1}$. Stand-level predictions using refit 
equations still differed by more than $6 \mathrm{~m}^{2} \mathrm{ha}^{-1}$ in some cases. The average removal of sugar maple ranged from $6.7 \mathrm{~m}^{2} \mathrm{ha}^{-1}$ to $8.1 \mathrm{~m}^{2} \mathrm{ha}^{-1}$ for the published equations, but was 7.1-7.2 $\mathrm{m}^{2} \mathrm{ha}^{-1}$ for all locally fit equations. Sugar maple was the dominant species in most stands and therefore the predictions for this species have a great deal of influence on final values.

\subsubsection{In cases of timber trespass}

Of the four stands randomly selected for hypothetical timber trespass calculations, Stands H1 and H2 had above-average pre-harvest sugar maple volume and Stands M1 and M2 had below-average sugar maple volume and a wider mix of species. In all stands, the highest volume removed was in sugar maple. $\mathrm{H} 2$ also had substantial removal of black cherry (Prunus serotina) and red maple; M1 had removals in sugar maple, red maple, American basswood, and yellow birch; M2 had removals in hophornbeam (Ostrya virginiana) and white ash (Fraxinus americana) in addition to the four species in M1.

For most stands and site qualities, the local coefficients resulted in larger volume estimates and higher stumpage values (Figure 2.4). The largest differences resulted from the highest site indices, which would be expected (data not shown). Overall, differences in estimated values of removed timber between predictions with published coefficients ranged from $\$ 350 \mathrm{ha}^{-1}$ (60\% of the average estimated value of removals) to $\$ 3 \mathrm{ha}^{-1}$ (1\% of the average estimated value of removals), with a mean of $\$ 30 \mathrm{ha}^{-1} \mathrm{~m}$ or $5 \%$ of the average estimated value. Differences between estimated values from predictions with locally fit coefficients ranged from $\$ 350 \mathrm{ha}^{-1}$ to $\$ 1 \mathrm{ha}^{-1}$, with a mean of $\$ 17 \mathrm{ha}^{-1}$, or $3 \%$ of the average estimated value. The refits of each equation resulted in considerable change in per acre value predictions. Differences ranged from $\$ 100 \mathrm{ha}^{-1}$ less for Raile's equation to a $\$ 94$ $\mathrm{ha}^{-1}$ increase after refitting Horn and Keller's ratios. 


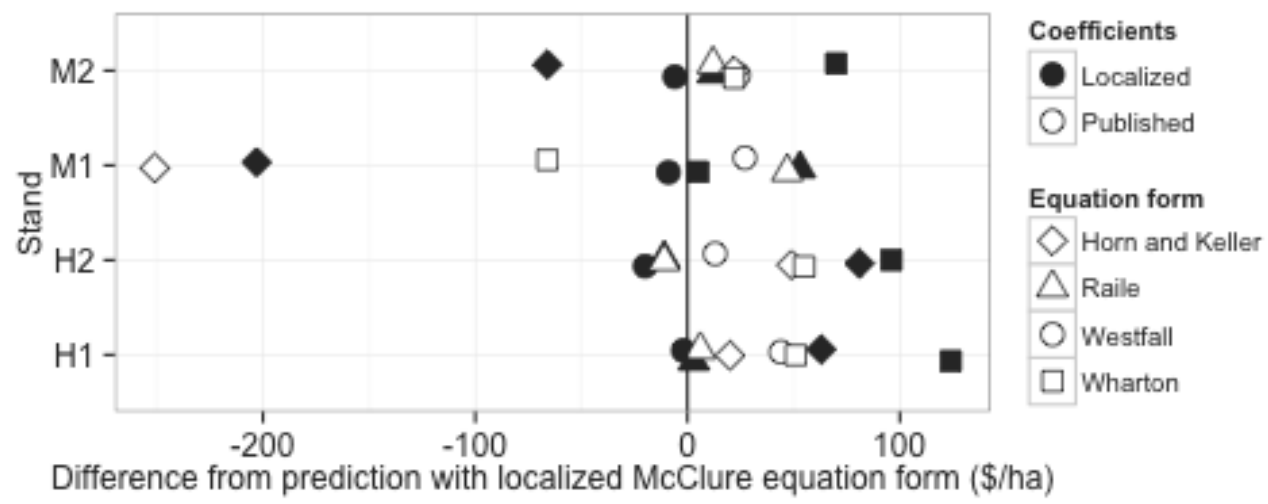

Figure 2.4: Difference in value of removed timber estimated using eight prediction equations at medium site indices, compared to McClure's localized equation form. Positive values indicate estimates larger than the estimates using McClure's form.

Raile's (1978) published coefficients resulted in larger dbh values for yellow birch. For stand M1 this resulted in higher values from predictions with Raile's coefficients than any other equation; for stand M2, which had lower yellow birch removal levels, the estimates using Raile's published and all other coefficients were very similar. Once Raile's equation was refit using local data, the differences in predictions for M1 were much smaller. In general, differences in predicted values were exaggerated by higher stumpage values.

\subsection{Discussion}

\subsubsection{Models with one predictor}

Of the two simplest equations, the equation form published by Wharton (1984) generated less accurate predictions of the known diameters. The relatively poor performance of the published coefficients may in part stem from the fact that Wharton's equation used stump 
diameter inside bark as a predictor, which had to be converted to diameter outside bark in order to work with our fitting dataset. This conversion was unnecessary when the equation was refit; still, the localized equation was less accurate than the others. Horn and Keller's equation form, a series of ratios for each diameter class, is essentially a segmented linear model. It is therefore more flexible than Wharton's equation, and performed better because of this. Visual assessment of the predictions showed that the equation represents the overall relationship of stump diameter to dbh quite well, but predicts approximately the mean dbh for each dsh. This fails to account for other variation in the data, which appears to result from variable stump heights as well as differences between the growth forms of different species.

\subsubsection{Gains from the inclusion of stump height}

Horn and Keller's (1957) equation was one of the earlier published equations, and its simple nature likely reflects the limits of time and calculation aids available when it was developed. The work appears to be aimed at improving a common "rule of thumb" of the day, and their ratios undoubtedly were more accurate. The reason for the omission of stump height as a predictor by Wharton (1984) is more complex. After the works of Horn and Keller (1957) and others were published, McClure (1968) and Raile (1978) found better predictions when using DSH as a predictor. Following Raile (1978), Bylin (1982) tested two of the fifteen species in his dataset and concluded that stump height and diameter were not significant predictors. Wharton (1984) did not test these predictors but instead cited Bylin and published equations for 17 northeastern species groups using only dsh as a predictor.

Previous testing on a dataset from a different region does not preclude the need for localized testing. Similarly, the published coefficients for any equation forms in the literature, even 
for similar species and regions, will never be as accurate as locally fit equations, at least on the refitting data. Further, Bylin's (1982) test of two species serves in no way as a conclusive reason why stump height should not be tested in predictive models. Westfall (2010) and Raile (1978) developed far more accurate prediction equations using stump height as an additional predictor.

Researchers in several different continents have concluded that simple linear equations are sufficient for predicting dbh when stump heights are fixed or minimally variable (Özçelík et al., 2010; Corral-Rivas et al., 2007; Bylin, 1982). Khatry Chhetri and Fowler (1996) argued that there is a greater need for inclusion of stump height as a predictor in

"subsistence" societies, where harvesting methods are less uniform than in "industrial" societies. Our data set suggests that while there may be some truth to that conclusion, there can also be considerable variation in the heights at which northern hardwood stems are cut in North America. The socioeconomic development of a region is not a definitive proxy for determining what predictors are significant in a model; terrain, stem condition, and the number of operators working in the stands that make up the dataset also contribute to the variability of stump heights in the data. Further, the superior descriptive statistics for the Westfall and McClure equation forms support the paramount importance of inclusion of stump height as a model predictor over other model attributes.

\subsubsection{Tests of equivalence}

Equivalence testing was performed on model predictions at the stem level, and also on basal area at the stand level. Tests of the intercept for published model forms show the significant bias of each equation. The null hypothesis was not rejected for any equation. Horn and Keller's ratios showed the least bias, but were also the most variable for individual stems, as evidenced by the tests of the slope. This reflects the segmented nature of Horn 
and Keller's ratios; each ratio fits closely to small subsets of the data. Because the equation form does not include stump height, however, considerable variance is expected. The tests of slope for dbh predictions for all stems ubiquitously led to rejection of the null hypothesis, suggesting that individual diameter predictions were similar.

The equivalence tests of basal area at the stand level resulted in a failure to reject the null hypothesis for all tests of the intercept. This is likely due to exaggeration of differences in predictions for certain species, although species-specific tests between each equation form were not conducted. The variance and bias noted in the earlier tests were magnified through the calculation of basal area. Overall trends in basal area predictions (tests of the intercept) and individual stand estimates (tests of the slope) show high variability using the published coefficients; this is unsurprising as it accords with the results of the tests on stem-level prediction.

Tests of the intercept for individual stem predictions using localized models resulted in the rejection of the null hypothesis, and thus pointed to significant similarity, only between Westfall and McClure's localized equations. Tests of the slope again resulted in rejection of the null hypothesis for all pairs; in all cases regressions on the fitted models had much less variance than regressions on models using published coefficients. Taken together, these results show that while the estimated slopes were all very close to 1 , dissimilarities between equations were evidenced by substantial variation between the mean predictions.

The null hypothesis was not rejected in the comparison of basal area predictions using the localized versions of Westfall and McClure's equation forms, despite its rejection for tests of dbh predictions on fitting data. In implementation at the stand level, model performance differs enough that the test does not support a hypothesis of similarity for the intercept, and thus the inclusion of stump height is not the only equation attribute influencing model performance. 


\subsubsection{Recommendations}

Among the conditioned equations, both Raile's and McClure's equation forms predicted more accurately on the fitting dataset than Westfall's. Westfall's (2010) includes stump height as a predictor in absolute and relative form, thereby accommodating the difference in distributions by reducing the influence that an extremely high or low stump height might have on predictions. The superior performance of even Raile's (1978) equation, conditioned to be inaccurate at higher stump heights, likely results from the fact that there were few stumps in the fitting dataset measured at heights close to dbh; the distributions of the heights at which stump diameters were measured on stumps and standing stems were similar. Regardless, the coefficients published by Raile (1978) are not recommended for use in northern hardwoods, because they result in improper conditioning of the model. Instead, collection of fitting data for use with McClure's equation form is recommended, because McClure's equation does not include published coefficients for most northern hardwood tree species. If fitting data cannot be collected, we provide coefficients calculated for the most common species groups in our dataset (Table 4), and recommend the use of Westfall's published equation and region-wide coefficients as an excellent alternative for stands with greater species diversity.

If the dsh to dbh prediction is being made to resolve a case of timber trespass, there are evident financial ramifications for the selection of an equation. It is important to note that one common approach to mitigating timber trespass losses is to double or triple the going stumpage rate, which in one scenario could result in as much as a $\$ 700$ or $\$ 1050$ difference per hectare (between using Raile's and Horn and Keller's published coefficients). That value represents the starkest contrast between an equation with stump height as a predictor and without. Such a difference at the very least highlights the importance of giving careful consideration to the characteristics and limitations of available equations. Because higher stumpage values led to even larger differences per acre values, it is clear that accurate 
predictions for both the most valuable and most common species are necessary.

\subsubsection{Whole tree taper equations as an alternative}

An equation for a neiloid frustrum such as that developed by Walters et al. (1986) could be an excellent alternative to the existing stump to breast height equation forms. Three measurements- two near ground level (approximating a stump) and one at breast heightwould be required for proper calibration of this model; two stump measurements would be necessary in application. A taper equation which included a neiloid form for the butt of the tree (for example, a segmented polynomial equation such as that published by Max and Burkhart (1976)) could be calibrated for stumps in a stand, thus allowing predictions of volume to be made directly from stump measurements. This would eliminate the potential errors that result from predicting $\mathrm{dbh}$ from the stump and then predicting volume from dbh. Drawbacks to this approach include the need for tree height, which is unknown in the case of timber trespass (though estimable from surrounding trees), and the need to make two measurements on each stump. Nevertheless, a clear next step in the field of forensic breast height predictions is the testing of neiloid frustrum equation forms and/or segmented polynomial equations to predict dbh and total tree volume.

\subsection{Conclusions}

Not all equations are created equal. This work clearly demonstrates the greater predictive accuracy of equations with stump height and stump diameter as predictors. Where precision and accuracy are paramount, the use of Raile's (1978) equation form, properly conditioned after McClure (1968), is recommended. Where fitting data cannot be collected, the equation form and coefficients put forth by Westfall (2010) are an alternative that also 
performs quite well. Use of an equation derived from the form of a neiloid frustrum may show even greater predictive ability, though requiring additional measurement. When an individual tree's diameter and volume are of interest, small differences in predictions can be exaggerated by species stumpage values and lead to valuation differences to the extent of hundreds of dollars worth of volume per hectare. 


\section{Chapter 3}

\section{Sustainability of the selection system in northern hardwood forests}

\subsection{Introduction}

The North American northern hardwood forest type has an extensive range, spanning New England and the Great Lakes region of the United States and the St. Lawrence and Acadia regions in Canada. These forests are a significant resource for both forest products and ecosystem services, and are actively managed throughout their range. Ownership and objectives vary across the extent of the forest type, making generalizations about the current and future conditions and management of these forests difficult. Despite this, assumptions about the state of the forests, contemporary management regimes, and consequences of management are widespread.

Northern hardwood silviculture has been studied for decades, resulting in published management guidelines that are assumed in academic and government agency publications 
to be commonly followed and accepted. In uneven-aged systems managed for continued growth and yield, especially those dominated by shade-tolerant species, the single-tree selection system is recommended (Nyland, 2002). Long-term studies and simulations have shown that this system ensures a regular supply of timber and improves stand quality over time (Kenefic and Nyland, 2007; Nyland, 2005; Reed et al., 1986). Though this management system has been validated repeatedly, concern remains that diameter-limit cutting and excessively high removal levels are widespread. Harvests of that sort threaten the future reproductive capacity of the forests, especially in non-industrial private landholdings (Nyland, 1992, 2005; Hull, 2011).

In this study we used field measurement of actively managed stands across a range of ownership types to assess and quantify management in northern hardwood forests of the Great Lakes region. We sampled harvested stands from a broad geographic area, and compared harvests to available guidelines to determine the extent to which they were followed. The dominance of shade tolerant sugar maple in this forest type and the prevalence of a well-vetted marking guideline make this region an excellent location for a study of modern compliance with an historically established management system.

\subsubsection{Northern hardwood management}

Northern hardwood stands are a prime source of valuable sawtimber and other forest products, including wood and harvest residues for bioenergy production (Munsell and Germain, 2007; Davis et al., 2012). Fragmentation of large parcels and a diversity of private landowner objectives put increasing pressure on a diminishing managed land base to provide these products (Haines et al., 2011). While many marking guidelines for sustainable production of sawtimber and pulpwood have been developed and published, a shared antecedent is the Arbogast (1957) guideline. In 1957, Carl Arbogast, a research 
forester with the US Forest Service, published the "Marking guides for northern hardwoods under the selection system". This marking guideline has become a central part of the northern hardwood selection system of management, especially in the Great Lakes-St. Lawrence region in which it was developed. The clearly stated purpose of this guideline was to instruct on the development of stand conditions that would lead to continuous growth and yield of sawtimber. The target stocking level in this guide was determined empirically from cutting trials in old-growth northern hardwoods in Michigan, USA, first published by Eyre and Zillgitt in 1953. Recommended stocking consists of $21.8 \mathrm{~m}^{2} \mathrm{ha}^{-1}$ of basal area in trees from 5 to $61 \mathrm{~cm}$, with $17.2 \mathrm{~m}^{2} \mathrm{ha}^{-1}$ in trees over $25 \mathrm{~cm}$.

Tubbs (1977), a commonly used publication, reiterates the stand structure recommended by Eyre and Zillgitt and Arbogast. Public agency guidelines from Michigan, Wisconsin, and Ontario either repeat or localize the same basic structure as a target for northern hardwood management (Michigan Department of Natural Resources, 1986; OMNR, 1998; Wisconsin Department of Natural Resources, 2010). It is therefore no surprise that Seymour et al. (2006) say that this structure is "virtually institutionalized" in the Great Lakes region and widely used throughout the applicable range. Millington et al. (2010), Nyland (2003), and Niese and Strong (1992) also describe it as one of the most commonly used selection system management approaches. Goodburn and Lorimer (1999) sampled stands in northern Wisconsin, and found that $70 \%$ of northern hardwood stands (7 of 10) and $80 \%$ of northern hardwood-hemlock stands (4 of 5) were managed using a selection system in accordance with Arbogast's guidelines. Management guidelines in eastern northern hardwood forests are more varied, though still emphasizing single-tree selection for long-term management of sugar maple- dominated forests. Publications specific to the northeast, such as Leak et al. (1987) and Filip (1973), describe a target stand structure with a smaller maximum diameter and a lower residual basal area than that described by Arbogast and Eyre and Zillgitt. This accommodates regeneration of less shade-tolerant species that are more common in the eastern range of the forest type. Leak et al. (1987) specify that where a stand has a higher proportion of sugar maple, larger sawtimber diameters and higher volumes may be 
retained. Thus, as stand conditions approach those more common in the Great Lakes-St. Lawrence region, management recommendations approach those described by Eyre and Zillgitt (1953) and Arbogast (1957).

\subsubsection{Northern hardwood ownership}

Throughout the extent of northern hardwood forests in the United States, the vast majority of growing stock removals are from state, municipal, and privately owned lands (FIA, 2011). Harvesting on private lands, industrial and non-industrial, far exceeds that from other ownerships. In the USA, nonindustrial private forest (NIPF) ownership is increasing, and NIPF lands are an important factor in current and future timber supply (Munsell et al., 2008; Kluender and Walkingstick, 2000). In Michigan, removals from state lands are also substantial in this forest type; in 2009, sugar maple removals per area on state-managed forests in Michigan were one and a half times greater than those in Wisconsin and almost seven times greater than in New York and Minnesota (FIA, 2011).

NIPF owners are thought to have a broad range of goals. Repeatedly, studies have shown that non-industrial private forestland owners are a diverse group, not one with a set of common traits (Kluender and Walkingstick, 2000; Erickson et al., 2002; Potter-Witter, 2005). The results from the US National Woodland Owner Survey (NWOS) showed that, in 2004, only $27 \%$ of family forest owners had undertaken timber harvesting in the previous five years (Butler and Leatherberry, 2004). Similarly, the results of the most recent NWOS in Michigan show that landowners gave a range of reasons for a timber harvest that occurred in the past five years (Butler et al., 2010). Those landowners who have harvested their land are again in the minority. Further, within the group of landowners who have recently harvested, primary objectives are varied and include improving residual quality, improving hunting or recreation, salvage logging, and cutting solely because "the price was right". 
State lands are the most actively managed public holdings in USA northern hardwood forests (FIA, 2011). Management goals and policies are set at the state level,. For example, the Michigan Department of Natural Resources (MDNR) aims to manage state northern hardwood forests as all-aged stands "with an emphasis on quality saw log production", while also considering economics and biodiversity (Price, 2008). Also, Michigan's state forests have been dual-certified by both the Forest Stewardship Council (FSC) and the Sustainable Forestry Initiative (SFI) since 2005 (Stokes, 2011).

Corporate forest ownership in the USA has changed dramatically, as large, vertically integrated companies have restructured. Ownership by timber investment management organizations (TIMOs) and real estate investment trusts (REITs) is now far more common. In 1994 the 10 largest landowners in the USA were industrial owners; by 2007, all but one of the 10 largest private landowners in the USA were TIMOs and REITs (Bliss et al., 2010). For these owners the primary goal in management is to generate revenue for investors, while also considering ecological function and ecosystem services (Ravenel et al., 2002). Especially for TIMOs, most of the anticipated revenue from forestland ownership is through land appreciation, not forest management (Froese et al., 2007). Corporate forestlands are commonly certified by SFI or FSC, and sustainability is thus an explicit management concern.

\subsection{Objectives}

Our objectives were to appraise the current silvicultural practice and long-term potential in Great Lakes northern hardwoods and make comparisons among corporate, NIPF, and state forest landowners, using a broad interpretation of an historically established silvicultural system in northern hardwoods as a benchmark. We hypothesized that a comparison of northern hardwood harvests to the recommended goal structure for the type would show 
that, overall, most stands are managed using the selection system in accordance with guidelines. This finding would concur with results published by similar studies (e.g., Goodburn and Lorimer 1999). We further hypothesized that some variability among ownership types would be present due to the varied nature of landowner objectives: State lands would be most commonly managed following published guidelines; corporate and NIPF harvesting practices would be more variable, with corporate harvesting tending to be heavier in larger size classes and NIPF harvesting practices ranging from lighter than recommended to heavier than recommended.

\subsection{Methods}

\subsubsection{Stand Selection}

A pseudorandom sample of 96 recently harvested stands was selected and sampled in 2010, spanning about 2 million hectares of northern hardwood forests bordering lakes Superior, Michigan and Huron in the USA. All sampled stands were of the northern hardwood cover type (SAF Cover Type 25, 26, 27), had a harvested area 8.1 ha or larger in size, and had been harvested within the prior 6 years. Stands under public ownership were within State Forests managed by the Michigan Department of Natural Resources. NIPF properties were owned by private landowners, though most harvests were conducted with assistance from consulting foresters. Corporate stands were sampled from the holdings of the three largest owners in Michigan.

State timber harvests were identified through contact with MDNR foresters across the region. A total of 41 stands on state land were sampled across 12 different Forest Management Units (FMUs). NIPF harvests were located using two different methods. 
Initially, landowners were selected randomly from a previously compiled list. This sample was supplemented by contacting consulting foresters working throughout the study area. A total of 28 non-industrial private forest stands were sampled, representing the population of NIPF holdings actively managed by individuals who are willing to communicate with researchers and provide access to their lands. Corporate stands were identified by contacting foresters working for three different corporations who own or manage large areas of forestland in Michigan. A total of 27 corporate stands were sampled (see Appendix A for stand locations).

\subsubsection{Field measurements}

Ten randomly located $100 \mathrm{~m}^{2}$ plots were installed in the harvested area of each stand, the area identified through conversations with managers and landowners and verified by evidence of marking and harvesting. On each plot the species and dbh were recorded for every tree over $10 \mathrm{~cm} \mathrm{dbh}$. All stumps appearing to have been cut in the most recent harvest were also measured. Species, diameter (the average of two perpendicular diameters), and height were recorded for each stump. Diameter at an arbitrary position below breast height was measured for a subsample of standing trees, selected randomly, with the sample size equal to the number of stumps in the plot and the range of heights approximately matching the range of heights of cut stumps. The height at which this lower-stem diameter was taken was also recorded. Additionally, a $4 \mathrm{~m}^{2}$ subplot was established within every other main plot for the sampling of species and dbh on stems less than $10 \mathrm{~cm} \mathrm{dbh}$. 


\subsubsection{Analytical methods}

Pre-harvest stocking was estimated using Westfall (2010)'s equation for predicting diameter at breast height from stump height and stump diameter. Localized coefficients for the seven most common species groups were obtained by refitting Westfall's equation to field data. These were used for predictions for $95 \%$ of measured stumps, and Westfall's published coefficients for the remaining species. Traditional summary statistics were calculated, including forest stocking variables such as basal area and trees per hectare, preand post-harvest. Species composition was examined and summaries about specific stands and the entire data set were created. Analysis of variance was used to test differences in pre- and post-harvest basal areas among landowner types; post hoc testing to determine which pairs of means differed was done using Tukey's Honestly Significant Difference. Pearson's chi-squared test was used to test statistical differences among harvest practices and landowner types.

\subsubsection{Stand management guidelines}

The target stand structure selected as a benchmark is found in Arbogast (1957) (Table 3.1); this structure was developed by Eyre and Zillgitt (1953) and republished by Tubbs (1977), as well as reiterated by others. The target diameter distribution has a rotated sigmoid shape, and defines a target structure in terms of both basal area and trees per unit area by size class. Acceptable ranges in the original publication are provided only for basal area

$\left( \pm 2.3 \mathrm{~m}^{2} \mathrm{ha}^{-1}\right)$, and more emphasis is placed on this attribute as a metric for assessment and marking. Basal area represents the growing space occupied by individual stems and size classes, and is strongly correlated with the volume removed in a harvest. 
Table 3.1

Target stand structure according to Arbogast (1957)

\begin{tabular}{|l|c|r|}
\hline Size class & Basal area $\left(\mathrm{m}^{2} / \mathrm{ha}\right)$ & Basal area $\left(\mathrm{ft}^{2} / \mathrm{ac}\right)$ \\
\hline Saplings $(<10 \mathrm{~cm} \mathrm{dbh})$ & 2.296 & 10 \\
\hline Poles $(10-25 \mathrm{~cm} \mathrm{dbh})$ & 3.444 & 15 \\
\hline Sawtimber $(>25 \mathrm{~cm} \mathrm{dbh})$ & 16.072 & 70 \\
\hline
\end{tabular}

Comparisons to Arbogast's marking guide were made using pre- and post-harvest basal area by product class. Arbogast's guidelines describe five pre-existing stand conditions, and recommended treatments. Condition 1, "Fully regulated", includes any stand with at least two size classes within or exceeding the acceptable range. Condition 2, "Overstocked with sawtimber but understocked with smaller timber", and Condition 3, "Understocked with sawtimber but overstocked with smaller timber", include stands where one size class was above the recommended range ("overstocked") and another was below the midpoint of the recommended range ("understocked"). Conditions 4 and 5, "understocked throughout entire structure" and "hemlock and/or yellow birch predominate", respectively, were not present in our sample.

Following this classification, the treatment recommended by Arbogast for each stand condition was compared to the treatment measured in sampled stands that had been harvested. For stands of Condition 1, the recommended treatment is to harvest mature timber, reducing stocking to within the recommended range in all size classes. For Conditions 2 and 3 the recommended treatments are different; stands of Condition 2 are treated to reduce sawtimber basal area to the recommended $16.1 \mathrm{~m}^{2} \mathrm{ha}^{-1}$ while stands of Condition 3 are harvested to a residual basal area of $19.5 \mathrm{~m}^{2} \mathrm{ha}^{-1}$ in poles and sawtimber. Stands were categorized by their level of compliance with these guidelines, using post-harvest stocking levels. Then, the 
following categories were used to classify harvests based on pre-harvest condition:

As recommended- residual stocking fell within Arbogast (1957)'s recommended range (Condition 1), or residual stocking met guidelines for stands of Conditions 2 and 3

Heavily cut overall- at least two size classes were cut to below the recommended range

Heavily cut in poles- pole basal area fell below recommended range, sawtimber fell within recommended range

Heavily cut in sawtimber- sawtimber cut to below recommended range; pole basal area fell within recommended range

Lightly cut overall- at least two size classes retained basal area above the recommended range

Lightly cut in poles- pole basal area fell above recommended range; sawtimber basal area fell within recommended range

Lightly cut in sawtimber- sawtimber basal area fell above recommended range; pole basal area fell within recommended range

\subsection{Results}

The median post-harvest basal area was quite consistent across state, NIPF and corporate ownership classes, at $23.3 \mathrm{~m}^{2} \mathrm{ha}^{-1}, 22.1 \mathrm{~m}^{2} \mathrm{ha}^{-1}$, and $20.8 \mathrm{~m}^{2} \mathrm{ha}^{-1}$, respectively (Figure 3.1). Median pre-harvest basal area was more variable, with the greatest value for state lands $\left(35.5 \mathrm{~m}^{2} \mathrm{ha}^{-1}\right)$, followed by NIPF $\left(32.0 \mathrm{~m}^{2} \mathrm{ha}^{-1}\right)$ and corporate $\left(29.5 \mathrm{~m}^{2} \mathrm{ha}^{-1}\right)$. As a consequence, removal trends paralleled the pre-harvest basal area trend. The mean removal over all ownerships was $11.3 \mathrm{~m}^{2} \mathrm{ha}^{-1}$, with a standard deviation of $5.1 \mathrm{~m}^{2} \mathrm{ha}^{-1}$. Analysis of variance showed a landowner type effect on pre-harvest basal area, with a very small effect size $\left(\mathrm{F}(2,93)=4.44, \mathrm{p}<0.05, \eta^{2}=0.09\right)$. Post-hoc testing showed the only difference was between state and corporate pre-harvest basal area levels (Tukey's HSD, p 
$<0.05)$.
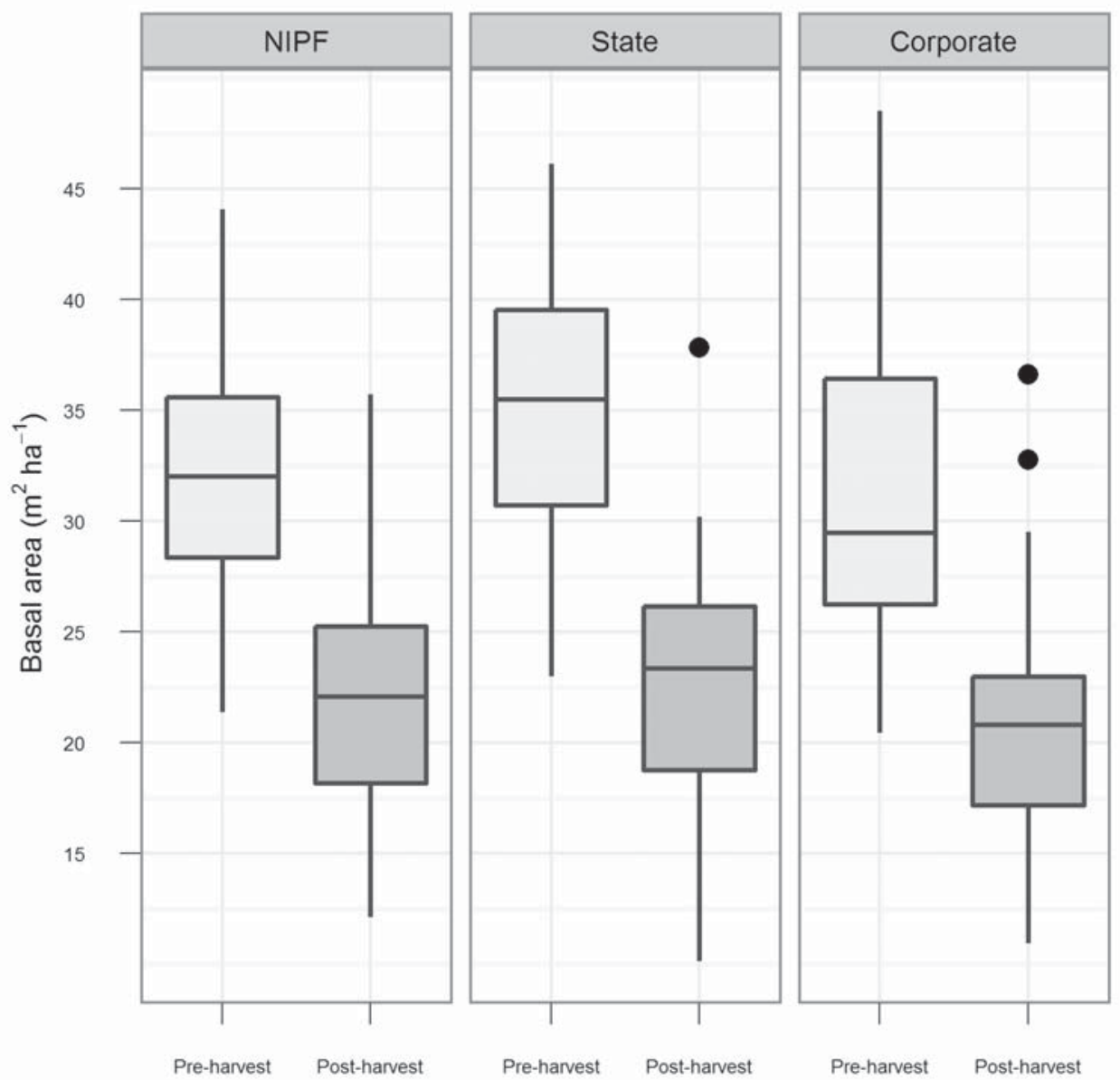

Figure 3.1: Comparison of pre- and post-harvest levels by ownership

There were no differences in residual stocking among landowner types, though substantial variation was found within each group. Stand-wise standard errors for post-harvest basal area, despite relatively small plot sizes, were acceptable for the comparisons of post-harvest stocking to guidelines. Only $2.6 \%$ of size classes ( 8 of 303 populated size classes) had a standard error larger than the $2.3 \mathrm{~m}^{2} \mathrm{ha}^{-1}$ range used for comparisons, suggesting that classification of the average stand was reliable. Far more stand-wise variance was present 
in estimates of pre-harvest stocking, especially in the sawtimber size classes. Pre-harvest stocking categories were much broader and therefore this variation had little influence on the comparison of stands to marking guidelines. Pre-harvest stocking of nearly every stand showed an approximately reverse-J shape (Figure 3.2). In 95 of 96 harvests, removals were distributed across the range of diameters measured.

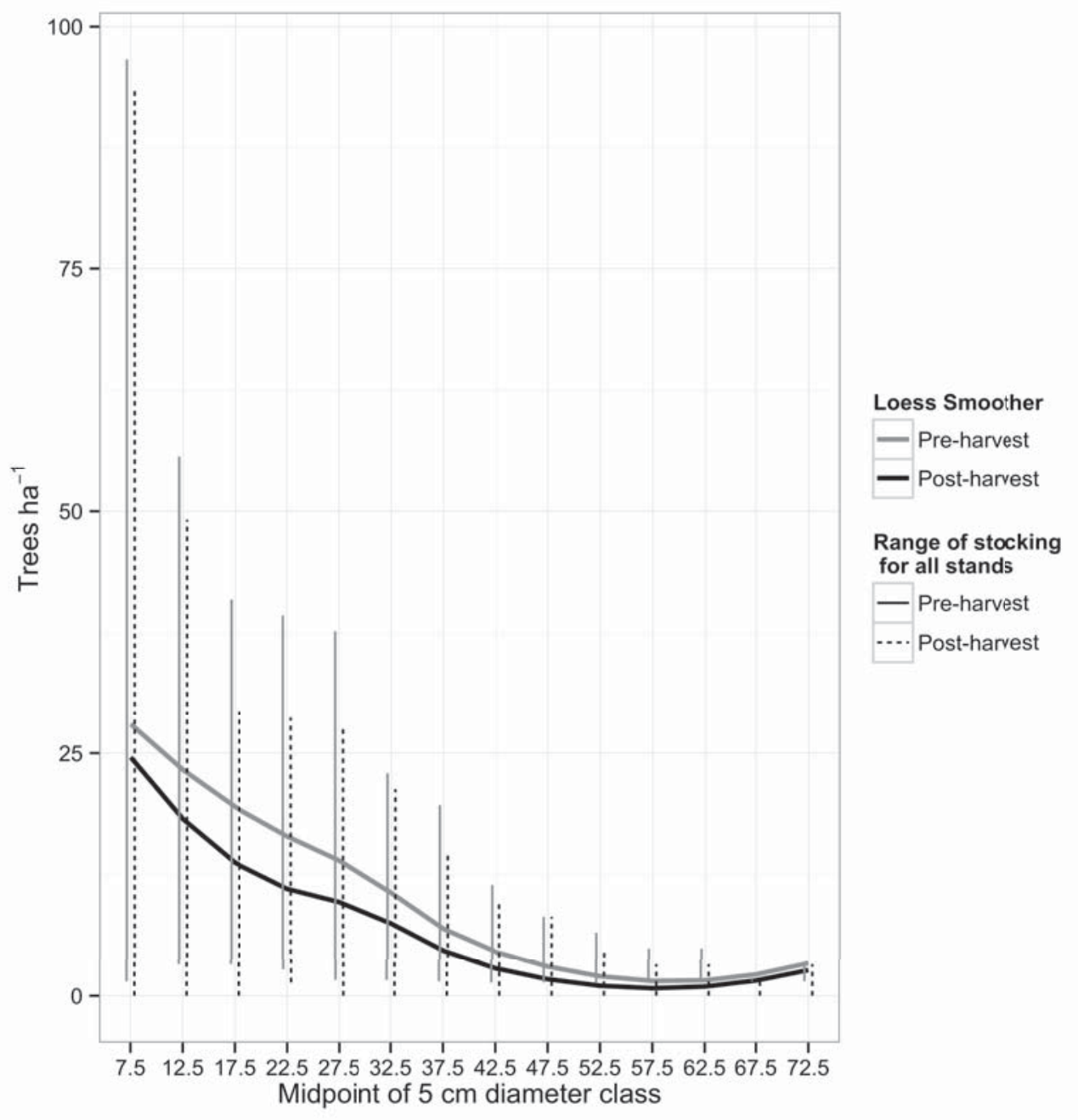

Figure 3.2: Pre- and post-harvest stocking in all stands by size class

The classification of pre-harvest conditions following Arbogast (1957) showed that 81 of 96 northern hardwood stands were in Condition 1, fully stocked or overstocked in all 
size classes (Table 3.2). Seven stands were overstocked with sawtimber and understocked with smaller timber; eight stands were understocked with sawtimber but overstocked with smaller timber. While stems less than $10 \mathrm{~cm}$ in dbh contributed to values of overall pre-and post-harvest stocking, the recommended value for these conditions was $2.3 \mathrm{~m}^{2} \mathrm{ha}^{-1} \pm 2.3$ $\mathrm{m}^{2} \mathrm{ha}^{-1}$. Thus the stocking for stems of this size did not influence the actual categorization of any stand. No differences in pre-harvest stand conditions among landowner type were found $\left(\chi^{2}(4, \mathrm{~N}=96)=3.33, \mathrm{p}=0.50\right.$, Cramer's $\left.\mathrm{V}=0.19\right)$.

Table 3.2

Pre-harvest conditions of northern hardwood stands, after Arbogast (1957)

\begin{tabular}{|l|l|c|c|c|c|}
\hline & & Total & Corporate & NIPF & State \\
\hline Class 1 & $\begin{array}{l}\text { Fully stocked or overstocked } \\
\text { in all size classes }\end{array}$ & 81 & 23 & 23 & 35 \\
\hline Class 2 & $\begin{array}{l}\text { Over stocked with sawtimber; } \\
\text { understocked with smaller } \\
\text { timber }\end{array}$ & 7 & 1 & 1 & 5 \\
\hline Class 3 & $\begin{array}{l}\text { Understocked with } \\
\text { sawtimber; overstocked } \\
\text { with smaller timber }\end{array}$ & 8 & 3 & 3 & 2 \\
\hline
\end{tabular}

Comparison of pre- and post-harvest stocking for each stand showed that 20 stands in total $(21 \%)$ were harvested as recommended, following Arbogast's (1957) guidelines (Table 3.3). Of the remaining stands, 40 (42\%) were harvested more heavily than recommended in some or all size classes, and 36 stands (38\%) were harvested more lightly than recommended in some or all size classes. Post-harvest classifications also show no difference among landowner type $\left(\chi^{2}(10, \mathrm{~N}=96)=9.58, \mathrm{p}=0.48\right.$, Cramer's $\left.\mathrm{V}=0.32\right)$. To assess the data more generally, stands were pooled into three broader categories ("As recommended","Lightly cut", and "Heavily cut") and tested. No coarser-scale differences were found with larger counts $\left(\chi^{2}(4, \mathrm{~N}=96)=3.49, \mathrm{p}=0.48\right.$, Cramer's $\left.\mathrm{V}=0.19\right)$. 
Table 3.3

Post-harvest assessments relative to Arbogast's (1957) marking guide

\begin{tabular}{|l|r|r|r|r|}
\hline & Total & Corporate & NIPF & State \\
\hline As recommended & 20 & 4 & 7 & 9 \\
\hline Lightly cut & 29 & 8 & 7 & 14 \\
\hline Lightly cut in poles only & 7 & 0 & 3 & 4 \\
\hline Heavily cut & 7 & 2 & 1 & 4 \\
\hline Heavily cut in poles only & 1 & 0 & 0 & 1 \\
\hline Heavily cut in sawtimber only & 32 & 13 & 10 & 9 \\
\hline
\end{tabular}

\subsection{Discussion}

\subsubsection{Idealized northern hardwood silviculture}

Our emphasis on comparisons to the ideal selection system structure, popularized by Arbogast (1957), was for several reasons. First, Arbogast's marking guide and the associated target structure are widely publicized and reproduced, and incorporated into regional guidelines if not recommended or required outright by state and provincial land management agencies across the northern hardwood forest region. Second, there is a precedent in peer-reviewed literature for use of this guide as a standard for appropriate management. Thirdly, and perhaps most importantly, this provides a clear and quantitative tool with which to assess harvesting and future productive potential of northern hardwoods.

We found no reason to suspect anything other than selection management in the northern hardwood forest we sampled. Shade-tolerant sugar maple was the predominant species 
and pre-harvest stand structure suggested a reverse-J shape in most stands. All stands had abundant pre-harvest basal area in at least two of three size classes, and $84 \%$ fell into pre-harvest Condition 1 (Fully stocked or overstocked in all size classes). The distribution of removals and residual structure together presented no evidence of intent to manage any stand using even-aged or two-aged silvicultural systems. Furthermore, pre-harvest conditions make it unlikely that managers were attempting even-to-uneven-aged conversion sensu Nyland (2003).

Recent research continues to validate the target stand structure described by Arbogast (1957). Crow et al. (2006) found $16.1 \mathrm{~m}^{2} \mathrm{ha}^{-1}$ of basal area in trees $11.7 \mathrm{~cm} \mathrm{dbh}$ and larger, with $20.7 \mathrm{~m}^{2} \mathrm{ha}^{-1}$ overall, to be the ideal basal area for sugar maple stands in Wisconsin and the Upper Peninsula of Michigan. Niese and Strong (1992) found that the net present value of a stand cut to Arbogast's suggested structure was the highest of seven treatments, after 40 years and four harvests.

Long term studies in New York and Michigan show that marking and harvesting according to Arbogast's recommendations does lead to a consistent yield of sawtimber over time (Bohn and Nyland, 2006; Kenefic and Nyland, 2000; Erickson et al., 1990). Volume removals in two consecutive harvest entries in a stand in western New York managed on a 20-year cutting cycle were approximately the same and from the same diameter range; future harvests are projected to provide a similar, steady yield (Kenefic and Nyland, 1999). A strong relationship between diameter and age in trees of all size and age classes suggests ingrowth (Kenefic and Nyland, 1999), showing that the repeated cuts were successful as regeneration treatments. Thus, harvests approximately following this management guideline are reasonably expected to regenerate dominant species and facilitate the continued production of additional high quality sawtimber into the future. 


\subsubsection{Northern hardwood silviculture in practice}

For post-harvest analysis, we used a fairly liberal interpretation of an unclear acceptability tolerance stated by Arbogast. Stands were more likely to fall within recommendations under our interpretation than they would have if the $\pm 2.3 \mathrm{~m}^{2} \mathrm{ha}^{-1}$ margin were applied to the overall basal area rather than to the stocking within each size class. This resulted in a great deal of flexibility in what harvests were classified as being cut as recommended by guidelines, accommodating a variety of possible selection system goals within the broad structure suggested by Arbogast. Still, only 20 of 96 stands were harvested in a manner indicating compliance with Arbogast's marking guideline or variations thereof. This differs substantially from the findings of Goodburn and Lorimer (1999), who found 70-80\% compliance with the guideline in the same forest type. Our sample size was much larger, and our sample selection process was less strict, which may account for some of the differences.

Selection system management following this guideline has been shown to create a balanced and sustainable structure, one that "can be reconstructed again and again at each stand entry with essentially constant yields from each cut" (Leak, 1996). This is recommended as a "standard approach" for stands dominated by shade tolerant species, regardless of age (Leak et al., 1987). While we do not have age data for these stands, pre-harvest stand structures suggest that management following selection-system would have been a likely and effective approach. Deviating substantially from this structure, either by cutting more heavily or more lightly, could substantially hinder the future potential of the stand to regenerate, to produce a steady supply of sawtimber, or to respond to other disturbance. Cutting more heavily than the guidelines recommend- especially in cases of highgrading or aggressive diameter-limit cuts- may result in diminishing yield and likely diminishing stand quality over time (Erickson et al., 1990; Nyland, 2005). Our data suggest there is some cause for this concern; we categorized more than $30 \%$ of the stands in each ownership 
type as being "Heavily cut in sawtimber only".

Of perhaps equal concern is cutting substantially more lightly than even a broad interpretation of Arbogast's guidelines suggests. If standard single-tree selection systems typically do not regenerate shade-intolerant species, that problem is only exacerbated by leaving a higher-than-recommended residual basal area. One third of the managed stands we sampled were cut more lightly than recommended for regeneration, an ecological concern to be considered apart from loss of possible revenue. Furthermore, pulpwood and timber products could have been removed from these stands without jeopardizing the future growth of the stand (Crow et al., 2006). Thus to harvest more lightly than management guidelines suggest has opportunity costs of potential revenue and reduces the likelihood that a harvest was a successful regeneration method.

While our hypotheses were mutually compatible, our findings support neither the assumption that Arbogast's system was widely applied nor our expectations about differences in management among landowner types. Variation was much more substantial within each landowner type than between types. Fifteen (52\%) corporately owned stands were cut more heavily than management guidelines suggest (13 cut more heavily in sawtimber only). However, there were also eight stands cut more lightly than recommended, so our hypothesis that corporate stands would have heavy removals was not exclusively supported by the data.

The variability present in the management of NIPF stands was congruent with our hypothesis. Ten of 28 stands were heavily cut in sawtimber, while an equal number were cut more lightly than Arbogast's guidelines recommend. Lighter harvesting could indicate a shorter cutting cycle, management objectives that emphasize non-timber values, or a highly selective cut. The expected diversity in management, therefore, was evident.

The MDNR develops and implements management plans locally at the forest management 
unit. Our results revealed that the FMUs with the highest removal levels were also those with the highest residual volume (data not shown). This suggests that these FMUs may be managing using a longer cutting cycle than other FMUs, and does not imply that removal levels reflect overly intense harvesting. This may also imply a substantial modification of the target stand structure described by Arbogast (1957) to accommodate a longer cutting cycle and higher residual volume, or management using a different target structure. Regardless, the vast majority of stands measured were cut more lightly than recommended, though levels were comparable to those found by Schwartz et al. (2005). Therefore, there is conflict among observable harvest levels, the MDNR's promotion of the Arbogast (1957) structure, and their stated goal of sawlog production on state lands.

\subsubsection{The relevance of management guidelines}

The two most important findings from this study are that selection system guidelines assessed in this study are not widely applied in the northern hardwood forests we sampled, and that there are no differences among the three landowner types compared. The lack of difference among landowners is primarily due to the diversity of management within each landowner type. We cannot conclude that most stands in any owner type are presently being managed to meet both sustainable harvesting levels and successful regeneration goals by following even a loose interpretation of a proven silvicultural system. Because stated goals, objectives, and management plans do not necessarily translate to activity in the woods, the implications for future timber and non-timber forest products are quite significant. Improved education for private landowners and accountability for public managers would help ensure the future productivity of the northern hardwood resource and the integrity of third-party certification programs.

We recognize that our sampling procedures were not entirely random, and any attempt to 
extrapolate these findings must carry this caveat. Many NIPF properties were identified with the assistance of consulting foresters, and state and corporate stands were identified by their respective managers. However, we have no reason to suspect that those selections were biased, especially since we communicated neither a priori hypotheses nor opinions for or against any silvicultural regime, and because many individuals were involved in the selection process even within each landowner type.

While these findings are significant in our study area, the potential explanations underlying them are of much broader importance. The results suggest that we might very well wonder if the Arbogast guideline has lost relevance, because modern managers choose other systems to meet variable objectives which may be more- or less- sustainable. This raises the question of whether the guideline, though widely promoted, was ever widely applied. Managers may no longer follow historic marking guidelines designed to meet specific goals because there are consequences that invalidate their relevance; e.g., higher rates of return from alternate guidelines, social pressures resulting in the implementation of alternate rotation lengths or lighter harvest levels, or ecologic motivations such as managing for greater resilience to a changing climate.

Of greater concern is that even a broad interpretation of this guideline purports that selection system management overall is not widely employed. Here and elsewhere, social pressures and non-timber objectives may lead to harvesting more lightly than recommended, a condition which is less well documented than unsustainably high harvest levels. Harvests must serve as regeneration cuts to successfully maintain a multi-aged stand; there are clear ecological consequences when harvests fail to follow the minimum removal levels described in published guidelines for regeneration in uneven-aged stands. If harvests do not fall within an acceptable range of intensity for an established management system, the sustainability of the forest resource and the future availability of timber products will not match that which could be expected from proper implementation of that system. This is not a concern unique to the region in which this study took place, but rather 
an important consideration in forecasting the future productivity of the managed land base on any scale.

\subsection{Conclusions}

Because our data do not support our hypotheses, it seems likely that the generalizations on which they were based are also inaccurate for the northern hardwood forests we sampled. There are few differences among the management trends and harvest intensities of NIPF, corporate, and state landowners in this area. All three landowner classes employ varying management, with some stands being cut more heavily than recommended, some more lightly, and some being managed in ways that have been shown to sustain productivity over time.

While long-term studies have validated the recommended stand structure for northern hardwoods, our findings show that management does not usually approach that target structure. Though management guidelines and management agencies recommend its implementation, field measurement of recent harvests does not indicate adherence to the guideline. Because current management does not closely resemble the selection system that is known to regenerate and sustain the structure of these forests, it should not be expected that the future managed landscape will resemble the current conditions. Likewise, future stands will not show the improvement in quality and health that would result from widespread implementation of that type of management. The specific economic and ecological impacts of what is actually occurring are not immediately evident from this study, but must certainly be considered in future work. 


\section{Chapter 4}

\section{An appraisal of a managed northern hardwood forest landscape with a harvest taxonomy}

\subsection{Introduction}

Current management determines the ecological and productive future of a landscape. Management activities are driven by landowner objectives, which are highly influential but are not physical attributes to be measured. While landowners can be surveyed about management activities and intentions, survey responses are not always reliable. Furthermore, intentions may not be accurately translated into implementation, causing the future productive potential of a stand to differ from what was expected. In place of sociological research, landowner objectives may be implied by empirically measured pre- and post-harvest stand structures. The intensity of a harvest, the species which were preferentially removed or which remain, and the structure of the residual stand together 
point to possible harvest intentions. For the most part, management plans are implemented independently from each other on stands owned and managed by private individuals as well as corporate and government entities; in aggregate, these stands are the managed forest landscape. To assess the individual harvests which together chart the future of these forests, a succinct system that distills the silvicultural literature relevant to North American northern hardwood forests into a hypothesized set of harvest characteristics and objectives was developed.

Recently harvested stands throughout the state of Michigan were sampled across three ownerships, to identify current management practices and their influence on the future of the region's forested landscape. A previous comparison of the same harvests against selected published guidelines showed that management within ownership groups was highly variable, with few differences among owner types (Chapter 3). That comparison also suggested that the Arbogast (1957) guideline, thought to be most commonly used in the Great Lakes region, was not widely or successfully employed within these stands. These findings did not fully describe current management, nor did they provide much information on future harvest potential. For the majority of stands a more detailed assessment of harvests is necessary to move beyond conjecture of management objectives and future potential.

A taxonomical system which describes typical northern hardwood silviculture for uneven-aged or uneven-sized stands was hypothesized. Six possible harvest types and three sub-types were postulated. A reticulated dichotomous key was then constructed, from which a more user-friendly graphic tool (hereafter referred to as "the chart") was developed (Figure 4.1). This tool facilitates classification of stands by unique combinations of harvest attributes pointing to plausible silvicultural goals. Classifications do not speak to actual objectives or motivations. They characterize what a given harvest likely accomplished, regardless of the manager's true intention. Application of this system across the harvested landscape results in the proportion of harvests which seem to have been conducted for profit 
maximization, long term volume production, and ecological considerations. Given that management activities flow from landowner objectives and goals, this type of assessment suggests the potential diversity in landowner objectives throughout the region, and offers insight into future management and landscape conditions.

\subsubsection{Classification systems}

Classification systems have been used in the past as a tool for rapid differentiation between management activities, especially for large numbers of stands. A classification chart for categorizing even-aged hardwood stands based on their current management and future potential was developed for stands in West Virginia (Fajvan et al., 1998). This classification scheme categorizes future productive potential for a stand based on change in mean stand diameter, percentage of acceptable and unacceptable growing stock removed and remaining, and total post-harvest basal area. Harvest classifications include "regenerative", "silvicultural", and "nonsilvicultural"; the latter categories are further broken down into those that will produce sawtimber within 10-15 years and those that will not.

Fajvan et al. (1998) concluded that for their study area in West Virginia, silvicultural harvests were carried out on $19 \%$ of non-industrial private (NIPF) stands, $25 \%$ of corporate stands and $67 \%$ of publicly owned stands. Thirty-one of 101 stands had sufficiently low residual stocking and quality to recommend that the stand be regenerated to ensure future sawlog potential; this implied that there was no potential for another harvest in the current rotation. Diameter-limit cutting was prevalent, and the removal of large-diameter trees directly influenced the predicted potential for future harvesting. Munsell et al. (2009) found similar results applying the chart of Fajvan et al. (1998) for hardwood stands in New York. Using the chart to classify management practices, they found that regeneration cuts were recommended for $42 \%$ of the stands, as there was no productive potential remaining in the 
post-harvest stocking.

A key difference from the 1998 work of Fajvan et al. and the harvest taxonomy developed here is that the final categories of the taxonomy describe plausible landowner objectives, not future productivity. The taxonomical system classifies harvests using both pre- and post-harvest stand characteristics. It results in objectives which combine estimates of future availability and variability of harvests with social considerations. The chart was developed using management guidelines published for northern hardwood forests, but the methodology could be easily applied in other regions to develop a similar key reflecting stand structures and harvesting activity typical in other forest types.

The system of harvest taxonmy is intended to describe commercial harvests occuring on the managed landscape. It can be used to forensically evaluate harvests, if pre-harvest measurements are made or estimated from post-harvest stand characteristics. Alternately, the system provides a rough outline of what decisions must be made and implemented to accomplish a stated goal. Implicit in the system is that a harvested stand contained more than $17 \mathrm{~m}^{2} \mathrm{ha}^{-1}$ and likely more than $23 \mathrm{~m}^{2} \mathrm{ha}^{-1}$ of basal area before harvest. Further, the taxonomy assumes that the most recent harvest was conducted primarily for one of the six objectives listed in the key. In dichotomous key theory, reticulations - instances where different branches are connected-allow for one incorrect answer to result in an accurate identification (Osborne, 1963). In the taxonomical chart, the use of reticulations allows for this in a related way, ensuring that one particular characteristic does not outweigh others in determining the final harvest classification. 


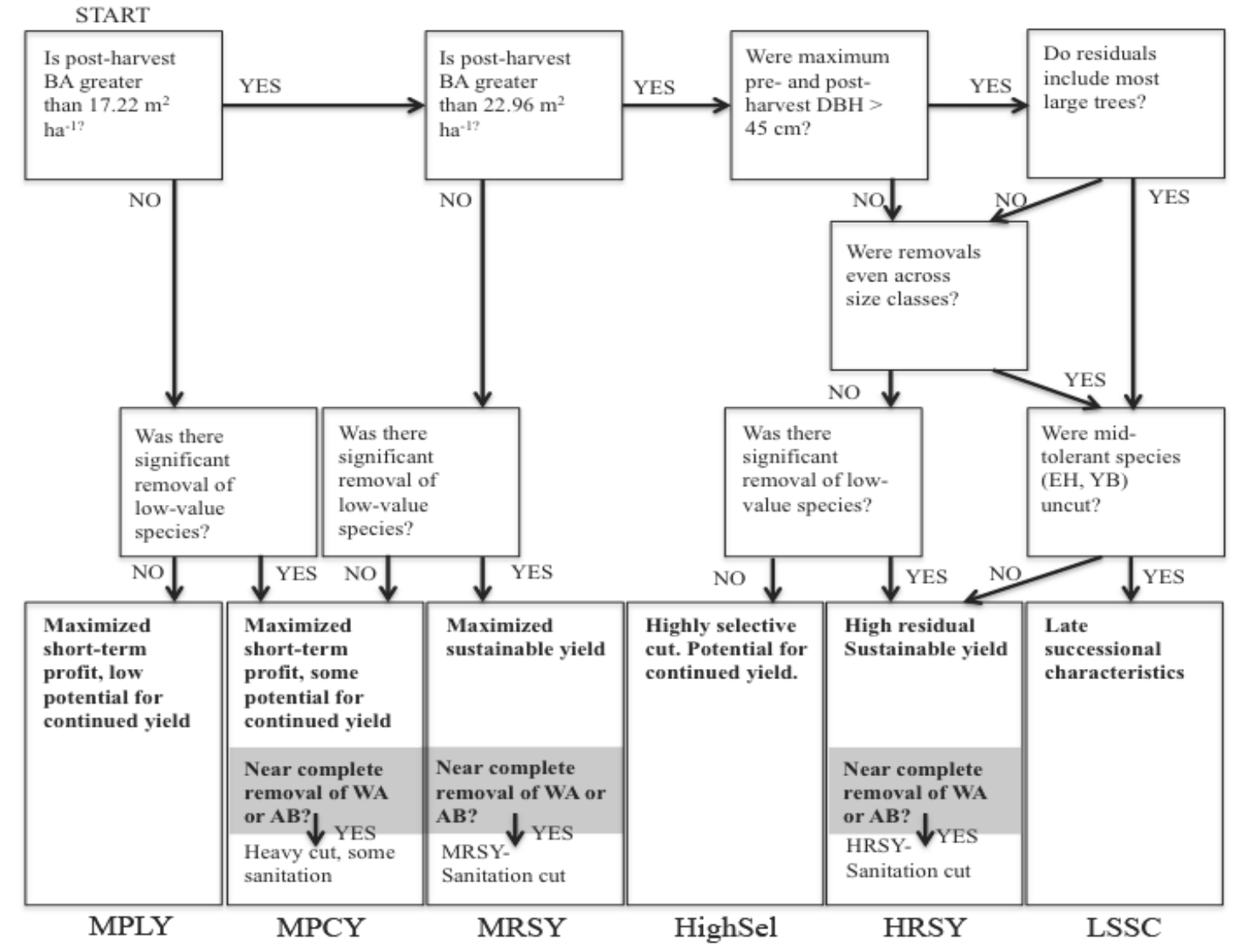

Figure 4.1: Graphical representation of harvest taxonomy

Species codes: $\mathrm{EH}=$ eastern hemlock (Tsuga canadensis), YB= yellow birch (Betula allegheniensis), $\mathrm{AB}=$ American beech (Fagus grandifolia), WA=white ash $($ Fraxinus americana) 
Specific quantitative criteria used in the chart (Figure 4.1) are defined as follows: near-complete removal- species of interest is more than $10 \%$ of total pre-harvest density; more than $80 \%$ of species basal area removed

removals even across size classes- at least half of occupied diameter classes have removals within one standard deviation of stand mean; removals occur in 2 or more diameter classes less than $27.5 \mathrm{~cm}$

residuals include most large trees- $60 \%$ or greater residual density, by diameter class, in all diameter classes greater than $45 \mathrm{~cm} ; 100 \%$ density in all diameter classes above $50 \mathrm{~cm}$

significant removal of low-value species- excluding valuable species (sugar maple, yellow birch, black cherry, and oaks), of all species that occupy more than $1.15 \mathrm{~m}^{2} \mathrm{ha}^{-1}$ basal area pre-harvest, at least half of species have $20 \%$ removal. Stands with no low-value species assigned "Yes".

Table 4.1

Abbreviations used for postulated harvest types

MPLY- Maximized short-term profit, low potential for future yield

MPCY-Maximized short-term profit, some potential for continued yield

HeavySan- High removal levels coupled with near-complete removal of locally threatened species, in this case, white ash or American beech

MRSY-Maximized residual for sustainable yield

Highly Selective Cut- High residual, only valuable trees removed

HRSY - High residual, sustainable yield

LSSC- Late-successional structural characteristics

San- denotes a sanitation cut of species of local or regional concern, in this case, white ash or American beech

\subsubsection{Description of harvest classifications}

Each unique harvest type was developed through a thorough review of the literature describing uneven-aged northern hardwoods management. The northern hardwoods forest (SAF Cover Type 25, 26, 27) covers much of the eastern United States and Canada. 
While the specific numbers and species in the taxonomy are unique to this forest type, the concepts and the harvest objectives are similar to those which form the context of management in other regions throughout world. These harvest types best describe uneven-aged management where a harvest serves as a partial regeneration cut. They have corollaries in even-aged management, and in even-to-uneven-aged conversion.

\subsubsection{Type 1: Maximized short-term profit, low potential for continued yield (MPLY)}

The maximum profit available to a landowner from a single harvest would maximize revenues, by cutting and selling all merchantable wood, and minimize costs by removing nothing else. This may include removal of all trees above a given merchantable diameter, or a preferential removal of species of high timber value, leaving behind less-valuable species.

Nyland (2005) compared simulated $35.6 \mathrm{~cm}$ and $40.6 \mathrm{~cm}$ diameter-limit harvests to selection system harvests. The initial entry for the diameter-limit harvests had a higher financial value than that of two of the three selection system harvests. Over a 90-year simulation, however, the diameter-limit cuts had widely varied yields, and over 90 years these cuts had neither the highest yield by volume nor by value (Nyland, 2005). Erickson et al. (1990) and Reed et al. (1986) also demonstrated that the highest revenues among a set of cutting trials were obtained with $30.5 \mathrm{~cm}$ and $40.6 \mathrm{~cm}$ diameter-limit cuts.

This type of harvest would be evident in part because removals would be concentrated in the larger size classes. Pre-harvest density may show a higher maximum diameter than post-harvest density; residual density would be primarily or entirely in lower diameter classes. Existing management guides set a maximum residual diameter between 45.7 and $61 \mathrm{~cm}$ (Adams and Ek, 1974; Arbogast, 1957). A residual maximum diameter below 45.7 $\mathrm{cm}$ may indicate a diameter-limit cut maximizing short-term profit and not a continuous 
yield of sawtimber over time. A decrease in maximum diameter, especially that of more valuable timber species, may also be a characteristic of many stands cut with a diameter-limit. Another metric is a large decrease in basal area, indicating heavy removals.

Harvests of this type maximize the profit of one harvest, but are not the most valuable option over time; Nyland (2005) simulated harvests using seletion system and diameter-limit cuts and found that the net present worth of diameter-limit cuts was lower in almost all instances. This type of harvest may be dysgenic, or reduce tree species diversity in the stand over time (Nyland, 2002, 2005; Erickson et al., 1990). Depending on the severity of the cut and the residual stocking, a harvest may leave little potential for the future production of sawtimber (Fajvan et al., 1998). Removal of the largest trees may also have detrimental effects to wildlife communities which may require them.

\subsubsection{Type 2: Maximized short-term profit, some potential for continued yield (MPCY)}

This type of harvest is similar to the MPLY cut, but less intensive. A selective cut of this type focuses primarily on the removal of large, valuable stems and those of more valuable species. Few if any low-value species are removed. It may be a diameter-limit cut with a higher diameter-limit, or may not be a strict diameter-limit cut, but instead reflect a situation wherein only select stems are removed rather than all trees above a certain size (i.e., high-grading). Depending on the initial stand condition, this type of harvest may appear to be severe, if the larger-diameter trees were a significant portion of the overall stand basal area, or it may have a less obvious but still detrimental effect on the stand's future productive potential.

Such harvests have historically been a method of removing only larger stems of one or more

desirable species (McGee et al., 1999). This type of harvest is an approach that has been 
shown to lead to sustainable growth and yield, as it includes no deliberate improvement of residual stand quality. Species and structural diversity are decreased within the stand.

\subsubsection{Type 3: Maximized sustainable yield (MRSY)}

Historically, uneven-aged management systems in northern hardwoods were designed to maintain a steady volume yield over time. Management of northern hardwoods is still thought to be focused primarily on this goal. Seymour et al. (2006), Schwartz et al. (2005), Crow et al. (2002), Goodburn and Lorimer (1999) and others describe management in terms of this aim, based primarily on the structural conditions described by Arbogast (1957). It has been shown repeatedly to be an effective management system for meeting certain goals, specifically, the goal for which it was developed: maximizing the production of "high quality hardwood timber" over time (Arbogast, 1957). Harvesting over relatively short intervals, using a single-tree selection system, is possible.

The residual density chosen under this harvest type is meant to allow sufficient light to reach the developing understory, while allowing for smaller trees to continually move into dominant positions in the canopy. As with Arbogast's (1957) system, it may favor the development of shade-tolerant species, specifically sugar maple (Crow et al., 2006). The system can be adapted to ensure the regeneration of other valuable and locally rare mid-tolerant species such as yellow birch and black cherry; these may be targeted as future crop trees rather than selected for removal. Low-value stems are removed, which improves the quality and financial value of the stand overall, over time (Fajvan et al., 1998; Erickson et al., 1990; Arbogast, 1957). 


\subsubsection{Type 4: Highly selective cut}

This type is similar to the profit-maximization categories MPCY and MPLY, but with less of the stand basal area removed. This type of harvest represents a selective high-grade (Nyland, 2002). If stand residual basal area is relatively high, strictly looking at the residual stand condition can mask that the harvest exclusively removed large trees of valuable species. Notable features of this type of harvest are that the residual density is not below sustainable levels, but stand structure and species diversity have been negatively impacted by the selective removal of valuable stems with no tending.

\subsubsection{Type 5: High residual, sustainable yield (HRSY)}

Observations made during field work suggested that there were stands with a relatively high post-harvest basal area. The HRSY category reflects harvests where the intention was to remove a relatively small proportion of the basal area, or conversely, to leave a relatively large proportion of the basal area. This harvest type includes some improvement of the residual stand quality by removing low-value stems. It is similar to the MRSY type, but has a residual basal area higher than most management guides recommend. A lighter harvest may be the direct result of landowner's desires and aesthetic preferences. Studies have shown that "lightly managed" stands, in which some dead and dying trees are removed and the understory cleared somewhat, are often preferred by the public (Gobster, 1996). A high residual basal area may also represent an objective of increasing old-forest characteristics in an actively managed stand (Gronewold et al., 2010). Selection system management with

a residual basal areas of $21 \mathrm{~m}^{2} \mathrm{ha}^{-1}$ or higher can also lead to stand-level total ecosystem carbon storage not significantly different from that in an unmanaged stand (Powers et al., 2011). 


\subsubsection{Type 6: Late-successional structural characteristics (LSSC)}

This type represents management which aims to promote structural and functional characteristics of a late-successional stand. Numerous studies have shown that the basal areas of old-growth uneven-aged northern hardwood stands are significantly larger than those of managed stands (Burton et al., 2009; Janowiak et al., 2008; Schwartz et al., 2005; Crow et al., 2002; McGee et al., 1999). Old-growth or late-successional forests are typified by a higher proportion of trees more than $50 \mathrm{~cm} \mathrm{dbh}$. Trees with cavities and standing dead trees are common, providing habitat for wildlife (Burton et al., 2009; Keeton, 2006; McGee et al., 1999). Another attribute common to such stands is the prevalence of species such as yellow birch and eastern hemlock (Burton et al., 2009; Keeton, 2006; Crow et al., 2002).

Old-growth stands are more structurally complex and heterogenous than managed stands (Keeton, 2006; Crow et al., 2002; McGee et al., 1999). Management for such characteristics can be accomplished through altering uneven-aged management systems to leave more dead or dying trees, and more trees in the larger size classes (Gronewold et al., 2010; Mladenoff et al., 1994). Alternately, entirely new management approaches have been proposed. Keeton (2006) described a new approach termed "structural complexity enhancement". The ideal structure for northern hardwoods includes a residual basal area

of $34 \mathrm{~m}^{2} \mathrm{ha}^{-1}$, a maximum dbh of $90 \mathrm{~cm}$, and a specified rotated sigmoid diameter distribution. Structural complexity enhancement can be combined with production of smaller volumes of timber, assuming a 20-25 year or longer entry cycle (Keeton, 2006). Management for old-growth characteristics is a long-term process, but each harvest would be expected to maintain and enhance stand attributes which will moved the stand towards this condition. 


\subsubsection{Sanitation cuts (Sub-category)}

A sanitation cutting is defined as "the removal of trees to improve stand health by stopping or reducing the actual or anticipated spread of insects and disease" (Helms, 1998). After disease or insect infection, salvage cutting is often a viable management option. In the northern hardwoods forests of Michigan, two species are threatened by advancing insects and diseases. Beech bark disease (BBD) is the combinatory effect of a scale insect (Cryptococcus fagisuga) and a fungal pathogen (Nectria spp.) on American beech. The emerald ash borer (Agrilus planipennis) (EAB) affects ash species, of which white ash is the most common. Near-complete removal of one of these species, especially if the level of removal is disproportionate to the removal of other species, suggests that the species was specifically targeted for removal.

Recommendations for management of BBD do not call for the complete removal of beech from a stand. If most or all beech are infected, however, a beech sanitation or salvage cut may remove most or all of the beech in the stand. Similarly, while ash sanitation cutting guidelines do not call for the complete removal of ash in the stand, some go as far as to recommend $99 \%$ removal of ash. The Wisconsin Department of Natural Resources suggests maintaining low density of ash species, less than $20 \%$ of the stand basal area (Eberhart et al., 2007). An ash sanitation or salvage cut could therefore be identified by the near-complete removal of ash within the stand.

Sanitation/salvage cutting is included as a sub-category for the MRSY and HRSY management types. It may be a contributor to the extreme removal levels which suggest profit maximization (HeavySan). Sanitation cutting is a management technique which seeks to improve stand health and vigor over the long-term, and therefore would be expected to be part of a management approach which maximizes growth and yield over time. 


\subsection{Study Objectives}

The goal of this work was to appraise the managed landscape of northern hardwood forests in Michigan using a system of harvest taxonomy. This was accomplished through three distinct objectives. The first was to "calibrate" the system by classifying published marking guidelines and optimized stand structures using the taxonomy. The second objective was to test harvests located throughout the state to diagnose potential landowner objectives and management accomplishments, and to analyze similarities and differences among private industrial (corporate), state, and non-industrial private (NIPF) management. It was hypothesized that most state stands would be managed for timber production, with some being managed for higher residual basal areas and late-successional stand characteristics. It was also expected that harvests of corporate stands would reflect goals of profit maximization and volume production, with stands falling into each of those categories. NIPF harvests were expected to show the most diversity in management, because of the diversity in reasons for ownership and management shown in the results of nationwide surveys (Butler et al., 2010). The final objective was to project a possible future for this landscape given current management trends, as indicated by taxonomical classifications.

\subsection{Methodology}

\subsubsection{Field Methodology}

Recently harvested stands greater than 8.1 ha (20 acres) in size were measured throughout the state of Michigan during the summer of 2010 (see Appendix A for stand locations). Stands were under three different owner types. Forty-one state stands were managed by 
the Michigan DNR, 27 corporate stands were under management from three different private industrial landowners in the Upper Peninsula, and 28 NIPF stands were owned by individuals and families. Most NIPF stands were managed with the assistance of a consulting forester.

In each stand, ten circular 0.01-ha plots were randomly installed. Species and diameter were measured for all stems greater than $10 \mathrm{~cm}$ in diameter. Pre-harvest density was estimated using a localized version of Raile (1978)'s equation for predicting dbh from stump diameters (see Chapter 5).

During the summer of 2011, 48 stands were resampled. Ten circular 0.04-ha plots were installed in each stand; whenever possible, plot centers were relocated and the new plots were centered in the same location. If the plot center could not be located, a new plot was installed. On average, 7 of 10 plot centers were relocated in each stand.

\subsubsection{Analytical methodology}

The goal structures from several published target diameter distributions were classified using the chart, to assess its accuracy. All measured harvests were quantitatively classified according to the chart. The distribution of harvest types among landowner types was compared using a Pearson's $\chi^{2}$ test. Classifications of stands on which two sets of measurements were made were compared to estimate the sensitivity of the taxonomical classifications to plot size and sampling variability. 


\subsection{Results}

All published recommendations applied with the removal of low-value species result in a classification of Maximized Residual, Sustainable Yield (Table 4.2, see Table 4.1 for acronyms). This is a fairly broad category; the residual basal area and maximum diameter vary among the tested structures, yet all fall into this classification.

Table 4.2

Assessment of published structures using harvest taxonomy

\begin{tabular}{|c|c|c|c|}
\hline Publication & Description & Observations and Caveats & Conclusion \\
\hline Arbogast 1957 & $\begin{array}{l}\text { Marking guideline and } \\
\text { target residual stand } \\
\text { structure }\end{array}$ & & MRSY \\
\hline Adams and Ek 1974 & $\begin{array}{l}\text { Optimal diameter } \\
\text { distributions for various } \\
\text { basal area levels }\end{array}$ & $\begin{array}{l}\text { Assuming that low-value } \\
\text { species are harvested }\end{array}$ & MRSY \\
\hline Martin 1982 & $\begin{array}{l}\text { Investment-efficient } \\
\text { stocking using several rates } \\
\text { of return, by refitting } \\
\text { Adams and Ek's work with } \\
\text { Weibull function }\end{array}$ & $\begin{array}{l}5 \% \text { and } 3 \% \text { on Good sites } \\
\text { All others ( } 1 \% \text { on Good; } 5 \text {, } \\
3,1 \% \text { on Fair Sites; } 3,1 \% \\
\text { Poor sites) }\end{array}$ & $\begin{array}{l}\text { MPCY } \\
\text { MRSY }\end{array}$ \\
\hline Bare and Opalach 1988 & $\begin{array}{l}\text { Re-optimization of Adams } \\
\text { and Ek's work to an } \\
\text { investment-efficient } \\
\text { diameter distribution }\end{array}$ & & MRSY \\
\hline Niese and Strong 1992 & $\begin{array}{l}\text { Trade-offs between stand } \\
\text { diversity and economics }\end{array}$ & $\begin{array}{l}\text { Their medium selection } \\
\text { treatment is "best" }\end{array}$ & MRSY \\
\hline Gove and Fairweather 1992 & $\begin{array}{l}\text { Re-optimization of data } \\
\text { collected in uneven-aged } \\
\text { northern hardwood stands }\end{array}$ & $\begin{array}{l}\text { Not a marking guide, just a } \\
\text { definition of structure. } \\
\text { Assuming harvests aim to } \\
\text { improve the quality of } \\
\text { residual, high-value species }\end{array}$ & MRSY \\
\hline
\end{tabular}


The numbers of harvests by category and owner type are presented in Figure 4.2 (harvest taxonomies reproduced from Figure 4.1; see Table 4.1 for acronyms).

\begin{tabular}{|c|c|c|c|c|c|}
\hline \multirow[t]{2}{*}{$\begin{array}{l}\text { Maximized } \\
\text { short-term } \\
\text { profit, low } \\
\text { potential for } \\
\text { continued yield } \\
\quad n=10\end{array}$} & $\begin{array}{l}\text { Maximized } \\
\text { short-term } \\
\text { profit, some } \\
\text { potential for } \\
\text { continued yield } \\
\quad n=22\end{array}$ & $\begin{array}{l}\text { Maximized } \\
\text { sustainable yield }\end{array}$ & $\begin{array}{l}\text { Highly selective } \\
\text { cut. Potential for } \\
\text { continued yield. }\end{array}$ & $\begin{array}{l}\text { High residual } \\
\text { Sustainable yield }\end{array}$ & $\begin{array}{l}\text { Late } \\
\text { successional } \\
\text { characteristics }\end{array}$ \\
\hline & $\begin{array}{l}\text { Near complete } \\
\text { removal of WA } \\
\text { or AB? } \\
\begin{array}{l}\text { Heavy cut, some } \\
\text { sanitation } \\
n=1\end{array}\end{array}$ & $\begin{array}{l}\text { Near complete } \\
\text { removal of WA or } \\
\text { AB? } \downarrow \text { YES } \\
\text { MRSY- } \\
\begin{array}{c}\text { Sanitation cut } \\
n=2\end{array}\end{array}$ & & $\begin{array}{c}\text { Near complete } \\
\text { removal of WA } \\
\text { or AB? } \\
\text { HRSY- } \downarrow \text { YES } \\
\text { Sanitation cut } \\
n=2\end{array}$ & \\
\hline
\end{tabular}

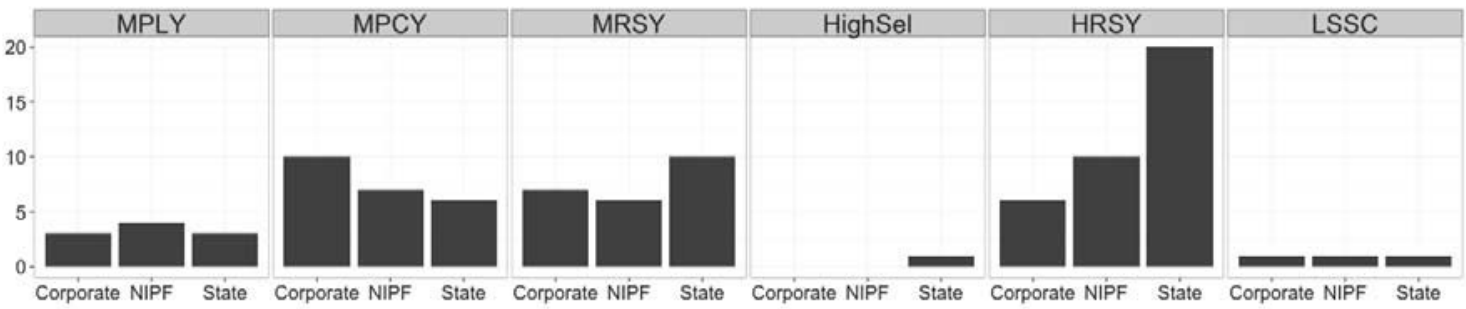

Figure 4.2: Graphical representation of harvest taxonomy, and results, from 96 stands measured in 2010 with $100 \mathrm{~m}^{2}$ plots.

The breakdown of harvest types by landowner for the 2010 dataset reveals that the classification distributions are similar (Figure 4.3). There were no differences among owner types $\left(\chi^{2}(14, \mathrm{~N}=96)=15.98, \mathrm{p}=0.31\right.$, Cramer's V=0.29). NIPF stands were primarily classified as MRSY or HRSY- meeting or exceeding recommended density, and differentiated from harvests conducted purely for profit. The vast majority of state stands had a classification of HRSY- harvests less intense than recommended in published guidelines. Numerous state and NIPF stands also were classified as MPCY, MPLY, or HeavySan, indicating heavy harvesting and some or no potential for similar yield in future harvests. Corporate stands were more often harvested in manners reflecting short-term profit goals. Overall, 34\% of stands were harvested in a manner which maximized short-term profit (MPLY or MPCY), 23\% were harvested in a manner suggesting maximized yield over time (MRSY), and 38\% were harvested with a higher residual than 
recommended for maximizing yield and regeneration (HRSY).

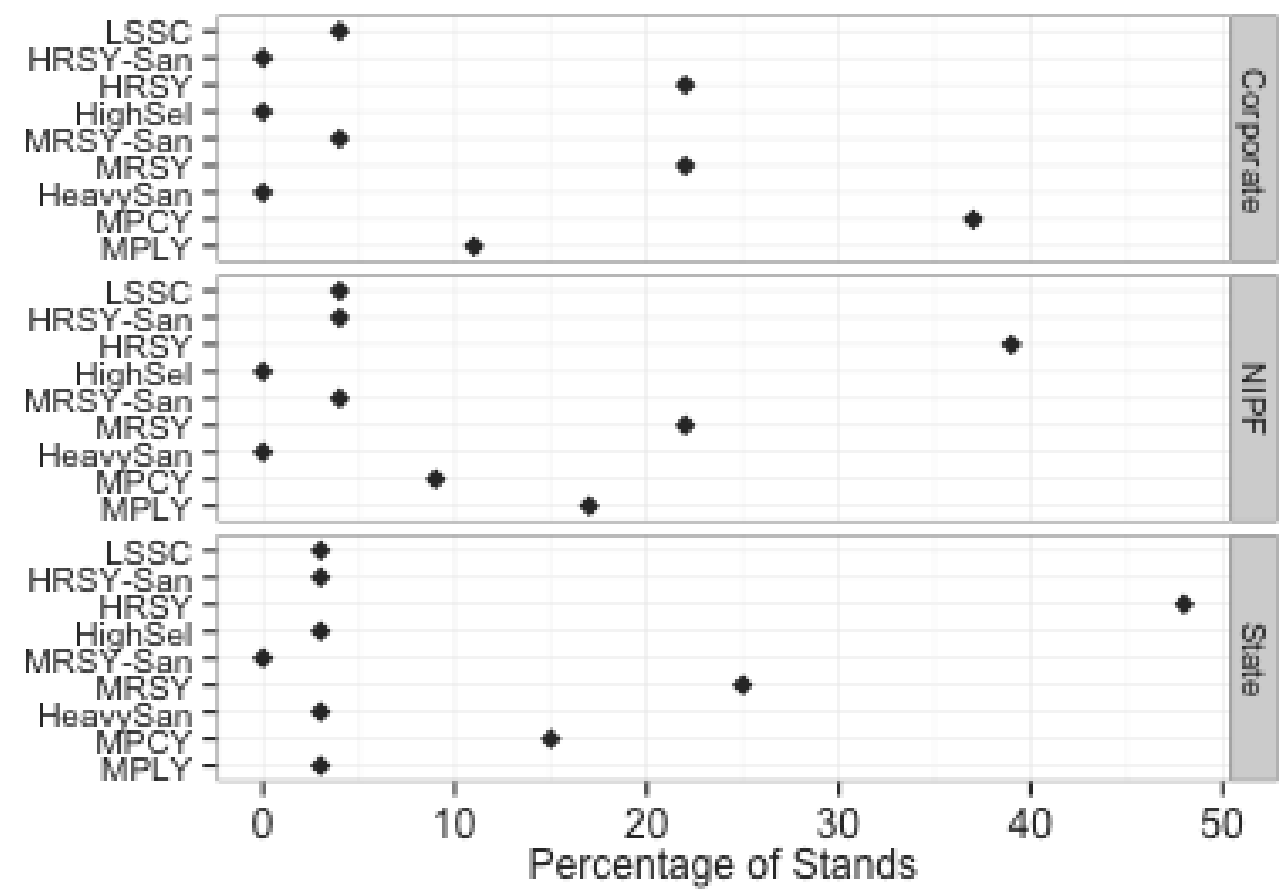

Figure 4.3: Harvest classifications by percentage. See Table 4.1 for acronyms.

Remeasurements made during 2011 resulted in smaller standard errors than 2010 estimates of basal area and trees per hectare by stand and size class (data not shown). The 48 stands which were remeasured in 2011 were classified using that year's data (Table 4.4). Forty percent of stand classifications were unchanged. The distribution of classifications changed between the two years, shifting from primarily HRSY classification in 2010 to primarily MPCY classification in 2011 (Table 4.3) and suggesting on average somewhat greater removals. Because LSSC and Sanitation classifications were not well represented in the 2010 dataset and not present in the 2011 dataset, Sanitation classifications were combined with broader classifications in Table 4.3. 
Table 4.3

Aggregate harvest classifications in 2010 and 2011

\begin{tabular}{|ccccc|}
\hline & \multicolumn{2}{c}{2010} & \multicolumn{2}{c|}{2011} \\
& $100 \mathrm{~m}^{2}$ plots & $400 \mathrm{~m}^{2}$ plots \\
\hline MPLY & 4 & $8 \%$ & 3 & $6 \%$ \\
MPCY & 13 & $27 \%$ & 19 & $40 \%$ \\
MRSY & 11 & $23 \%$ & 14 & $29 \%$ \\
HRSY & 19 & $40 \%$ & 12 & $25 \%$ \\
LSSC & 1 & $2 \%$ & 0 & $0 \%$ \\
\hline
\end{tabular}

Table 4.4

Contingency table of 2010 and 2011 classifications

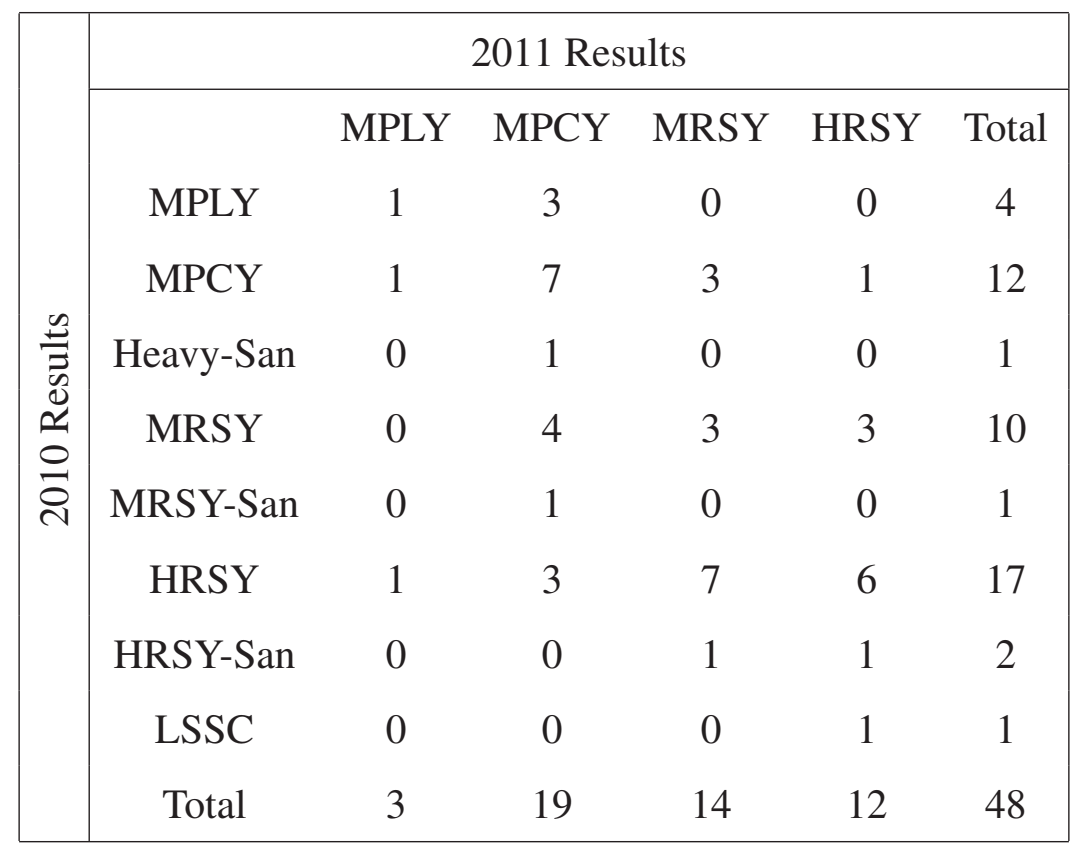




\subsection{Discussion}

All published management guidelines and structural optimizations were classified as MRSY- Maximized Residual, Sustainable Yield, with the exception of Martin's structural recommendations for high rates of return on high-quality sites. In that case, the classification was MPCY- Maximized Profit, Continued Yield, representing high removals where growth is presumed to be higher than average. Because the MRSY classification encapsulated all of the structures described in the tested publications, it can be concluded that the classification encompasses numerous and diverse management approaches, if they successfully produce a steady supply of timber. The converse is that stands not classified as MRSY are not being harvested in accordance with any common guideline designed for long-term sawtimber production, based on the results in Table 4.2. Furthermore, there are consequences of lost future productivity, stand degradation, and limited regeneration when a harvest intended to produce sawtimber does not fall into that category. This distinction is key to differentiate MRSY and LSSC harvests; the long-term objective of an LSSC harvest is restoration of specific structural characteristics with minimal sawtimber production, and thus a "loss" of sawtimber productivity is no loss at all. The implications of a harvest falling "between" those categories (HRSY) will be discussed further.

\subsubsection{Harvest classifications by ownership}

The harvest classifications using 2010 data show three things clearly- first, there were no distinct differences between state, corporate, and NIPF land management. Second, stands throughout Michigan are being harvested in a manner suggesting short-term profit maximization and having a range of negative ramifications for future development and productive potential. Third, numerous other stands are being harvested more lightly 
than published recommendations for regeneration and timber production. This may indicate the difficulty in reconciling competing objectives such as minimal ecological and aesthetic impacts in harvesting and long-term forest growth and resilience. Hypotheses of differences among landowners were not wholly supported by these findings.

Ten of 96 stands were cut so heavily that there is likely low potential for continued yield; 23 of 96 stands were cut in a manner that indicated maximization of short-term profit, but with both high- and low-value species removed. This indicates some effort to improve growing conditions for remaining higher-value stems and therefore suggests there is potential for continued yield and stand improvement in the future. The state had more high-residual harvests, corporate owners had more high-profit harvests, and NIPF owners had the most even distribution (Figure 4.3). Five stands, representing a range of removal levels and residual basal areas, were apparent sanitation cuts. Three stands with high post-harvest basal area had characteristics that may indicate management for late-successional characteristics. Stands in which only a few trees were removed, if those were the most valuable trees, would also have been distinguishable from the other high-residual stands; no harvests fit this type.

NIPF harvests were very diverse, matching possible objectives reported in the National Woodland Owner Survey (Butler et al., 2010). The NWOS from 2010 in Michigan shows that recent harvests were conducted for reasons that included following a management plan, improving residual stand quality, and improving hunting and recreation. A small percentage of recent harvests were reportedly conducted primarily for financial reasons. The results of the taxonomic classifications support this; only eleven of 28 NIPF stands were harvested in a manner that suggests that profit-maximization was a greater factor in management decisions than long-term sustainability.

This also opposes the idea that NIPF landowners are high-grading or implementing profit-driven harvests with no concern for future growth and yield (Hull, 2011). Reasons 
for this difference between Michigan harvests and harvests studied in West Virginia (Fajvan et al., 1998) and New York (Munsell et al., 2009) are not obvious. Munsell et al. (2008), however, found that harvests in Mississippi generally resulted in a better overall stand quality, while diameter-limit cutting was much more prevalent in New York. Michigan NIPF owners appear to manage more similarly to those in Mississippi than those in New York.

Perhaps the most surprising was the diversity of management observed in stands owned by the state and managed by the Michigan Department of Natural Resources. Previous studies have indicated that the state has a multiple-use approach, where stands are managed for timber products, wildlife habitat, and aesthetics. Schwartz et al. (2005) expected state stands to be harvested with a residual of $18.4 \mathrm{~m}^{2} \mathrm{ha}^{-1}\left(80 \mathrm{ft}^{2} \mathrm{ac}^{-1}\right)$, and in fact found an average residual basal area higher than that. The minimum stand basal area reported by Schwartz et al. (2005) was $17.1 \mathrm{~m}^{2} \mathrm{ha}^{-1}$, whereas the minimum state stand basal area in this study was $10.1 \mathrm{~m}^{2} \mathrm{ha}^{-1}$. The wide variety in state harvesting practices may indicate differences among Forest Management Units, or a variety of objectives within and among FMUs. The latter seems more likely, as spatial statistical testing showed no geographical patterns in the classification of stands (results not shown). Nevertheless, that $18 \%$ of these stands were MPLY or MPCY harvests suggests that the management of state land is also subject to profit maximization at the expense of long-term forest growth and yield.

\subsubsection{Future implications}

One third of stands were cut more heavily than most guidelines suggest; more than one third were cut more lightly. This is similar to the results of the comparison of harvests against only the 1957 Arbogast guideline (Chapter 2), and in contrast to the findings of Fajvan et al. (1998) and Munsell et al. (2009). Both of those studies found the majority of stands 
were high-graded and had little future potential for growth and yield. Extremes of highand low-intensity cutting are noteworthy because they simultaneously affirm and dispel stereotypes. In this study, corporate stands on average were twice as likely to be harvested for short-term profit than NIPF and state managers (48\% vs $26 \%$ and 18\%, respectively). Stands in the holdings of three different corporate landowners were measured, all of whom as privately owned companies would presumably be primarily interested in generation of revenue. Even these companies, however, had $48 \%$ of harvests classified as MRSY and HRSY, indicating management conducive to continued growth and yield over time.

The MPCY and MPLY harvests were characterized by high removals coupled with some tending of residual growing stock (the former), or where no tending was discernable (the latter). This is extensible to the proportion of stands in which removals diminish future productive capacity. If each stand is assumed to have equal area, and an equal number were harvested between 2005-2010, $10 \%$ of harvests each year drastically reduce the productivity of northern hardwood stands, and more than $20 \%$ reduce future productive potential and diversity to some extent. These findings are approximately constant across the three ownerships studied.

The high prevalence of HRSY classifications is notable and unexpected. The residual density in an HRSY harvest is comparable to that of high-residual selection system harvests which (Powers et al., 2011) found to have total ecosystem carbon levels not different from those of unmanaged northern hardwood stands. Thus total ecosystem carbon storage in an HRSY is potentially comparable to that in an unmanaged stand, and higher than MRSY and other classifications. However, the level of intensity may not facilitate regeneration of even shade-tolerant tree species (Matonis et al., 2011). While this approach is likely aesthetically pleasing- creating less slash and maintaining a low-density understory- the ecological ramifications are complex. When a harvest fails as a regeneration cut, at some point in the future there will be trees of a certain size and age "missing" from the stand. On a landscape level, this could noticeably reduce the available supply and increase the 
price of pulp or sawtimber for several years. If this occurs in a few stands it clearly will not have a huge impact, however, $36 \%$ of surveyed harvests fit this description according to the taxonomy. Managers of the $23 \%$ of stands which were classified as MRSY, which could be expected to produce another harvest of equal or greater quality during the next cutting cycle, would then be under more intense pressure to cut above sustainable harvest levels to take up the slack from reduced supply coming from light-intensity harvests and previously degraded stands.

\subsubsection{Influence of plot size on classifications}

The classification of stands which were remeasured in 2011 showed that the taxonomical classifications vary primarily with estimates of post-harvest basal area and the level of removal of low-value species. Of the stands that were remeasured, 40\% (19 stands) were classified the same way using 2010 and 2011 data. For another 20 stands, the classification changed as the result of the estimate of post-harvest basal area crossing one of the thresholds in the chart, either 17.22 or $22.96 \mathrm{~m}^{2} \mathrm{ha}^{-1}$. Differentiation of harvests based on those thresholds is quite influential on the final classification, especially for stands with extremely high or low post-harvest basal area. The remaining harvests changed classification because removals of low-value species differed between the two sets of data.

The taxonomic system is of course dependent on the accuracy and precision of the sample. It is clear that sampling using small plots or widely heterogenous stands could result in inaccurate classification due to nonrepresentative data. In this work, the 2011 data were collected from plots four times larger than the 2010 plots. While both provide unbiased estimates of stand characteristics, the variance in the 2011 data was much smaller. Because the larger plots installed in 2011 provide more accurate data about the harvests, 
classifications based on the 2011 data are more, there is a greater cause for concern. The 2011 classifications showed that a greater proportion of harvests were profit-maxizing and fewer harvests appeared to include tending of future growing stock.

Extrapolations must be made with caution, however, because the 2011 data were collected from only half of the stands. Katz and McSweeney (1979) provide a helpful discussion on the loss of power resulting from the use of $\chi^{2}$ tests on misclassified data. Without knowing the relative rates of misclassification which result from comparing data from plots of differing size, the most prudent decision was not to test for statistical differences between the 2010 and 2011 data. It should also be noted that the power of the $\chi^{2}$ test conducted on the distributions of classifications by owner type on the 2010 data is less than 0.38 , which would be the assumed power based on the effect size and data; the true power is dependent on the exact misclassification rate (Katz and McSweeney, 1979).

Results from the use of this taxonomical system are in no way conclusive. The accuracy of the system is difficult to quantify or even test. The "calibration" using published recommendations certainly suggests that the MRSY classification is flexible enough to capture a variety of stand structures; the chart did not misclassify any published structure designed for long-term, consistent sawtimber production by assigning it another objective. Simulated or measured harvests which were known to be conducted for other objectives could be classified to further test the chart. These are tests of the output, however, and not of the procedure itself. Tests of misclassification of categorical data require the "true" category to be known (Katz and McSweeney, 1979). The decision nodes of the taxonomy could perhaps be redefined as parameters in distinct models which predict each harvest classification; this would facilitate the use of a parametric sensitivity analysis (Hoare et al., 2008), but would also fundamentally change the interconnected, reticulated nature of the taxonomy. The effective classification of stands depends on the effective construction of an accurate and unbiased system. This taxonomy may not be the ideal incarnation of such a system, and perhaps should be better considered a template for an efficient harvest 
assessment protocol, improvable through more rigorous validation against test data.

Finally, there may be other management objectives not clearly captured by the chart. Creation and maintenance of specific wildlife habitats and development of recreational areas were not explicitly represented as management objectives; the taxonomy was designed to describe commercial harvests including the removal of some sawtimber-sized trees. Experimental implementations of silvicultural techniques not common in North American forests-femelschlag and its variants, for example-will likely be misclassified if encountered (Puettmann et al., 2009). Additional data that could be used to make additional or clarifying nodes in the chart might include time since previous harvests, relative composition of advance and post-harvest regeneration, and the age distribution within the stand. An excellent validation of the chart would be to survey landowners regarding management objectives and intended harvest goals; there is no guarantee, however, that landowners who conducted a strongly profit-motivated, short-term harvest would freely state this on a survey (Egan and Jones, 1993). Future research which includes both silvicultural and sociological assessments would be beneficial to match actual landowner objectives with the hypothesized objectives on which the chart is based, and to probe differences between harvest intentions and accomplishments.

\subsection{Conclusions}

There is a clear methodological strength in the application of a quantitative harvest taxonomy. This approach allowed a rapid comparison of harvests to numerous management guidelines as well as to plausible, but not recommended goals. The result is a more complete understanding of what effect each harvest had on the resultant stand structure and what the original management objectives may have been. 
Both residual stand composition and harvest removals suggest possible management goals, and a consideration of silviculture and landowner intentions beyond those presumed by any one management guideline provides a more complete picture. The taxonomical classifications suggest that in $33 \%$ of harvests, long-term productive capacity may have been decreased through short-term profit maximization. Some of these stands may not be a continued source of forest products or other ecosystem services which depend upon a healthy, resilient forest structure. There were many harvests which did not remove as much timber as management guidelines allow. Some harvests seem to have successfully encouraged development of late-successional stand characteristics, maintaining large diameter stems and mid-tolerant species. Other harvests may not have been successful as regeneration cuts; stand basal area and structural diversity were decreased in a manner that may not have facilitated the growth of a new cohort. Overall, the results of this field study and analysis show a great diversity of management in the northern hardwoods of the region. 


\section{Chapter 5}

\section{Describing northern hardwood stand}

\section{structure using kernel density estimation and data-driven binning methods}

\subsection{Introduction}

A diameter distribution, or the frequency distribution of trees by diameter class, is a tool used to describe important structural characteristics of a forest stand. Pre- and post-harvest stand structures may indicate future development trajectories based on known patterns of growth and development, and reflect how harvesting altered the diameter distribution. The relative distributions of trees of different sizes and species may be expressed as continuous functions, or as discrete distributions (i.e., histograms). Likewise, distributions can be quantified and modelled with a close fitting curve, or qualitatively labelled based on attributes of a smoothing function. Because distribution curves have been used to study and explain stand dynamics, methods for fitting curves have also been the subject of much 
biometric research.

The shape of the curve representing stand structure can be used to compare stands to one another, facilitating research focused specifically on identifying and naming the structures of old-growth (unmanaged) stands. Empirically observed old-growth structures have also been identified as equilibrium structures using mathematical modelling (Zhang et al., 2001; Lorimer and Frelich, 1984). A structural distribution similar to old-growth stands is of interest because it likely provides suitable habitats for wildlife and understory plant species

adapted to those stands, as well as maintaining desirable aesthetic qualities for recreators and landowners (Keeton, 2006; Gobster, 1996). Because of this, research has also focused on contrasting old-growth structures with those identified in second-growth unmanaged and managed stands.

\subsubsection{Past use in research and management}

Continuous distributions are approximated using a variety of methods of fitting curves to unbinned frequency data, e.g., stems or basal area per unit area by diameter class. Diameter distributions may also be modelled discretely using binned frequency data, producing histograms and piece-wise functions, or allowing further parametric or nonparametric smoothing. Examples in the literature range from use of multiple (segmented) curves to fit as closely as possible to the diameter distribution (Liu et al., 2002; Cao and Burkhart, 1984) to approximating curve shape based on the signs of coefficients in a multiple linear regression on bin heights (Janowiak et al., 2008; Schwartz et al., 2005; Leak, 1996). For binned data, both the binwidth chosen and the closeness of the fit required influence the shape of the resulting curve. Histograms of frequency data are used in the calculation of the $q$-factor rooted in de Liocourt's 1898 work (Meyer, 1952), where the value of $q$ is the ratio of the number of trees in one diameter class to trees in the next largest class. The 
$q$ values most commonly discussed in North American literature for northern hardwoods (e.g. an inverse-J shape with a constant $q$-factor of 1.3) are calculated using 2 inch or $5 \mathrm{~cm}$ diameter classes (Schwartz et al., 2005; Leak et al., 1987; Leak and Gottsacker, 1985). The impact of the diameter class width on the shape of curves fit to binned data and subsequent interpretations of stand structure is not discussed in forestry literature, though the impact of binwidth on curves and objective methods for binwidth selection have been proposed by neurologists (Shimazaki and Shinomoto, 2007), physicists (Knuth, 2006; Lafferty and Wyatt, 1995), and statisticians (Wand, 1997; Wand and Jones, 1995).

A common application of diameter distribution curves is growth and yield modelling. This includes the prediction of future diameter distributions for management planning and the specific prediction of products and yield (Gul et al., 2005; Wang and Rennolls, 2005; Cao, 2004; Liu et al., 2002; Knoebel and Burkhart, 1991; Cao and Burkhart, 1984; Hyink and Moser, 1983). Policy requirements may necessitate this; Maltamo et al. (2000), for example, state that because silvicultural planning in Finland is now allowed to be more varied than in the past, curves that describe diameter distributions more exactly are now required for more accurate long-term harvest planning and growth projections. Many different technical approaches have been used to create curves for modelling purposes. At times the intention of such approaches is implied rather than explicitly stated; Gove et al. (2008), Zhang and Liu (2006) and Zutter et al. (1986), for example, present new methods for fitting diameter distribution curves without any detailed explanation for the utility of their work.

The distribution of diameters within an unmanaged, uneven-sized stand has been used as an indicator of the sustainability and stability of the stand. In managed stands, sustainability equates to the presence of a balanced structure, one that allows annual or periodic removal of growing stock without changing the overall structure or volume of the forest (Meyer, 1952). Lorimer and Frelich (1984) fit diameter distribution curves to "assess the degree to which a forest has approached equilibrium". The generic reverse-J shape, in which 
the number of trees in each size class diminishes with increasing diameter, comes from the negative exponential curve family. This implies a constant rate of diminishing, as in Meyer's 1952 constant $q$-factor. A similar curve shape is the rotated sigmoid curve, which is differentiated from a negative exponential curve by the presence of an additional "hump" in the middle diameter classes, where there are more trees than in the smaller or larger classes. Leak (2002) argued that though rotated sigmoid curves may occur where a stand initially has a strong rotated sigmoid character or immediately after a harvest or disturbance, negative exponential curves are the predominant shape found in northern hardwood stands. Conversely, Frelich (2002), without being specific, describes an approximately rotated sigmoid diameter distribution as the expected structure for a "multi-aged" (old-growth) stand. Goff and West (1975) found that old-growth stands in northern Wisconsin tended towards a rotated sigmoid form; Lorimer and Frelich (1984) modeled sugar maple equilibrium distributions using stand table projections and also found an approximately rotated sigmoid shape in final curves represented with Weibull functions. Both of those studies identified shapes through visual assessment of curves plotted on semilogarithmic axes.

The repeated observation of rotated sigmoid structures in both field measurements and growth models prompted a great deal of research to identify the rotated sigmoid distribution in other stands. Leak (1996) developed a test for the presence of rotated sigmoid shapes in the broader context of identifying sustainable structures in old-growth stands. Similar work was done by Goodburn and Lorimer (1999). Schwartz et al. (2005) and Janowiak et al. (2008) expanded Leak (1996)'s test for rotated sigmoid shapes into a test that distinguishes among increasing- $q$, rotated sigmoid, and negative exponential distributions, as well as identifying unimodal and concave structures. Increasing- $q$ shapes represent a pattern where the $q$-ratios increase with diameter, rather than the constant $q$-ratio in a negative exponential shape. Other structures differentiated by this test are concave and unimodal- concave structures have fewer trees in the middle diameter classes than in smaller or larger classes, and unimodal curves more closely resemble the structure common in even-aged stands 
(Nyland, 2002). Many studies were conducted to identify and distinguish among various sustainable structures in unmanaged stands, as well as to determine the sustainability of management activities by testing for the three diameter distribution shapes thought to be equilibrium shapes (Schwartz et al., 2005).

Histograms of stand structure are the basis for a system of naming the curve that best fits the overall structural shape, developed by Leak (1996) and used or honed by others (e.g., Janowiak et al., 2008; Schwartz et al., 2005; Goodburn and Lorimer, 1999). This procedure involves performing linear regression to predict the logarithm of trees per hectare from all possible combinations of the diameter class midpoint from each histogram bin (dbh [diameter at breast height, 4.5 feet or $1.3 \mathrm{~m}$ ], $\mathrm{dbh}^{2}$, and $\mathrm{dbh}^{3}$ ). The signs from the coefficients of the best-fitting equation (that with the highest $\mathrm{R}^{2}$ value) are referenced against Table 5.1 and the diameter distribution of the stand assigned the name associated with that set of signs. All applications of this approach thus far have used histograms with 5 cm binwidths (e.g., Diaci et al., 2011; Alessandrini et al., 2011; Gronewold et al., 2010; Janowiak et al., 2008).

Goodburn and Lorimer (1999) found rotated sigmoid and negative exponential stands in both old-growth and managed stands. Janowiak et al. (2008) found rotated sigmoid and negative exponential curve shapes in unmanaged stands, and increasing- $q$ and rotated sigmoid curves in managed stands. Similarly, Schwartz et al. (2005) found increasing- $q$, rotated sigmoid, and negative exponential diameter distributions in managed stands in northern Michigan. Gronewold et al. (2010) tested stand structural changes over time in managed stands that were old-growth at the start of the study. They used the named distributions to make recommendations as to what intensities of single-tree selection harvests may best create ecological conditions resembling those in old-growth unmanaged stands. Schwartz et al. (2005) tested 25 stands under state and corporate ownership in the Upper Peninsula of Michigan and found no correlations between management intensity and curve shape. All stands had typically "balanced" curve shapes. Similar results were 
found by Janowiak et al. (2008) and Goodburn and Lorimer (1999) in managed stands. The system has since been adopted and used to measure old-growth and managed stands in Europe (Diaci et al., 2011; Alessandrini et al., 2011).

The polynomial regression-based approach appears to be the simplest and most commonly employed method of discretely classifying diameter distributions shape by name. While it has not been widely used in North America outside of the Great Lakes region of the United States, its application in Europe suggests that it has natural appeal as a qualitative metric of stand structure. The procedure uses histograms of frequency data, a commonly accepted form of presenting such data. The polynomial regression equations used are straightforward to fit and can be clearly compared against a small set of possibilities (Table 5.1); while other functions such as segmented polynomials, or the Weibull or Burr Type III distributions may provide more closely fitting curves to a single set of stand data, they lack the ease of between-stand comparison which is made possible by categorical comparisons. 


\section{Table 5.1}

Method using signs of significant coefficients in polynomial regression models to determine diameter distribution shape in northern hardwood stands. From Janowiak et al. (2008). Reproduced with permission of the Society of American Foresters via Copyright Clearance Center. See Appendix D for documentation of this permission.

\begin{tabular}{cccc}
\hline \multicolumn{3}{c}{ Coefficient } & \\
\cline { 1 - 2 } $\mathrm{dbh}$ & $\mathrm{dbh}^{2}$ & $\mathrm{dbh}^{3}$ & Distribution shape \\
\hline- & $\mathrm{ns}^{*}$ & $\mathrm{~ns}$ & $\mathrm{NE}$ \\
$\mathrm{ns}$ & - & $\mathrm{ns}$ & $\mathrm{IQ}$ \\
$\mathrm{ns}$ & $\mathrm{ns}$ & - & $\mathrm{IQ}$ \\
- & + & $\mathrm{ns}$ & $\mathrm{CO}$ \\
- & $\mathrm{ns}$ & + & $\mathrm{CO}$ \\
+ & - & $\mathrm{ns}$ & $\mathrm{UNI}$ \\
+ & $\mathrm{ns}$ & - & $\mathrm{UNI}$ \\
- & $\mathrm{ns}$ & - & $\mathrm{IQ}$ \\
$\mathrm{ns}$ & - & + & Variable \\
$\mathrm{ns}$ & + & - & $\mathrm{UNI}$ \\
- & + & - & RS \\
+ & - & + & Variable \\
\hline
\end{tabular}

When distribution shapes were determined to be variable, the second best-fitting significant model was used. Regression model classifications are as follows: NE, negative exponential; IQ, increasing- $q$; RS, rotated sigmoid; $\mathrm{CO}$, concave; UNI, unimodal.

*ns indicates nonsignificant coefficients.

The polynomial regression approach as used in past studies assumes uneven-sized stand structures should take only five named, discrete types. If the best fitting polynomial 
regression equation does not have signs that match one of those categories, the second-best fitting curve is chosen. If neither of the two best fitting curves has signs representing a named structure, the stand structure is termed "ns" for non-significant ("Unknown" was used in this study), a catch-all category containing multiple structures. These are likely to be dissimilar to each other, and includes stands for which the signs of the regression curve did not match any of the named categories and stands for which none of the predictors in the polynomial regression was significant.

A histogram is a simple nonparametric description of a dataset. More flexible nonparametric approaches, such as kernel density estimation, have been demonstrated to be more efficient and have a more optimal tradeoff between variance and bias, smoothing the data without losing important features (Wand and Jones, 1995). These are more suited to characterizing the true shape of the data, rather than discrete classification. Similar to the binwidth of a histogram, the scale of the kernel (bandwidth) chosen is important as it determines the amount of smoothing applied to the data. Bin placement has no influence on kernel density estimates (Wand and Jones, 1995) as there are no bins.

\subsubsection{Data-driven binning methods}

Binning, as the basis for histogram construction, smooths the data prior to the fitting of polynomial regression curves. The regressions are fit using only the midpoints of the bins; the named curve shape is therefore the shape representing the best-fitting curve to a set of pseudo-data. The use of different bin widths to construct histograms essentially creates multiple sets of pseudo-data for a given stand, all of which smooth the distribution of the data differently.

Histograms can be created using a variety of data-driven methods developed in other fields. 
Three methods were the focus of this study, referred to as Wand, Knuth, and AIC. All three algorithms use the minimum diameter in the stand as the starting point for the first bin in the histogram, and each optimizes binning using bins of equal widths. The Wand approach uses "plug-in smoothing" (Wand, 1997; Wand and Jones, 1995). The true function underlying the distribution is estimated using kernel density smoothing, and then compared to binned functions of different binwidths. The binwidth that minimizes the mean integrated square error (MISE) between the binned and estimated functions is selected.

The Knuth approach (Knuth, 2006) rejects the use of the MISE, on the grounds that the MISE is an estimate because the true density is unknown. Because of this, Bayesian statistical theory is employed instead. The posterior probability of a piece-wise constant model, for which the prior is uniform, is calculated. The optimal number of bins is the mode of the marginal posterior. Empty (non-populated) bins are included in the model explicitly, because they are assigned a non-zero probability when the posterior is calculated. The optimal number of bins is divided by the range of the data to determine the width of each bin, and histograms are generated using that information.

Akaike's Information Criterion (AIC) is a common criterion used in comparing statistical models. AIC is generally used to compare models with different numbers of predictors, weighting models with fewer parameters to compensate for the improved predictive ability from adding additional parameters (Akaike, 1973). The AIC approach to histogram creation is applied by drawing on mathematical statistics to calculate the log-likelihood of a histogram with bins of varying numbers, and comparing them through the application of AIC as a penalty for increasing numbers of bins. The number of bins chosen is that for which the AIC is maximized (Mildenberger et al., 2009).

Kernel density estimation is an alternate nonparametric smoothing method (Wand and Jones, 1995). Kernel density estimation (KDE) approximates a curve using a "moving window" that averages the density of the data within the window based on the densities 
of kernels (pre-defined, symmetric functions) centered on each data point. The kernel density approach underlying commonly available KDE software packages (Wand, 2011; R Development Core Team, 2012) is actually a binned kernel density estimation, wherein a system of linear binning weighs data points in relation to proximity to a pre-established grid of points. Binned kernel density estimation is computationally more efficient, while also providing density estimates "virtually indistinguishable" from non-binned density estimates (Wand and Jones, 1995). Binning for KDE facilitates more effective smoothing of the data via kernel density estimation calculations, as opposed to binning for histogram construction, the sole function of which is to smooth the data.

The influence of plot size on diameter distribution curves must also be considered. Published literature includes curves fitted to plots ranging from 0.012 ha (Cao and Burkhart, 1984) to 3.2 ha (Janowiak et al., 2008) in size and a large range in total sampled area, as the scope of studies ranges from plot- to landscape-level. Janowiak et al. (2008) argued that a total of at least 0.4 ha (for their study, $13 \%$ of the stand area) was sufficient to represent the shape of the entire population of a 3.2 ha managed stand. Rubin et al. (2006) suggested that accurate detection of negative exponential shapes was dependent on both plot size and true maximum tree diameter, where the method of detection was not clearly defined but seemed to refer to drawing samples containing trees of larger diameters from a known population. They used simulated data to show the effects of plot size, maximum diameter, and binwidth on shape, focused primarily on negative exponential curves. Studies also show that the minimum diameter chosen can influence the fit of a curve and choice of curve shape (Zutter et al., 1986; Janowiak et al., 2010). Truncation of the diameter distribution may be especially influential on the differentiation between rotated sigmoid and increasing- $q$ curves, where the inclusion of small diameter classes which contain large numbers of trees and may have low $q$ ratios results in a rotated sigmoid classification, while omission of these classes may result in a classification of increasing- $q$ (Janowiak et al., 2010). 


\subsection{Goal and objectives}

The overarching goal of this study was to assess the sensitivity and flexibility of the polynomial regression approach using several different data-driven binning algorithms, and to compare that method of curve naming and classification to kernel density estimation as an alternative nonparametric approach. This included first a comparison of the binning algorithms, to determine how similar "ideal" binwidths were to each other and to the standard $5 \mathrm{~cm}$ bin used in northern hardwood management, using both preand post-harvest stand data. The second objective was to test the sensitivity of the regression-based classification to selection algorithm and binwidth. A final comparison was made between discrimination based on kernel density estimates and discrimination following the regression-based classifications, to compare the two methods of describing stand structure.

\subsection{Methodology}

Data used for this study came from 48 recently harvested northern hardwood stands that were sampled in 2010 and remeasured in 2011 (see Appendix A for stand locations). All stands were harvested between 2004 and 2010. Stands were owned and managed by three different landowner types; 12 stands were under private industrial management, 14 were owned by nonindustrial private landowners, and 22 were on state forestland. Stands were distributed across the Upper Peninsula and northern Lower Peninsula of Michigan.

Ten $100 \mathrm{~m}^{2}$ plots were installed in each stand in 2010. Ten $400 \mathrm{~m}^{2}$ plots were installed in 2011, with effort made to locate them on the same centers as the 2010 plots. On average, 7 of 10 plot centers were successfully re-located and re-measured in the second year. The 
$400 \mathrm{~m}^{2}$ plot measurement included the distance from plot center to each stem, allowing $100 \mathrm{~m}^{2}$ plot data to be isolated and used. Species and dbh were measured on trees over 10 $\mathrm{cm}$ in 2010 and on all stems over $1.37 \mathrm{~m}$ in height in 2011. In 2010, trees under $10 \mathrm{~cm}$ dbh were measured in smaller $\left(4 \mathrm{~m}^{2}\right)$ understory plots installed in every other overstory plot.

Species, height, and diameter (the average of two cross-sectional diameters) were recorded for each stump in each overstory plot, the $100 \mathrm{~m}^{2}$ plots in 2010 and $400 \mathrm{~m}^{2}$ plots in 2011. Data collection in 2010 also included measurement of stump heights and diameters on randomly selected standing trees in each plot, with stump heights and species approximately matching those of stumps measured within the same plot, to be used as fitting data for predicting tree diameters from stumps.

Pre-harvest stand densities were estimated using a stump-to-breast height prediction equation localized using fitting data collected on standing trees. Species groups were assigned following the groupings used by Scott (1981). The seven most common species groups in the fitting and stump datasets were balsam fir (Abies balsamea), sugar maple (Acer saccharum), poplars and ashes (Populus spp. and Fraxinus spp.), birches (Betula spp.), American beech (Fagus grandifolia), American basswood (Tilia americana), and red maple (Acer rubrum). Raile's (1978) equation form was used with localized coefficients for those seven species groups; conditioning of the equation so that stump diameter equaled breast diameter when stump height equalled breast height followed McClure (1968). For the less common species, generic coefficients were created from the entire fitting dataset and used to predict diameter at breast height from stump measurements using the same equation form from Raile (1978).

In order to determine the extent to which the histogram construction approach influences the results of the regression-based curve naming methodology, multiple binwidth optimization algorithms were used. The AIC and Wand methodologies for histogram creation were implemented in $\mathrm{R}$ ( $\mathrm{R}$ Development Core Team, 2012) using readily available 
software packages (Mildenberger et al., 2009; Wand, 2011). The Knuth approach is described in Knuth (2006); the publication includes code for use with MATLAB (MATLAB, 2010) from which $\mathrm{R}$ code was written to perform the same functions. Each binwidth calculation algorithm was applied to each of 48 stands, using data from $100 \mathrm{~m}^{2}$ plots installed in 2010, $100 \mathrm{~m}^{2}$ plots measured in 2011, and $400 \mathrm{~m}^{2}$ plots measured in 2011 .

The regression-based classification scheme was applied to a total of 30 pre-harvest histograms for each stand, using 10 unique binwidths for pre-harvest stocking and three different plot size/year combinations. The 10 unique binwidths included 3, 5, and $7 \mathrm{~cm}$ fixed widths, the optimal binwidths generated by the Knuth, Wand, and AIC algorithms, the average binwidth generated for each plot size and year (data from $100 \mathrm{~m}^{2}$ plots measured in 2010 and 2011 and $400 \mathrm{~m}^{2}$ plots measured in 2011), and the dataset-wide average "optimal binwidth". Post-harvest, 21 curves were created for each stand, using only the minimum from all algorithms, the average binwidth generated from each algorithm for each stand, and 3,5 , and $7 \mathrm{~cm}$ binwidths.

Kernel density estimation was also used to represent the stand structure. The default R function was used to fit a kernel density estimate of the diameter distribution of each stand. Kolmogorov-Smirnov tests were used to compare all possible pairs of kernel density estimation for the 48 stands sampled- a total of 1128 pairs. A Bonferroni correction was applied to control the family-wise error rate for these tests $(\alpha=0.1)$. The relationships between kernel density estimates were then illustrated using network diagrams, where each stand is a vertex and each non significant difference is indicated by an edge (a line) connecting two vertices (see Appendix B for a more complete description of network diagram construction). Network diagrams are simply visualizations of the relationships and connections between points; shorter distances between points suggest that they are directly connected or share mutual connections. 


\subsection{Results}

\subsubsection{Comparison of binning algorithms}

The pre-harvest data consistently resulted in narrower binwidths and more bins (Table 5.2). Pre-harvest binwidths were also less variable; the standard deviation of the set of binwidths calculated for each algorithm and plot size were substantially larger for the post-harvest binwidths.

The Wand algorithm binwidths were on average smaller than the Knuth and AIC binwidths. The minimum binwidth for a given stand was generated using the Wand algorithm for $43 \%$ and $52 \%$ of stands with $100 \mathrm{~m}^{2}$ plots from 2010 and 2011, and for $69 \%$ of stands using 400 $\mathrm{m}^{2}$ plots. Binwidths from the Knuth and AIC algorithms were often similar to one another.

Of the three binning algorithms used, the Wand algorithm was the only one that consistently assigned bins smaller than the $5 \mathrm{~cm}$ widths currently used in histograms of stand structure. The AIC and Knuth algorithms generally produced histograms that smoothed the data more than either the $5 \mathrm{~cm}$ or the histograms from the Wand algorithm. The AIC and Wand binning algorithms produced mean and median binwidths that increased from pre- to post-harvest, and decreased by plot size. The Knuth algorithm produced mean binwidths that decreased from pre- to post-harvest, while median binwidths increased from pre- to post-harvest, and both the mean and the median were smaller for larger plot sizes. 
Table 5.2

Optimal binwidths $(\mathrm{cm})$ calculated using each algorithm averaged by algorithm, plot size, and across the dataset. Standard deviations in parentheses.

\begin{tabular}{|c|c|c|c|c|c|c|c|c|c|c|c|c|}
\hline & \multicolumn{4}{|c|}{$\begin{array}{c}\text { Optimal Wand } \\
\text { width on all stands }\end{array}$} & \multicolumn{4}{|c|}{$\begin{array}{c}\text { Optimal AIC } \\
\text { width on all stands }\end{array}$} & \multicolumn{4}{|c|}{$\begin{array}{c}\text { Optimal Knuth } \\
\text { width on all stands }\end{array}$} \\
\hline & \multicolumn{2}{|c|}{ Mean } & \multicolumn{2}{|c|}{ Median } & \multicolumn{2}{|c|}{ Mean } & \multicolumn{2}{|c|}{ Median } & \multicolumn{2}{|c|}{ Mean } & \multicolumn{2}{|c|}{ Median } \\
\hline & Pre & Post & Pre & Post & Pre & Post & Pre & Post & Pre & Post & Pre & Post \\
\hline \multirow{2}{*}{$2010100 \mathrm{~m}^{2}$} & 8.1 & 8.5 & 7.8 & 8.1 & 11.5 & 11.5 & 11.8 & & 12.1 & 10.5 & 10.4 & 10.3 \\
\hline & $(2.6)$ & $(2.9)$ & - & - & $(8.0)$ & $(9.9)$ & - & - & (6.5) & (7.1) & - & - \\
\hline \multirow{2}{*}{$2011100 \mathrm{~m}^{2}$} & 8.7 & & 8.1 & 8.8 & 12.6 & 13.7 & 12.1 & 9.7 & 12.1 & 10.3 & 9.3 & 8.3 \\
\hline & (2.9) & $(2.9)$ & - & - & $(11.5)$ & )$(12.1$ & & - & $(8.4)$ & $(9.2)$ & - & - \\
\hline \multirow{2}{*}{$2011400 \mathrm{~m}^{2}$} & 5.3 & 5.5 & 5.1 & 5.4 & 5.2 & 6.0 & 6.2 & 4.4 & 8.4 & 9.6 & 5.1 & 7.7 \\
\hline & (1.6) & (1.6) & - & - & $(2.2)$ & (5.6) & - & - & (6) & (7.1) & - & - \\
\hline
\end{tabular}

Table 5.3

Pre-harvest binwidth $(\mathrm{cm})$ summaries by plot size. Standard deviations in parentheses.

\begin{tabular}{|rcccc|}
\hline & $\begin{array}{c}\text { Mean optimal } \\
\text { Wand width }\end{array}$ & $\begin{array}{c}\text { Mean optimal } \\
\text { Knuth width }\end{array}$ & $\begin{array}{c}\text { Mean optimal } \\
\text { AIC width }\end{array}$ & $\begin{array}{c}\text { Mean optimal } \\
\text { overall width }\end{array}$ \\
\hline \multirow{2}{*}{$100 \mathrm{~m}^{2}$} & 8.4 & 12.1 & 12.1 & 10.8 \\
& $(2.7)$ & $(9.8)$ & $(7.7)$ & $(7.6)$ \\
$400 \mathrm{~m}^{2}$ & 5.3 & 5.2 & 8.4 & 6.3 \\
& $(1.6)$ & $(2.2)$ & $(6.0)$ & $(4.1)$ \\
\hline
\end{tabular}


All average binwidths for each size class using each algorithm were larger than the standard $5 \mathrm{~cm}$ class currently used in stand structure diagrams. However, the minimum binwidth generated for almost all (36 of 48) stands was less than $5 \mathrm{~cm}$. To compare histograms with binwidths both larger and smaller than the norm, the fixed binwidths of 3 and $7 \mathrm{~cm}$ were also used to create histograms and apply the regression-based classification algorithm.

The number of bins generated in a stand determines the binwidth and the range of diameters within the stand, as well as the number of $(\mathrm{x}, \mathrm{y})$ data pairs that are used in fitting the polynomial regression equation. The mode number of bins generated using each algorithm was, in almost all cases, fewer than the number of bins used when bins were $5 \mathrm{~cm}$ wide (Table 5.4). More bins were generated in a given stand using the Wand algorithm than the other algorithms.

\section{Table 5.4}

Mode number of bins calculated using each binning algorithm

\begin{tabular}{|ccccccccccccc|}
\hline & \multicolumn{2}{c}{ Wand } & \multicolumn{2}{c}{ AIC } & \multicolumn{2}{c}{ Knuth } & \multicolumn{2}{c}{$3 \mathrm{~cm}$ bins } & \multicolumn{2}{c}{$5 \mathrm{~cm}$ bins } & \multicolumn{2}{c}{$7 \mathrm{~cm}$ bins } \\
& Pre & Post & Pre & Post & Pre & Post & Pre & Post & Pre & Post & Pre & Post \\
$100 \mathrm{~m}^{2}$ & 7 & 5 & 3 & 2 & 3 & 2 & 14 & 12 & 9 & 8 & 6 & 5 \\
$400 \mathrm{~m}^{2}$ & 13 & 10 & 10 & 10 & 10 & 4 & 18 & 18 & 12 & 12 & 8 & 8 \\
\hline
\end{tabular}

An example of the best-fitting curves fit using different bin widths is provided in Figure 5.1; the kernel density estimate for the distribution of diameters in the same stand is shown in Figure 5.2. The shape of the distribution of diameters in this stand was classified as Unknown using bins of $3 \mathrm{~cm}$ and $7 \mathrm{~cm}$ widths and the optimal width calculated using the Wand algorithm. Polynomial regression using bins of the optimal widths from the AIC and Knuth algorithms resulted in a best-fitting curve with characteristics of a negative exponential curve; regression using the midpoints of $5 \mathrm{~cm}$ wide bins (shown in the 
histogram in the figure) resulted in an increasing- $q$ diameter distribution curve.

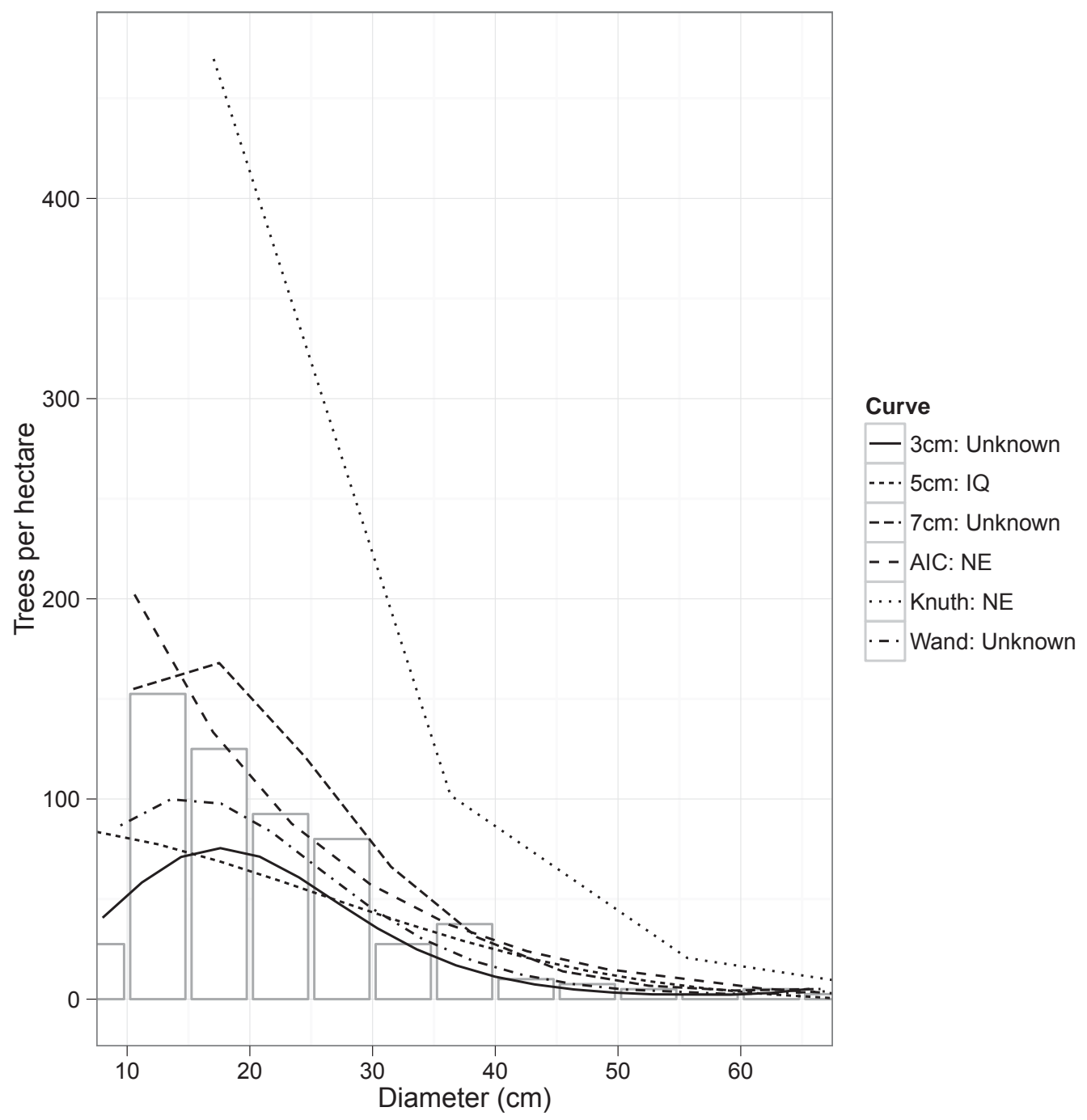

Figure 5.1: Best-fitting curves and one histogram fit to a stand using pre-harvest data from $400 \mathrm{~m}^{2}$ plots. NE, negative exponential; IQ, increasing- $q$; UNI, unimodal. 


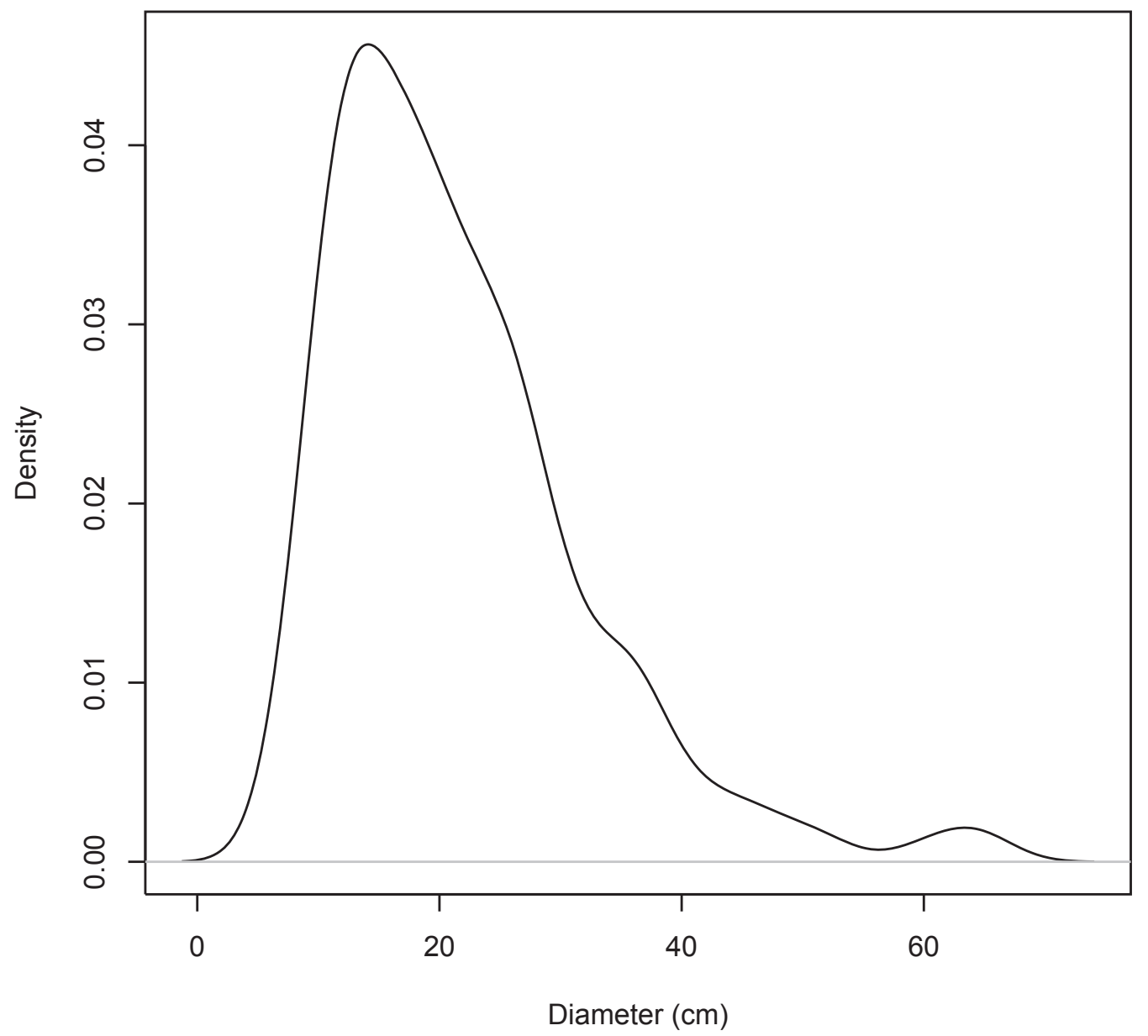

Figure 5.2: Kernel density estimate of distribution of diameters in one stand, based on pre-harvest data from $400 \mathrm{~m}^{2}$ plots. 
Table 5.5

Percentage of pre-harvest categorical classification similarity between different algorithms with similar binwidths, $400 \mathrm{~m}^{2}$ plots.

\begin{tabular}{|lcccc|}
\hline & $3 \mathrm{~cm}$ & $5 \mathrm{~cm}$ & $5.3 \mathrm{~cm}$ (Wand average) & Wand individual \\
\hline $3 \mathrm{~cm}$ & 100 & - & - & - \\
$5 \mathrm{~cm}$ & 83 & 100 & - & - \\
$5.3 \mathrm{~cm}$ (Wand average) & 75 & 90 & 100 & - \\
Wand Individual & 75 & 67 & 63 & 100 \\
\hline
\end{tabular}

Figure 5.3 shows some trends observable using data from $400 \mathrm{~m}^{2}$ plots. Each horizontal line of points represents results from one stand. The color and size of the points show the algorithm used to bin the data and the size of the binwidth. Notable trends include that Unknown classifications were most commonly assigned using the largest and smallest binwidths. IQ classifications were most common for binwidths between 2 and $10 \mathrm{~cm}$ in size; UNI classifications were most commonly assigned when binwidths ranged from 4-9 cm (Figure 5.4). Some stands showed strong consistency. Stand 48 in Figure 5.3 was always classified as Unknown; stand 44 was only assigned IQ. In most other stands, however, two or three different curve shapes were assigned depending on the binwidth used; many stands varied between UNI and IQ depending on width. Additional diagrams showing classifications by binwidth are found in Appendix C. 


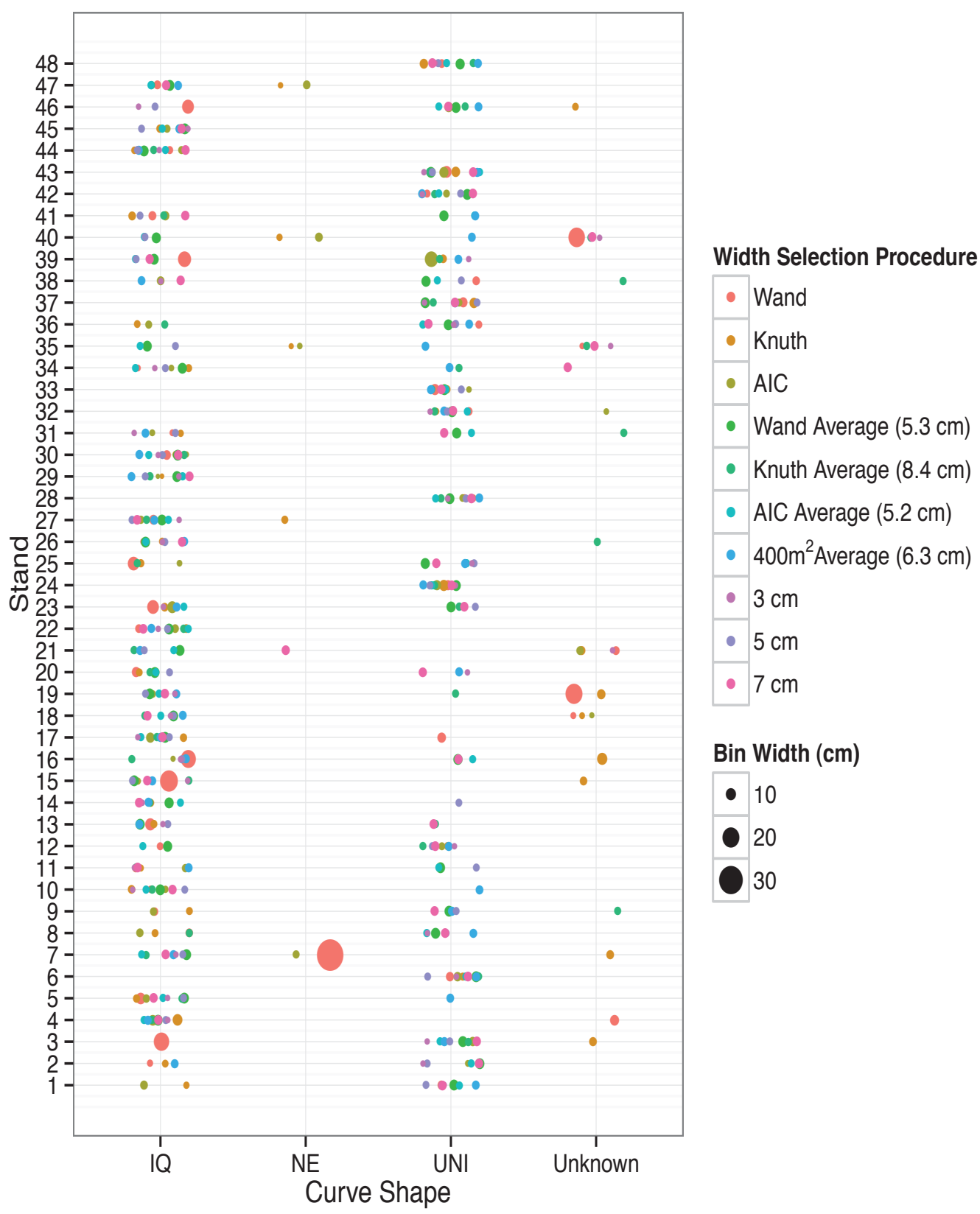

Figure 5.3: Pre-harvest curve shapes for each stand assigned to histograms of varying binwidth from each binning algorithm, using 2011 data, $400 \mathrm{~m}^{2}$ plots. NE, negative exponential; IQ, increasing- $q$; RS, rotated sigmoid; CO, concave; UNI, unimodal. 


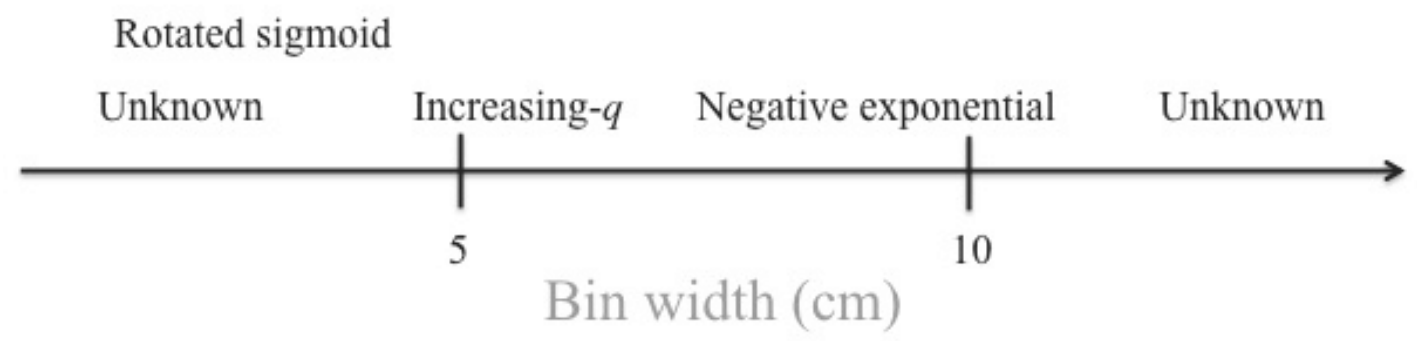

Figure 5.4: Generalized trends in polynomial regression-based classification by binwidth

\subsubsection{Kernel Density Estimation}

The relationships between pre-harvest stand structures are illustrated with a network diagram which shows the overall lack of difference between the pre-harvest structures of most stands (Figure 5.5). In the figure, each stand is connected to other stands for which the kernel density estimates were not significantly different when tested using a Kolmogorov-Smirnov test $(\alpha=0.1)$. Points that are close together are not more similar than points which are further apart, but groups of stands which have many similar pairs may be seen as clustered together (Appendix B). The similarities and lack thereof among stands with a common classification may also be best seen graphically (Figure 5.6, $\alpha=0.1$ ). The key aspect of Figure 5.6 are the differences among curve shapes that the polynomial regression approach names the same, evidenced by a lack of an edge between many pairs. The nodes are labeled with the distribution names given to the stand based on the polynomial regression classifications, using $5 \mathrm{~cm}$ binwidth classes.

Tests of kernel density estimates on pre-harvest data showed that, on average, stands were not different from 10 other stands using the Kolmogorov-Smirnov tests (Table 5.6). The highest degree of association was found where one stand was not dissimilar to 25 others. 
Two stands were dissimilar to all other stands and each other. The largest "cliques" presentinstances where all stands were not dissimilar to one another-contained only 4 , suggesting relatively wide diversity among the stands. Tests of post-harvest KDE far more frequently resulted in a rejection of the hypothesis of similarity; on average, stands were not dissimilar to 8 other stands. In contrast to this, the pre-harvest classifications for $400 \mathrm{~m}^{2}$ plots with $5 \mathrm{~cm}$ bin widths resulted in 27 stands with Increasing- $q$ classifications and 21 with Unimodal. The polynomial regression-based classifications in one sense imply one clique of size 27 and one clique of size 21, based on the qualitative labels. Testing of coefficients of the best-fitting polynomial regression equations would further differentiate the stands and presumably result in more, smaller cliques within the broad categorical classifications.

Initial kernel density estimates were performed using a default bandwidth, where the bandwidth is data-dependent and equals the standard deviation of a Gaussian kernel ( $R$ Development Core Team, 2012). The default bandwidths calculated were unique for each stand; using $400 \mathrm{~m}^{2}$ data, bandwidths ranged from 2.1 to 5.5 , with a mean of 3.2. Kernel density estimates were also made using fixed bandwidths of 2 and 5. Kolmogorov-Smirnov tests showed that more pairs were different using both fixed bandwidths than with the default bandwidth calculated for each stand.

Table 5.6

Cliques and relationships from network analysis of pre- and post-harvest kernel density estimates using $400 \mathrm{~m}^{2}$ plot data

\begin{tabular}{|lccc|}
\hline & Pre-harvest & Pre-harvest, IQ only & Post-harvest \\
\cline { 2 - 4 } Mean degree of association & 10 & 6 & 8 \\
Lowest degree of association & 0 & 0 & 0 \\
Highest degree of association & 25 & 12 & 20 \\
Largest clique size & 4 & 4 & 4 \\
\hline
\end{tabular}




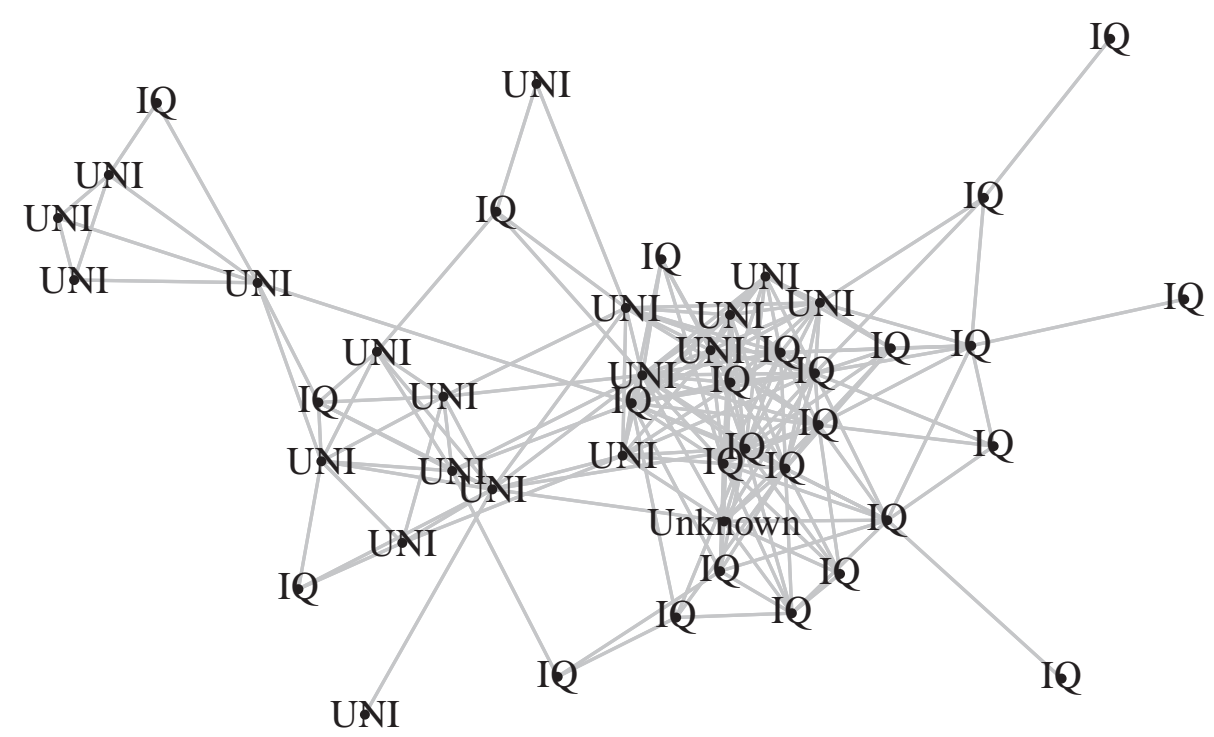

Figure 5.5: Network diagram showing pairs of kernel density estimates of pre-harvest stand structures that were not significantly different using 2011 data, $400 \mathrm{~m}^{2}$ plots. Letter codes refer to polynomial regression-based classifications using $5 \mathrm{~cm}$ binwidths. 
IQ

IQ

IQ

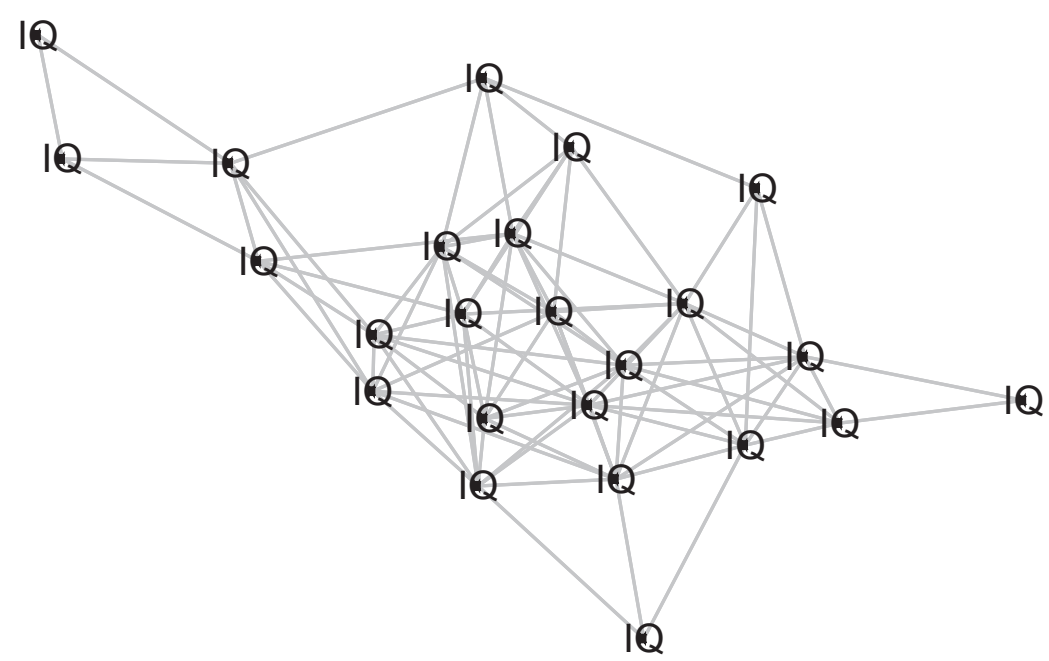

Figure 5.6: Network diagram showing pairs of stands classified as IQ using the polynomial regression procedure for which kernel density estimates were not significantly different using 2011 data, $400 \mathrm{~m}^{2}$ plots. Letter codes refer to classifications using $5 \mathrm{~cm}$ binwidths. 
The number of stand pairs for which the kernel density estimates were not different and the classifications were the same was calculated using the edges and vertices from each network (Table 5.7). The classifications using the $5 \mathrm{~cm}$ binwidth were associated with no difference between kernel density estimates more often than classifications using 3 or $7 \mathrm{~cm}$ widths.

Table 5.7

Percentage of edges connecting vertices with the same named classifications.

\begin{tabular}{|lcc|}
\hline & \multicolumn{2}{c|}{ Percentage } \\
Binwidth & Pre-harvest & Post-harvest \\
\hline Wand (width varies) & 44 & - \\
Wand Average $(5.3 \mathrm{~cm})$ & 60 & - \\
$3 \mathrm{~cm}$ & 47 & 39 \\
$5 \mathrm{~cm}$ & 55 & 42 \\
$7 \mathrm{~cm}$ & 48 & 33 \\
\hline
\end{tabular}

\subsection{Discussion}

\subsubsection{Comparison of binning algorithms}

Generally, the binning algorithms balance the characterization of the shape of the data and the noise present within the data; each algorithm uses a different approach to find this balance. With larger plots, there is lower sampling variance and more confidence in the representativeness of the sample. Small binwidths are produced from the algorithms, 
because the stand structure can be more accurately characterized with a more complex histogram. Data collected on smaller plots show higher variance. The binning algorithms select larger optimal binwidths for these data, which smooth the data and reduce the noise present. Selection system management, properly implemented, generally homogenizes stand structure (Janowiak et al., 2008); therefore smaller post-harvest binwidths would be expected output from the algorithms. This was not the observed trend, however; possibly, because of the diversity of management intensities observed in the sample, it is not surprising that larger post-harvest binwidths were the norm for these stands (see Chapters 3 and 4, inter alia Table 4.3).

\subsubsection{Application of the polynomial regression-based classification system to histograms constructed with binning algorithms}

The most significant finding from the classification of curves fit to histograms with varying binwidths is the lack of any strong patterns present in the curve shapes assigned. This is highlighted for one stand in Figure 5.1. This finding is further illustrated in Figure 5.3 which reflects that across all stands, selection procedure, binwidth, and classified curve shape are not strongly related. For some stands, the structural pattern appears to be "strong" enough that the same classification occurs for all binwidths. See, for example, stands 42, 43, 44, and 48 (Figure 5.3). In other stands, however, there appears to be no relationship between binwidth and classification (stands 39 and 40).

The range of binwidths and classifications show that the polynomial regression-based naming procedure is influenced by neither bin placement nor binwidth in a predictable way. A wide range of binwidths and multiple algorithms were used, and yet no pattern was detected. This suggests that there is not a substantial benefit to the use of a binning algorithm such as the Wand algorithm in place of the standard $5 \mathrm{~cm}$ bins commonly 
utilized. Similarly, there is no clear benefit to using 3 or $7 \mathrm{~cm}$ binwidths rather than 5 $\mathrm{cm}$. However, all are preferable to the AIC and Knuth data-driven binning methods. The AIC and Knuth algorithms consistently produced larger binwidths which smoothed the data more. Subsequently, stand structures were labelled Unknown, generally because there were no significant predictors from the polynomial regression equations. The binwidth trends likely follow patterns of variance by diameter class within the stand. The Knuth algorithm explicitly treats empty diameter classes- bins with zeroes in them- and this may account for some of the differences between this algorithm and the others.

Overall, the lack of clear connection between classification variation and binwidths suggests that the curve shape classifications from the regression-based approach may not reliably represent the pattern of diameter distributions in a stand (Figure 5.3). Curve shape classifications were not consistent in any pattern for a given stand when regression was performed using different fixed or algorithm-produced binwidths. This conclusion is further substantiated by variation among classifications using bins of similar widths (Table 5.5). For the $400 \mathrm{~m}^{2}$ plots, 41 of 48 stands (85\%) were assigned the same classifications for $5 \mathrm{~cm}$ and AIC Average $(5.2 \mathrm{~cm})$ bins. Between the $5 \mathrm{~cm}$ and the Wand Average $(5.3$ $\mathrm{cm})$ bins, 42 of 48 stands ( $88 \%$ ) were assigned the same classification. This includes the same 41 stands for which the AIC and $5 \mathrm{~cm}$ bins were similar. Forty-seven of 48 stands were assigned the same categorical classification using 5.2 and $5.3 \mathrm{~cm}$ wide bins. Similar comparisons cannot be made using the $100 \mathrm{~m}^{2}$ data, because the range of the binwidths calculated using the smaller plots was much larger.

These comparisons show the consistencies and inconsistencies in classifications using histograms of very similar widths. The Wand binning algorithm also used a different starting point than the others. The binning algorithms differed from the fixed binwidths and averages in that all algorithms used the minimum value sampled as the left end point of the first bin, as opposed to truncating at the minimum populated bin of pre-defined size. The lower percentage of similar classifications between the Wand individual and other 
binwidths shows that shifting the starting point of a histogram can change the classification assigned by the regression-based classification procedure.

The categorical classification approach involves both nonparametric smoothing- histogram construction- and parametric, polynomial regression. Very low $\mathrm{R}^{2}$ values were common across the numerous curves that were fit. The polynomial regression functions tested represent smooth curves, which did not fit well to variable data from stands under varied management. This is in contrast to the findings of Janowiak et al. (2008), who found non-significant distributions only when using less than 0.05 ha sampled area; in this study non-significant distributions were found at the stand level using total sampled areas of 0.1 and 0.4 ha. Stand identification procedures for this study were less strict in terms of identifying the intent of multiple harvest entries, however, which may account for some of these differences; the homogeneity Janowiak et al. (2008) found within consistently managed stands was less evident in the stands sampled for this work, for which only the most recent harvest information was known.

Much of the research in this field is focused on the shapes of sustainable, steady-state stand structures (Leak, 2002; Lorimer and Frelich, 1984; Goff and West, 1975). A managed stand may through the application of the polynomial regression-based approach be assigned a curve name suggesting that the structure of the stand resembles that of an old-growth, unmanaged stand, be it IQ, RS, or NE. Stands with similar curve shape classifications are presumed to have similar structure, but this study's data include stands classified as IQ using the regression-based approach and $5 \mathrm{~cm}$ bins, with maximum diameters ranging from $47 \mathrm{~cm}$ to $92 \mathrm{~cm}$. Clearly these do not have the same structure, although the shapes of the diameter distributions were classified the same way. Because certain curve shapes are thought to develop through different disturbance histories, they are also interpreted as indicators of stand disturbance and development history (Diaci et al., 2011). Both the sensitivity of the classification to bin width and the insensitivity to maximum diameter make such connections tenuous and highlights the importance of using curve shape 
classifications along with many other descriptors of stand structure to draw conclusions about stand histories and to make management recommendations.

\subsubsection{Kernel density estimation}

The kernel density estimation of stand structural differences was faster and far less sensitive to binning than the regression-based approach. The curves are difficult to compare visually, because they do not all have the same axes; the Kolmogorov-Smirnov test was used as a statistically appropriate method of comparing the distributions. A major drawback, however, was the fact that more than 1000 pairwise Kolmogorov-Smirnov tests needed to be conducted in order to test curves from all stands. A Bonferroni adjustment was implemented to maintain the family-wise error rate at $\alpha=0.1$. The power of the tests, however, was substantially diminished because of this approach. An alternative which may be more effective is the use of regression-based tests of equivalence, which would test for similarity rather than dissimilarity (Wellek, 2010). Another potential criticism of this methodology is the seemingly arbitrary choice of $\alpha$ level of the Kolmogorov-Smirnov test, although this method of comparison is not more arbitrary than the restricted set of possible curves used in the regression-based procedure. The kernel density estimates are a closer fit to the data, and are not constrained to a limited set of shapes the way the polynomial regression-based system is limited to a set of polynomial regression curves. The lack of constraints leads to the complex set of relationships seen in the network diagrams.

The bandwidth employed by the binned kernel density estimation procedure was a default calculation, based on the standard deviation of a Gaussian kernel. While bandwidths can be fixed or set as a different function of the data, the use of the default appeared to smooth the data in a manner well suited for these comparisons. More pairs of stands were different using the default as opposed to using manually set bandwidths of 2 and 5 (the high and 
low range of the default bandwidths of the dataset). While other available kernel density estimation packages (e.g. Wand, 2011) use default bandwidths designed to oversmooth the data, the built-in function in $\mathrm{R}$ defaults to a mathematically appropriate bandwidth and was sufficient.

\subsubsection{Integration and comparison of the regression-based classification and kernel density estimation approaches}

The lack of a "right answer"- knowledge of the true shape of the structural distribution within a stand- makes comparisons difficult, especially given the weaknesses and uncertainties of the regression-based classification approach. The discriminatory abilities of the two approaches, however, were compared to show the similarities and differences among stands differentiated by one approach or the other. Comparisons between the KDE and regression-based categorical classifications were focused primarily on the status quo binwidth $(5 \mathrm{~cm})$ and the $3 \mathrm{~cm}$ binwidth, where the most relevant differences were expected. Similarly, the data from $400 \mathrm{~m}^{2}$ plots were used for more of these analyses, because trends were most clearly present and density estimates had smaller stand- and size class-wise standard errors.

When compared to the classifications using the regression-based approach, many stands with similar named structures had similar density distributions, but not all. For example, not all IQ stands were similar to all other IQ stands. Stands classified as NE were not similar to each other, but were similar to IQ and UNI stands. Overall, it is clear that the regression-based classification procedure does not discriminate between similar and dissimilar stands in the same manner as a Kolmogorov-Smirnov test of density distributions. The presence of cliques indicates strong commonalities among stands; the curve shapes present in stands that are part of cliques may indicate common or 
typical structures. Most stands, however, were not different from numerous other stands, and were not part of distinct groupings. Further tests on the regression equations used by the regression-based classification procedure may show additional differences among stands that receive similar classifications, and indicate common structures within a given classification. For example, Diaci et al. (2011) used analysis of covariance to test for differences among the intercepts and slopes of the fitted regressions of stands with different species compositions, known histories, and locations within different forests. Quantification of differences between stands, or of sub-categories within broad categories, would help determine the similarities and variability of stand structures within each named category.

Rather than a linear continuum of stand densities, the results of the network analysis suggest that the relationship among stands is more complex. While approximate curve shapes may exist along a continuum, additional variables such as the maximum diameter present in the stand result in dissimilarity among stands for which the named curve shape is the same. These sorts of differences are representative of actual structural differences among the stands that are masked by assigning them all the same named structure, because the classifications use only curve shapes without comparing or differentiating among curve parameters. Goff and West (1975) described a straightforward pattern of the change in northern hardwood stand structure with stand maximum diameter as the stand develops. In the stands in this study, the named curve shape did not follow the diameter trend found by Goff and West (1975). This may be an artifact of the polynomial regression fitting and selection procedure, or may suggest that the relationship between stand structure and diameter in managed stands is less predictable than in unmanaged stands, because trees are more often removed following a manager's goals and a marking guideline rather than through competition- and disturbance-induced mortality.

Curve shape classification of pre-harvest structure represents the structure of the stand before the most recent entry. Because harvests by nature either deliberately or incidentally 
alter stand structure, post-harvest structures are likely to also be assigned different curve shape classifications. Post harvest structure immediately after harvest may be a potentially inaccurate representation of the harvest goal. Harvests may be conducted with a goal of creating a certain structure immediately or facilitating its development years after the harvest. Therefore, the immediate focus of this work was to explore the way curve shape classifications changed using various binning and smoothing approaches, rather than to explore the immediate impacts of harvests on the shape of diameter distributions.

An alternative metric of comparison that would be an interesting focus of future work would be to compare the shapes of the polynomial regression equations that are generated in the classification procedure to parametrically defined shapes of the named curves, and to compare both against the KDE. This would be a somewhat hazardous and potentially subjective comparison, however, because of the challenges of comparing parametric and nonparametric estimators. Were all three curves appropriately scaled to the same axes, both visual comparison and quantitative analysis of the cumulative distribution functions for each curve fit to the diameter distribution could be conducted. This would be especially valuable for cases where the $\mathrm{R}^{2}$ values for the polynomial regressions were relatively low, and where the polynomial regression-based classification procedure resulted in an Unknown curve shape. It would also potentially validate the use of kernel density estimation in place of the regression-based procedure. Additionally, such a comparison could show if there are generalized (named) curve shapes for which the polynomial regressions selected by the procedure frequently fit more or less closely to the generalized curve they are intended to reflect. 


\subsubsection{Application and limitations of findings}

The power of different sampling intensities to correctly capture stand diameter distributions certainly influences the results of this work. While Schwartz et al. (2005) and Janowiak et al. (2008) conducted complete censuses of small (4.0 and 3.2 ha, respectively) areas within a stand, our plots were randomly located throughout the harvested areas of larger stands. According to the principles described by Rubin et al. (2006), the minimum sampled area needed to identify a negative exponential distribution depends upon the maximum diameter, basal area, and baseline mortality of the stand. While we do not know the baseline mortality of our sampled stands, an examination of the maximum diameter and basal area of each stand suggests that negative exponential distributions would only be identifiable in a subset of the stands sampled using the $400 \mathrm{~m}^{2}$ plot sizes. This is likely one explanation for the fact that few negative exponential curves were identified using those plot sizes. These were pre-harvest, when the stand basal area and maximum diameter were higher and necessitated a smaller sampling intensity.

Likewise, Janowiak et al. (2008) recommend a minimum sampling intensity larger than the intensity used for some stands in this study. However, Schwartz et al. (2005) identified NE

curves using a sampling intensity comparable to the $400 \mathrm{~m}^{2}$ plots employed here. This may indicate that the polynomial regression-based approach, which was used by Schwartz et al. (2005), is more effective at identifying this shape at lower sampling intensities. Similarly, Janowiak et al. (2008) observed that stands were classified as UNI on smaller spatial scales but as IQ on larger scales; this suggests that some of the UNI stands identified in this study may have similarly been classified as IQ were a larger area sampled. However, given the sensitivity of the classification system, the most common and/or more stable curve shape names assigned may be unique to a histogram created with $5 \mathrm{~cm}$ bins. 


\subsection{Conclusions}

A close examination of methodologies used to fit curves shows both the utility of testing the discriminative capabilities of such procedures and the need for caution in interpreting named curve shapes as descriptors of structure. The use of data-driven binning algorithms does not result in polynomial regression curves that are better-fitting than the standard 5 $\mathrm{cm}$ binwidth currently the status quo. Rather, the algorithms employed using larger plot sizes on average calculated optimal binwidths close to the $5 \mathrm{~cm}$ status quo, affirming that the empirically derived binwidth adopted by the profession is well-suited to representing the distribution of diameters in the average northern hardwood stand.

The generation of numerous histograms for each stand and subsequent assignment of curve shape names using the polynomial regression-based approach did show the sensitivity of the approach to binwidths. There were no definitive trends relating the size of the binwidth or the algorithm employed and the name assigned to the curve, other than especially wide binwidths leading to Unknown classifications. The lack of trend highlights the limitations of the categorical, regression-based approach to naming the structure of a managed northern hardwood stand. Histograms made with slightly different binwidths result in assigning different shapes to the structure of the same stand. The results of the KDE, visualized using network analytics, show the more complex relationships between stand structures. Similarities between stand structures represented using more closely-fitted kernel density estimates are only represented about $50 \%$ of the time using the polynomial regression. Conversely, stands that have other characteristics suggesting strong structural differences, such as maximum dbh and basal area, are assigned similar classifications using the regression-based approach.

An adaptation or improvement of the polynomial regression-based categorization approach is not suggested, as this work did not identify a binning technique or algorithm which 
reduces the sensitivity of the regression-based approach. While the method is quickly employed, it is sensitive to binwidth and it is difficult to determine what is the "ideal" binwidth to use; one could reach different conclusions about individual plots, stands, and from entire studies using slightly different binwidths and binning algorithms. Binned or unbinned kernel density estimates can be employed as an additional nonparametric model of stand structure which is fit more closely to the data. Kolmogorov-Smirnov or equivalence tests can be used to test the similarities of distributions between stands and plots. Network analysis in conjunction with these findings yields additional, useful data about stands that share common structure and those that differ. By employing these additional forms of analysis, the findings from categorizing the regression-based approach can be tempered and further explained in the context of multiple stands with differing histories, under different management, and with potentially different future trajectories. 


\section{Chapter 6}

\section{Conclusions}

To efficiently describe harvests in northern hardwood stands, a localized diameter at breast height prediction equation was used to reconstruct pre-harvest conditions from post-harvest data. Key differences among available equations used to estimate tree diameter from stump diameter for northern hardwood species were the inclusion of stump height as a predictor, and the mathematics of conditioning so that stump diameter equaled breast diameter when stump height equaled breast height. The best-performing equation was found to be a localized version of Raile's (1978) equation form, using conditioning from McClure (1968).

Predictions using the equation forms that included stump height as a predictor consistently had a higher $\mathrm{R}^{2}$ (or $\mathrm{I}^{2}$ ) and lower root mean square error than those using equation forms with only stump diameter as a predictor. Among those equations with stump height as a predictor, Raile's (1978) form with published conditioning and with the correct conditioning from McClure (1968) was more accurate than Westfall's (2010) equation form. Dollar value estimates showed the difference in application of the McClure (1968) equation form and other published and localized equations. In a hypothetical case of timber 
trespass, the difference between this equation and other available options averaged $\$ 50$ per hectare for a stand of medium site index. This highlighted the financial value of using an equation of superior performance. Coefficients for the most common species measured were developed for McClure's localization of Raile's equation, and are now available for use by others who may need to make similar predictions.

McClure's localization was subsequently used with Raile's (1978) equation form to predict the pre-harvest stand conditions for stands measured in 2010 and 2011. Estimates of pre-harvest structure and removals were first compared to published management guidelines for the selection system, represented broadly by a liberal interpretation of Arbogast's 1957 marking guideline. This guideline was the precursor to guidelines recommended by state and federal land management agencies in the United States and provincial agencies in Canada. Contrary to expectations, the results of this initial assessment showed few differences among the management of stands under state, corporate, and NIPF ownership. Instead, management under all ownerships was quite varied.

Less than one third (20 of 96) of the measured stands were harvested in a manner following the marking guideline used as a benchmark for implementation of the selection system. Forty-two percent were harvested more heavily than recommended and 38\% were harvested more lightly. Both extrema have potentially negative impacts on the sustainability of sawtimber production in the region. A concern is that harvests that leave a residual stocking higher than recommended may inhibit the regeneration of midtolerant and shade intolerant tree species, and may even prevent sufficient regeneration of shade tolerant species. Alternately, harvests more intensive than recommended are likely to make future yields less consistent. These may represent selective or diameter-limit cuts that could have a dysgenic effect over time.

The Arbogast (1957) guideline represents a system of management designed to maximize 
the production of sawtimber over time, at a relatively low rate of return. While the comparison against this guideline yielded important results- the lack of difference among landowners being most notable- it also raised important questions about the possible objectives that led to harvesting in manners not in accordance with selection system guidelines. A harvest taxonomy was constructed to distinguish plausible management objectives based on harvest activities. This taxonomic approach used pre- and post-harvest stand characteristics to distinguish among possible management objectives, ranging from the short-term maximization of profit to carbon sequestration and the development of late successional stand characteristics.

The taxonomic system was tested against a range of published guidelines developed for the production of various wood products, and found to consistently classify published target structures as indicative of "maximized residual, sustained yield" management, that being the classification that suggested the greatest continuity in stand productivity of both sawtimber and ecosystem services. The application of the taxonomic system to the 96 stands measured in 2010 resulted in harvest classifications in similar proportion to the results of the comparison against the Arbogast guideline alone. Approximately one third of harvests were classified as MRSY harvests; slightly more than one third were classified as having a higher-than-recommended residual stocking, possibly associated with maximizing forest carbon but potentially purporting limited regeneration of a new cohort. Proportions by ownership were again in contrast to expected findings that there would be notable differences among the management practices of state, private industrial, and NIPF landowners. A higher proportion of state harvests were high-residual, and a higher proportion of industrial harvests were profit-maximizing, but the differences in proportions were not statistically significant.

Lastly, analyses were conducted using the pre-harvest estimates and post-harvest measurements from the 48 stands on which two years of measurements were made. Methodologies for the construction of histograms representing stand diameter distributions 
were tested through the application of three different data-driven binning algorithms. Two of the three binning algorithms output binwidths that were on average much larger than those currently used; the Wand (1997) algorithm did not smooth the data as dramatically and is a viable alternative to fixed binwidths, although not distinctly superior. This finding demonstrated that data-driven binning methods have no clear advantage to using fixed bin widths, and in fact may smooth the data more than the standard $5 \mathrm{~cm}$ bin used.

The outputs from these algorithms, along with several fixed binwidths, were used to construct histograms. A commonly approach of using polynomial regressions of the midpoints of binned data to categorize diameter distributions was then applied, wherein the signs of significant coefficients are used to assign named distribution shapes. This analysis revealed the hypothesized sensitivity of the polynomial-regression based approach to small differences in binwidth and bin placement; it also showed that there were no predictable patterns in this sensitivity. The discriminative ability of the regression-based approach was compared to Kolmogorov-Smirnov tests of kernel density estimates of the diameter distribution in each stand. These tests further highlighted that the categorical naming of diameter distributions using polynomial-regression discriminates between stands when curves are not meaningfully different, and fails to discriminate between stands which have meaningfully different diameter distributions.

The primary contributions of this work are the comparison of stand management by various landowners against published management guidelines and postulated management objectives, and the investigation of diameter distribution curve fitting and naming procedures. Application of data-driven binning algorithms in the construction of histograms showing stand structure and stocking validates the continued use of five centimeter bins; simultaneously, however, the evident sensitivity of the regression-based curve classification approach raises some concerns about the interpretation of the named shape assigned to a stand. Similarly, the harvest taxonomy developed is a succinct synthesis of possible northern hardwood management objectives, expanding upon the 
comparison against the Arbogast (1957) guideline that suggested management was not following this guideline and instead seeking to meet more varied objectives. The testing of published stump to breast height prediction equations facilitated answering the core research questions, and is a useful contribution in its own right. This work as a whole is a series of bridges over gaps between the fields of stand dynamics, forest biometrics, and silviculture, broadening the landscape of forest science through implementation of quantitative analyses and interpretation of the results. 


\section{References}

Adams, D.M., and A.R. Ek. "Optimizing the management of uneven-aged forest stands." Canadian Journal Forest Research 4, 3: (1974) 274-287.

Akaike, H. "Information theory and an extension of the maximum likelihood principle." In Second international symposium on information theory. Springer Verlag, 1973, volume 1, 267-281.

Alemdag, I.S., and T.G. Honer. "Metric relationships between breast-height and stump diameters for eleven tree species from eastern and central Canada." Information Report. Forest Management Institute Canada. .

Alessandrini, A., F. Biondi, A. Di Filippo, E. Ziaco, and G. Piovesan. “Tree size distribution at increasing spatial scales converges to the rotated sigmoid curve in two old-growth beech stands of the Italian Apennines." Forest Ecology and Management 262, 11: (2011) 1950-1962.

Arbogast, C.J. "Marking guides for northern hardwoods under the selection system." Station Paper LS-56, U.S. Department of Agriculture, Forest Service, Lake States Forest Experiment Station, 1957.

Avery, T.E., and H.E. Burkhart. Forest measurements. New York: McGraw-Hill Higher Education, 2002.

Bare, B.B., and D. Opalach. "Notes: Determining investment-efficient diameter distributions for uneven-aged northern hardwoods." Forest Science 34, 1: (1988) 243-249.

Bliss, J.C., E.C. Kelly, J. Abrams, C. Bailey, and J. Dyer. "Disintegration of the US industrial forest estate: dynamics, trajectories, and questions." Small-Scale Forestry 9, 1: (2010) 53-66. 
Bohn, K.K., and R.D. Nyland. "Long-term monitoring of stand development after selection system silviculture in uneven-aged northern harwoods of New York State." In Long-term Silvicultural \& Ecological Studies: Results for Science and Management, edited by Lloyd C. Irland, Ann E. Camp, John C. Brissette, and Zachary R. Donohew, Yale University, New Haven, CT, 2006.

Bones, J.T. "Estimating dbh from stump diameter in the Pacific Northwest." Research Note 186, U.S. Department of Agriculture, Forest Service, Pacific Northwest Forest and Range Experiment Station, 1960.

Burton, J.I., E.K. Zenner, L.E. Frelich, and M.W. Cornett. "Patterns of plant community structure within and among primary and second-growth northern hardwood forest stands." Forest Ecology and Management 258, 11: (2009) 2556-2568.

Butler, B.J., and E.C. Leatherberry. "America's family forest owners.” Journal of Forestry 102, 7: (2004) 4-14.

Butler, B.J., P.D. Miles, and M.H. Hansen. "National Woodland Owner Survey Tabler web-application version 1.0." Technical report, http://fiatools.fs.fed.us/NWOS/tablemaker.jsp, 2010. http://fiatools.fs . fed.us/NWOS/tablemaker.jsp.

Bylin, C.V. "Estimating dbh from stump diameter for 15 southern species." Research Paper SO-182, U.S. Department of Agriculture, Forest Service, Southern Forest Experiment Station, 1982.

Cao, Q.V. "Predicting parameters of a Weibull function for modeling diameter distribution." Forest Science 50, 5: (2004) 682-685.

Cao, Q.V., and H.E. Burkhart. "A segmented distribution approach for modeling diameter frequency data." Forest Science 30, 1: (1984) 129-137.

Corral-Rivas, J.J., M. Barrio-Anta, O.A. Aguirre-Calderón, and U. Diéguez-Aranda. "Use of stump diameter to estimate diameter at breast height and tree volume for major pine species in El Salto, Durango (Mexico).” Forestry 80, 1: (2007) 29-40.

Crow, T.R., D.S. Buckley, E.A. Nauertz, and J.C. Zasada. "Effects of management on the composition and structure of northern hardwood forests in Upper Michigan." Forest Science 48, 1: (2002) 129-145.

Crow, T.R., C.H. Tubbs, R.D. Jacobs, and R.R. Oberg. "Stocking and structure for maximum growth in sugar maple selection stands." Research Paper NC-199, U.S. Department of Agriculture, Forest Service, North Central Forest Experiment Station, 2006. 
Curtis, R.O., and J.D. Arney. "Estimating DBH [diameter at breast height] from stump diameters on second-growth Douglas-fir." Technical report, U.S. Department of Agriculture, Forest Service, Pacific Northwest Forest and Range Experiment Station, 1977.

Davis, S.C., M. Dietze, E. DeLucia, C. Field, S.P. Hamburg, S. Loarie, W. Parton, M. Potts, B. Ramage, D. Wang, et al. "Harvesting Carbon from Eastern US Forests: Opportunities and Impacts of an Expanding Bioenergy Industry." Forests 3, 2: (2012) 370-397.

Demaerschalk, J.P., and S.A.Y. Omule. "Estimating breast height diameters from stump measurements in British Columbia." The Forestry Chronicle 58, 3: (1982) 143-145.

Diaci, J., D. Rozenbergar, I. Anic, S. Mikac, M. Saniga, S. Kucbel, C. Visnjic, and D. Ballian. "Structural dynamics and synchronous silver fir decline in mixed old-growth mountain forests in Eastern and Southeastern Europe.' Forestry 84, 5: (2011) 479-491.

Dixon, G.E., and C.E. Keyser. "Lake States (LS) variant overview: Forest Vegetation Simulator." Technical report, U.S. Department of Agriculture, Forest Service, Forest Management Service Center, 2008.

Eberhart, T.L., A.J. Storer, and L.M. Nagel. "Ash basal area reduction model.” Technical report, http://www.ashmodel.org/version_2.0/2inch/2inch.htm, 2007. http://www . ashmodel.org/version_2.0/2inch/2inch.htm.

Egan, A., and S. Jones. "Do landowner practices reflect beliefs? Implications of an extension-research partnership." Journal of Forestry 91, 1: (1993) 39-45.

Erickson, D.L., R.L. Ryan, and R. De Young. "Woodlots in the rural landscape: landowner motivations and management attitudes in a Michigan (USA) case study." Landscape and Urban Planning 58, 2-4: (2002) 101-112.

Erickson, M.D., D.D. Reed, and G.D. Morz. "Stand development and economic analysis of alternative cutting methods in northern hardwoods: 32-year results." Northern Journal of Applied Forestry 7, 4: (1990) 153-158.

Eyre, F.H., and W.M. Zillgitt. "Partial cuttings in northern hardwoods of the Lake States: Twenty-year experimental results." Technical Bulletin LS-1076, U.S. Department of Agriculture, Forest Service, Lake States Forest Experiment Station, 1953.

Fajvan, M.A., S.T. Grushecky, and C.C. Hassler. "The effects of harvesting practices on West Virginia’s wood supply." Journal of Forestry 96, 5: (1998) 33-39.

FIA. "Forest Inventory Data Online. USFS National Forest Inventory and Analysis database." Technical report, US Forest Service, http://apps.fs.fed.us/fido/, 2011. 
Filip, S. "Cutting and cultural methods for managing northern hardwoods in the Northeastern United States." General Technical Report NE-5, U.S. Department of Agriculture, Forest Service, Northeastern Forest Experiment Station, 1973.

Frelich, L.E. Forest dynamics and disturbance regimes: Studies from temperate evergreen-deciduous forests. Cambridge University Press, 2002.

Froese, R., M. Hyslop, C. Miller, B. Garmon, H. McDiarmid, A. Shaw, L. Leefers, M. Lorenzo, S. Brown, and M. Shy. "Large-tract forestland ownership change: Land use, conservation, and prosperity in Michigan's Upper Peninsula." Technical report, 2007.

Fruchterman, T.M.J., and E.M. Reingold. "Graph drawing by force-directed placement." Software: Practice and experience 21, 11: (1991) 1129-1164.

Garcia, O. "What is a diameter distribution?" In Proceedings of the Symposium on Intregrated Forest Management Systems, edited by M. Minowa, and S. Tsuyuki. Tsukuba, Japan: Japan Society of Forest Planning Press., 1991, 11-29.

Gobster, P.H. "Forest aesthetics, biodiversity, and the perceived appropriateness of ecosystem management practices." General Technical Report, PNW-GTR-369, U.S. Department of Agriculture, Forest Service, Pacific Northwest Research Station, 1996.

Goff, F.G., and D. West. "Canopy-understory interaction effects on forest population structure." Forest Science 21, 2: (1975) 98-108.

Goodburn, J.M., and C.G. Lorimer. "Population structure in old-growth and managed northern hardwoods: An examination of the balanced diameter distribution concept." Forest Ecology and Management 118, 1-3: (1999) 11-29.

Gove, J.H., M.J. Ducey, W.B. Leak, and L. Zhang. "Rotated sigmoid structures in managed uneven-aged northern hardwood stands: a look at the Burr Type III distribution." Forestry 81, 2: (2008) 161-176.

Gove, J.H., and S.E. Fairweather. "Optimizing the management of uneven-aged forest stands: a stochastic approach.” Forest Science 38, 3: (1992) 623-640.

Gronewold, C.A., A.W. D'Amato, and B.J. Palik. "The influence of cutting cycle and stocking level on the structure and composition of managed old-growth northern hardwoods." Forest Ecology and Management 259, 6: (2010) 1151-1160.

Gul, A.U., M. Misir, N. Misir, and H. Yavuz. "Calculation of uneven-aged stand structures with the negative exponential diameter distribution and Sterba's modified competition density rule." Forest Ecology and Management 214, 1-3: (2005) 212-220.

Haines, A.L., T.T. Kennedy, and D.L. McFarlane. "Parcelization: Forest Change Agent in Northern Wisconsin.” Journal of Forestry 109, 2: (2011) 101-108. 
Hampf, F. E. "Relationship of stump diameter to dbh for yellow-poplar in the Northeast." Research Note NE-43, U.S. Department of Agriculture, Forest Service, Northeastern Forest Experiment Station, 1955.

Hann, D.W. "Relationship of stump diameter to diameter at breast height for seven tree species in Arizona and New Mexico." Research Note INT-212, U.S. Department of Agriculture, Forest Service, Intermountain Forest and Range Experiment Station, 1976.

Helms, J.A. The dictionary of forestry. CAB International, 1998.

Hoare, A., D.G. Regan, and D.P. Wilson. "Sampling and sensitivity analyses tools (SaSAT) for computational modelling." Theoretical Biology and Medical Modelling 5, 4.

Horn, A.G., and R.C. Keller. "Tree diameter at breast height in relation to stump diameter by species group." Technical Note 507, U.S. Department of Agriculture, Forest Service, Lake States Forest Experiment Station, 1957.

Hull, R. B. "Forestry's conundrum: High value, low relevance." Journal of Forestry 109: (2011) 50-56.

Hyink, D.M., and J.W. Moser. "A generalized framework for projecting forest yield and stand structure using diameter distributions.” Forest Science 29, 1: (1983) 85-95.

Janowiak, M., L.M. Nagel, and C. Webster. "Minimum tree size and interpretation of stand structure in uneven-aged northern hardwoods." Northern Journal of Applied Forestry 27, 1: (2010) 34-37.

Janowiak, M.K., L.M. Nagel, and C.R. Webster. "Spatial scale and stand structure in northern hardwood forests: Implications for quantifying diameter distributions." Forest Science 54, 5: (2008) 497-506.

Johnson, P.S., and D.R. Weigel. "Models for estimating DBH from stump diameter for Southern Indiana oaks.” Northern Journal of Applied Forestry 7, 2: (1990) 79-81.

Katz, B.M., and M. McSweeney. "Misclassification errors and categorical data analysis." The Journal of Experimental Educational 331-338.

Keeton, W.S. "Managing for late-successional/old-growth characteristics in northern hardwood-conifer forests." Forest Ecology and Management 235, 1-3: (2006) 129-142.

Kenefic, L.S., and R.D. Nyland. "Sugar maple height-diameter and age-diameter relationships in an uneven-aged northern hardwood stand." Northern Journal of Applied Forestry 16, 1: (1999) 43-47.

. "Habitat diversity in uneven-aged northern hardwood stands: A case study." Research Paper NE-714, U.S. Department of Agriculture, Forest Service, Northeastern Research Station, 2000. 
. "Cavity trees, snags, and selection cutting: A northern hardwood case study." Northern Journal of Applied Forestry 24, 3: (2007) 192-197.

Khatry Chhetri, D.B., and G.W. Fowler. "Estimating diameter at breast height and basal diameter of trees from stump measurements in Nepal's lower temperate broad-leaved forests." Forest Ecology and Management 81, 1-3: (1996) 75-84.

Kluender, R.A., and T.L. Walkingstick. "Rethinking how nonindustrial landowners view their lands." Southern Journal of Applied Forestry 24, 3: (2000) 150-158.

Knoebel, B.R., and H.E. Burkhart. "A bivariate distribution approach to modeling forest diameter distributions at two points in time." Biometrics 47, 1: (1991) 241-253.

Knuth, K.H. "Optimal data-based binning for histograms." ArXiv Physics e-Prints .

Lafferty, GD, and TR Wyatt. "Where to stick your data points: The treatment of measurements within wide bins." Nuclear Instruments and Methods in Physics Research Section A: Accelerators, Spectrometers, Detectors and Associated Equipment 355, 2-3: (1995) 541-547.

Leak, W.B. "Long-term structural change in uneven-aged northern hardwoods." Forest Science 42, 2: (1996) 160-165.

. "Origin of sigmoid diameter distributions." Research Paper NE-718, U.S. Department of Agriculture, Forest Service, Northeastern Research Station, 2002.

Leak, W.B., and J.H. Gottsacker. "New approaches to uneven-age management in New England." Northern Journal of Applied Forestry 2, 1: (1985) 28-31.

Leak, W.B., D.S. Solomon, and P. DeBald. "Silvicultural guide for northern hardwood types in the Northeast (revised)." Research Paper NE-603, U.S. Department of Agriculture, Forest Service, Northeastern Research Station, 1987.

de Liocourt, F. "De l'amenagement des sapinieres, English translation:(2001) On the amelioration of fir forests, translated by Maria Nygren." Bulletin trimestriel, Societe forestiere de Franche-Comte et Belfort, juillet 396-409.

Liu, C., L. Zhang, C.J. Davis, D.S. Solomon, and J.H. Gove. "A finite mixture model for characterizing the diameter distributions of mixed-species forest stands." Forest Science 48, 4: (2002) 653-661.

Lorimer, C.G., and L.E. Frelich. "A simulation of equilibrium diameter distributions of sugar maple (Acer saccharum)." Bulletin of the Torrey Botanical Club 111, 2: (1984) 193-199. 
Maltamo, Matti, Annika Kangas, Janne Uuttera, Tatu Torniainen, and Jussi Saramäki. "Comparison of percentile based prediction methods and the Weibull distribution in describing the diameter distribution of heterogeneous Scots pine stands." Forest Ecology and Management 133, 3: (2000) 263 - 274. http://wWw.sciencedirect.com/science/article/ B6T6X-40T9GXV-7/2/3c5a2541933a97179ad104f584c40764.

Martin, G.L. "Investment-efficient stocking guides for all-aged northern hardwood forests." Research Report R3129, University of Wisconsin College of Agriculture and Life Science, 1982.

MATLAB. version 7.10.0 (R2010a). Natick, Massachusetts: The MathWorks Inc., 2010.

Matonis, M.S.., M.B. Walters, and J.D.A. Millington. "Gap-, stand-, and landscape-scale factors contribute to poor sugar maple regeneration after timber harvest." Forest Ecology and Management 262, 2: (2011) 286-298.

Max, T.A., and H.E. Burkhart. "Segmented polynomial regression applied to taper equations." Forest Science 22, 3: (1976) 283-289.

McClure, J.P. "Predicting tree dbh from stump measurements in the southeast." Research Note SE-99, U.S. Department of Agriculture, Forest Service, Southeastern Forest Experiment Station, 1968.

McGee, G.G., D.J. Leopold, and R.D. Nyland. "Structural characteristics of old-growth, maturing, and partially cut northern hardwood forests." Ecological Applications 9, 4: (1999) 1316-1329.

Meyer, H.A. "Structure, growth, and drain in balanced uneven-aged forests." Journal of Forestry 50, 2: (1952) 85-92.

Michigan Department of Natural Resources. "Northern hardwoods on Michigan State Forests." Technical report, www.dnr.state.mi.us/publications/pdfs/ForestsLandWater/ForestCertificationPub/ForestMgtAndNorthCentralMgtGuidelines, 1986.

_. "Average stumpage price report for 10/01/2008 to 09/30/2009." Technical report, http://www.michigandnr.com/ftp/forestry/tsreports/ StumpagePriceReports/12_Month_Stumpage_Price_Reports/ 2009 _Stumpage_Price_Reports/4th_Qtr_Oct_2009.pdf, 2011.

Mildenberger, T., Y. Rozenholc, and D. Zasada. histogram: Construction of regular and irregular histograms with different options for automatic choice of bins, $\mathrm{R}$ package version 0.0-23 edition, 2009. 
Millington, J.D.A., M.B. Walters, M.S. Matonis, and J. Liu. "Effects of local and regional landscape characteristics on wildlife distribution across managed forests." Forest Ecology and Management 259: (2010) 1102-1110.

Mladenoff, D.J., M.A. White, T.R. Crow, and J. Pastor. "Applying principles of landscape design and management to integrate old-growth forest enhancement and commodity use." Conservation Biology 8, 3: (1994) 752-762.

Munsell, J.F., and R.H. Germain. "Woody biomass energy: An opportunity for silviculture on nonindustrial private forestlands in New York." Journal of Forestry 105, 8: (2007) 398-402.

Munsell, J.F., R.H. Germain, V.A. Luzadis, and E. Bevilacqua. "Owner intentions, previous harvests, and future timber yield on fifty working nonindustrial private forestlands in New York State.” Northern Journal of Applied Forestry 26, 2: (2009) 45-51.

Munsell, J.F., R.H. Germain, and I.A. Munn. "A tale of two forests: Case study comparisons of sustained yield management on Mississippi and New York nonindustrial private forestland." Journal of Forestry 106, 8: (2008) 431-439.

Myers, C. A. "Estimating volumes and diameters at breast height from stump diameters, southwestern ponderosa pine." Research Note RM-9, U.S. Department of Agriculture, Forest Service, Rocky Mountain Forest and Range Experiment Station, 1963.

Naficy, C., A. Sala, E.G. Keeling, J. Graham, and T.H. DeLuca. "Interactive effects of historical logging and fire exclusion on ponderosa pine forest structure in the northern Rockies." Ecological Applications 20, 7: (2010) 1851-1864.

Niese, J.N., and T. F. Strong. "Economic and tree diversity trade-offs in managed northern hardwoods.” Canadian Journal of Forest Research 22: (1992) 1807-1813.

Nyland, R.D. "Exploitation and greed in eastern hardwood forests." Journal of Forestry 90, 1: (1992) 33-37.

-. Silviculture: Concepts and applications. McGraw-Hill Co., 2002.

- "Even-to uneven-aged: The challenges of conversion." Forest Ecology and Management 172, 2-3: (2003) 291-300.

- "Diameter-limit cutting and silviculture: A comparison of long-term yields and values for uneven-aged sugar maple stands." Northern Journal of Applied Forestry 22, 2: (2005) 111-116.

Oliver, C.D., B.C. Larson, et al. Forest stand dynamics. McGraw-Hill, Inc., 1990.

Oliver, C.D., and E.P. Stephens. "Reconstruction of a mixed-species forest in central New England.” Ecology 562-572. 
OMNR. "A silvicultural guide for the tolerant hardwood forest in Ontario." Technical report, Ontario Ministry of Natural Resources. Queen's Printer for Ontario., http://www.web2.mnr.gov.on.ca/mnr/forests/

forestdoc/guidelines/hrdwd/pdf/cover.pdf., 1998.

Osborne, D.V. "Some aspects of the theory of dichotomous keys." New Phytologist 144-160.

Özçelík, R., J. Brooks, M. Diamantopoulou, and H. Wiant. "Estimating breast height diameter and volume from stump diameter for three economically important species in Turkey." Scandanavian Journal of Forest Research 25, 1: (2010) 32-45.

Pinheiro, J., D. Bates, S. DebRoy, D. Sarkar, and R Development Core Team. nlme: Linear and Nonlinear Mixed Effects Models, 2010. R package version 3.1-97.

Pokharel, B., and R.E. Froese. "Evaluating alternative implementations of the Lake States FVS diameter increment model." Forest Ecology and Management 255, 5-6: (2008) 1759-1771.

Potter-Witter, K. "A cross-sectional analysis of Michigan nonindustrial private forest landowners." Northern Journal of Applied Forestry 22, 2: (2005) 132-138.

Powers, M., R. Kolka, B. Palik, R. McDonald, and M. Jurgensen. "Long-term management impacts on carbon storage in Lake States forests." Forest Ecology and Management 262, 3: (2011) 424-431.

Price, D.L. "Michigan State Forest Management Plan." Technical report, Michigan Department of Natural Resources and Environment Forest, Mineral, and Fire Management and Wildlife Divisions, www.michigan.gov/documents/dnr/ FSFMPDraftJan2008_222799_7.pdf, 2008.

Puettmann, K.J., K.D. Coates, and C.C. Messier. A critique of silviculture: managing for complexity. Cambridge Univ Press, 2009.

R Development Core Team. R: A Language and Environment for Statistical Computing. R Foundation for Statistical Computing, Vienna, Austria, 2012.

Raile, G. "Estimating DBH from stump dimensions." In Proc. 1977 Midwest Forest Mensurationists Meeting. USDA For. Serv. Gen. Tech. Rep. NC-46, North Central For. Exp. Stn., St. Paul, MN. 1978, 30-33.

Raile, G.K., W.B. Smith, and C.A. Weist. "A net volume equation for Michigan's Upper and Lower Peninsulas." General Technical Report NC-80, U.S. Department of Agriculture, Forest Service, North Central Forest Experiment Station, 1982. 
Ravenel, R., M. Tyrrell, and R. (Eds). Mendelsohn. "Institutional timberland investment." Technical report, http://environment.yale.edu/gisf/files/pdfs /yff_reviews/05.03.pdf., 2002.

Reed, D.D., M.J. Holmes, and J.A. Johnson. "A 22-year study of stand development and financial return in northern hardwoods." Northern Journal of Applied Forestry 3, 1: (1986) 35-38.

Robinson, A.P., R.A. Duursma, and J.D. Marshall. "A regression-based equivalence test for model validation: shifting the burden of proof." Tree Physiology 25, 7: (2005) 903-913.

Robinson, A.P., and R.E. Froese. "Model validation using equivalence tests." Ecological Modelling 176, 3-4: (2004) 349-358.

Rubin, B.D., P.D. Manion, and D. Faber-Langendoen. "Diameter distributions and structural sustainability in forests." Forest Ecology and Management 222, 1-3: (2006) 427-438.

Schwartz, J.W., L.M. Nagel, and C.R. Webster. "Effects of uneven-aged management on diameter distribution and species composition of northern hardwoods in Upper Michigan." Forest Ecology and Management 211, 3: (2005) 356-370.

Scott, C.T. "Northeastern forest survey revised cubic-foot volume equations." Research Note NE-304, U.S. Department of Agriculture, Forest Service, Northeastern Forest Experiment Station, 1981.

Seymour, R.S., J. Guldin, D. Marshall, and B. Palik. "Large-scale, long-term silvicultural experiments in the United States: historical overview and contemporary examples." Allgemeine Forst und Jagdzeitung 177: (2006) 104-112.

Sharma, M., and H.E. Burkhart. "Selecting a level of conditioning for the segmented polynomial taper equation.” Forest Science 49, 2: (2003) 324-330.

Shimazaki, H., and S. Shinomoto. "A method for selecting the bin size of a time histogram." Neural Computation 19, 6: (2007) 1503-1527.

Simpson, B.T., and H.V. Wiant, Jr. "Accuracy of timber trespass cruises.” Northern Journal of Applied Forestry 9, 1: (1992) 35-36.

Stokes, R. "Michigan state forests and forest certification." Technical report, Michigan Department of Natural Resources, www.michigan.gov/documents/dnr/ MessageFromTheDirector_345398_7.pdf, 2011.

Thomas, J. W. "Wildlife habitats in managed forests-the Blue Mountains of Oregon and Washington." Agricultural Handbook 553, U.S. Department of Agriculture, Forest Service, 1979. 
Tubbs, C.H. "Manager's handbook for northern hardwoods in the north-central states." General Technical Report NC-39, U.S. Department of Agriculture, Forest Service, North Central Forest Experiment Station, 1977.

Walters, D.K., D.W. Hann, et al. Taper equations for six conifer species in southwest Oregon. Forest Research Lab, College of Forestry, Oregon State University, 1986.

Wand, M.P. "Data-based choice of histogram bin width." The American Statistician 51, 1: (1997) 59-64.

. KernSmooth: Functions for kernel smoothing for Wand and Jones (1995), R package version 2.23-7 edition, 2011.

Wand, M.P., and M.C. Jones. Kernel smoothing, volume 60. Chapman Hall, 1995.

Wang, M., and K. Rennolls. "Tree diameter distribution modelling: Introducing the logit-logistic distribution." Canadian Journal of Forest Research 35, 6: (2005) 1305-1313.

Wellek, S. Testing statistical hypotheses of equivalence and noninferiority. Chapman and Hall, 2010.

Westfall, J.A. "New models for predicting diameter at breast height from stump dimensions." Northern Journal of Applied Forestry 27, 1: (2010) 21-27.

Wharton, E.H. "Predicting diameter at breast height from stump diameters for northeastern tree species." Research Note NE-322, U.S. Department of Agriculture, Forest Service, Northeastern Forest Experiment Station, 1984.

Wiant, H.V., and T.B. Williams. "Lower bole diameter and volume of four Appalachian hardwoods.” Northern Journal of Applied Forestry 4, 4: (1987) 212-212.

Wisconsin Department of Natural Resources. "Silviculture and Forest Aesthetics Handbook, 2431.5." Online, 2010. http://dnr.wi.gov/forestry/ publications/Handbooks/24315/.

Zhang, L., J.H. Gove, C. Liu, and W.B. Leak. "A finite mixture of two Weibull distributions for modeling the diameter distributions of rotated-sigmoid, uneven-aged stands." Canadian Journal of Forest Research 31, 9: (2001) 1654-1659.

Zhang, L., and C. Liu. "Fitting irregular diameter distributions of forest stands by Weibull, modified Weibull, and mixture Weibull models." Journal of Forest Research 11, 5: (2006) 369-372.

Zutter, B.R., R.G. Oderwald, P.A. Murphy, and R.M. Farrar. "Characterizing diameter distributions with modified data types and forms of the Weibull distribution." Forest Science 32, 1: (1986) 37-48. 
Appendix A

\section{Stand locations}




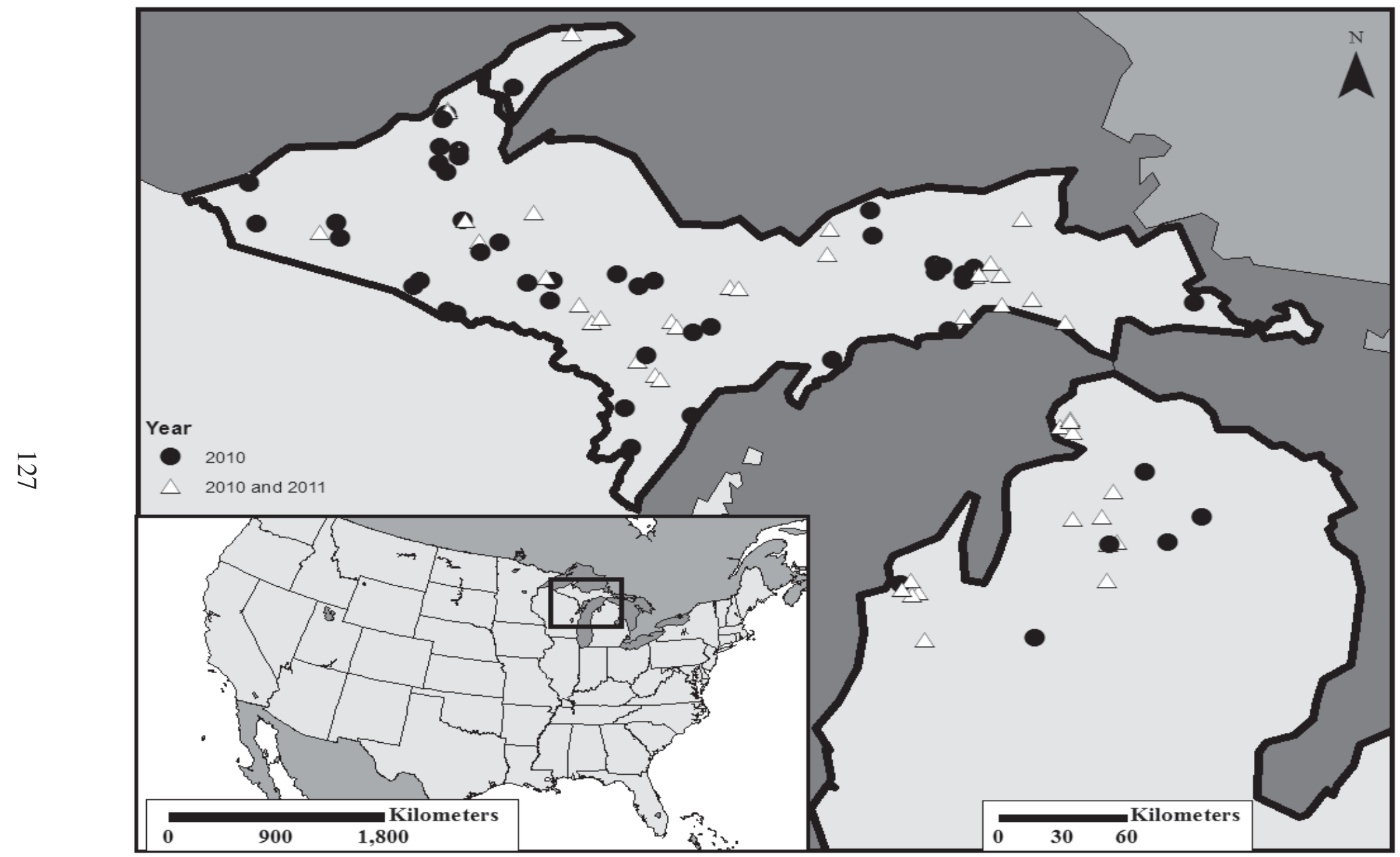

Appendix A. Locations of northern hardwood stands measured in 2010 and 2011 


\section{Appendix B}

\section{Fruchterman-Reingold layout}

The Fruchterman-Reingold layout procedure for a network diagram uses an algorithm which simulated "forces" between points to meet basic aesthetic criteria for a graph (Fruchterman and Reingold, 1991). The procedure mimics a system in which all of the vertices are metal rings and all of the edges are springs connecting them. In the mathematics behind the layout calculation, vertices are also treated as having attractive and repulsive forces, being attracted to vertices with a shared edge, but repelling all so that points are not too close to each other. In a way the vertices are like magnets which attract vertices to which they are connected by an edge, but also repel them if they get too close so they don't overlap. The algorithm creates a graph which balances the hypothetical energies which would exist in a system which was made up of such magnets connected by springs, generally in a way that evenly spaces vertices and tries to produce uniform edge lengths (Fruchterman and Reingold, 1991). The distance between points generally reflects whether vertices are similar to each other or share similarities with other vertices, but the specific distance reflects the characteristics of the entire network and not the relationship between any two vertices.

This layout was selected from among the available layouts contained in the software package. The network diagrams created were more aesthetically pleasing and had fewer overlapping edges and nodes than other options. 
Appendix C

Curve shape classifications by bin width and plot size 


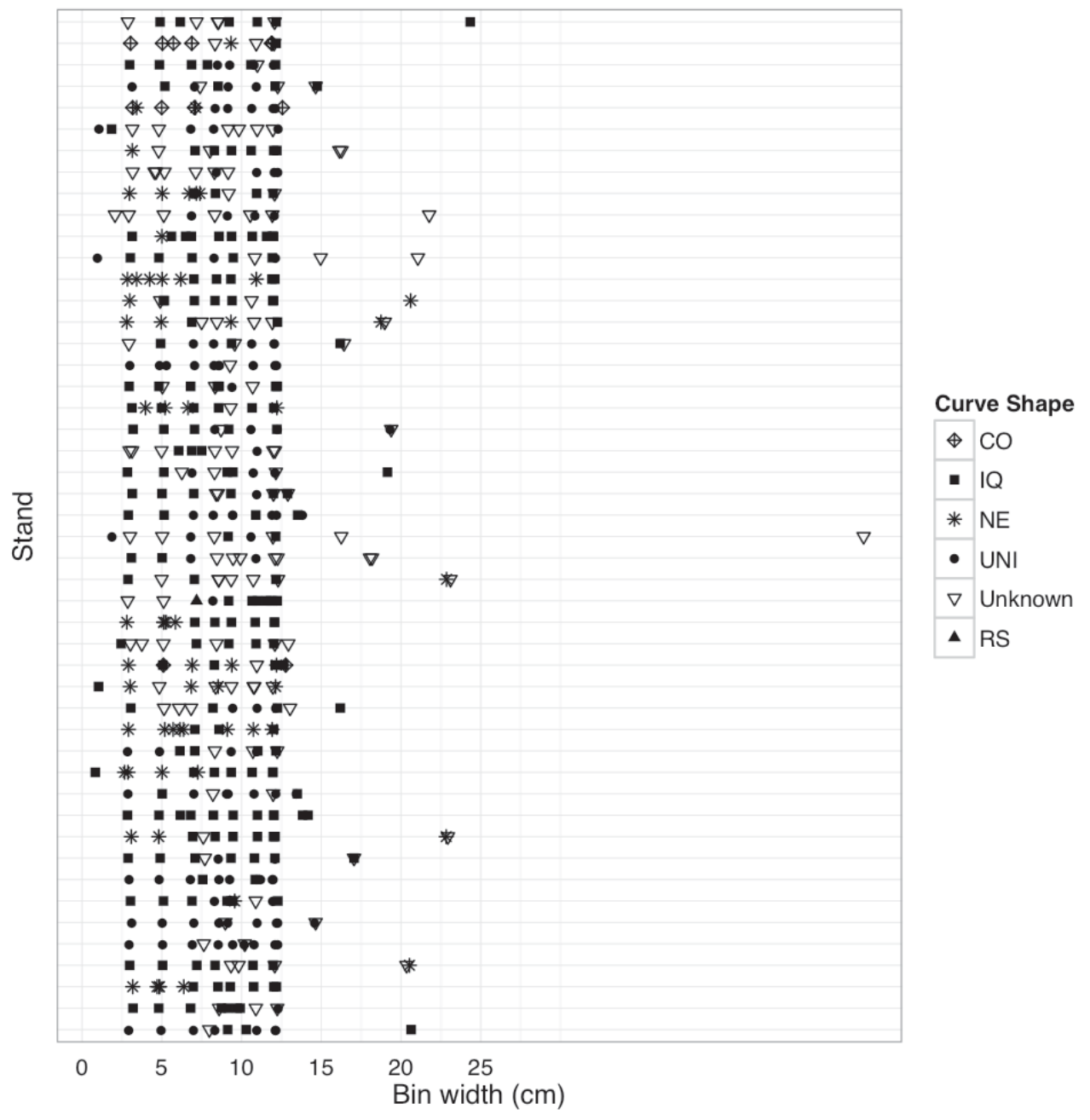

Relationship between bin widths and curve shapes using pre-harvest 2010 data, $100 \mathrm{~m}^{2}$ plots 


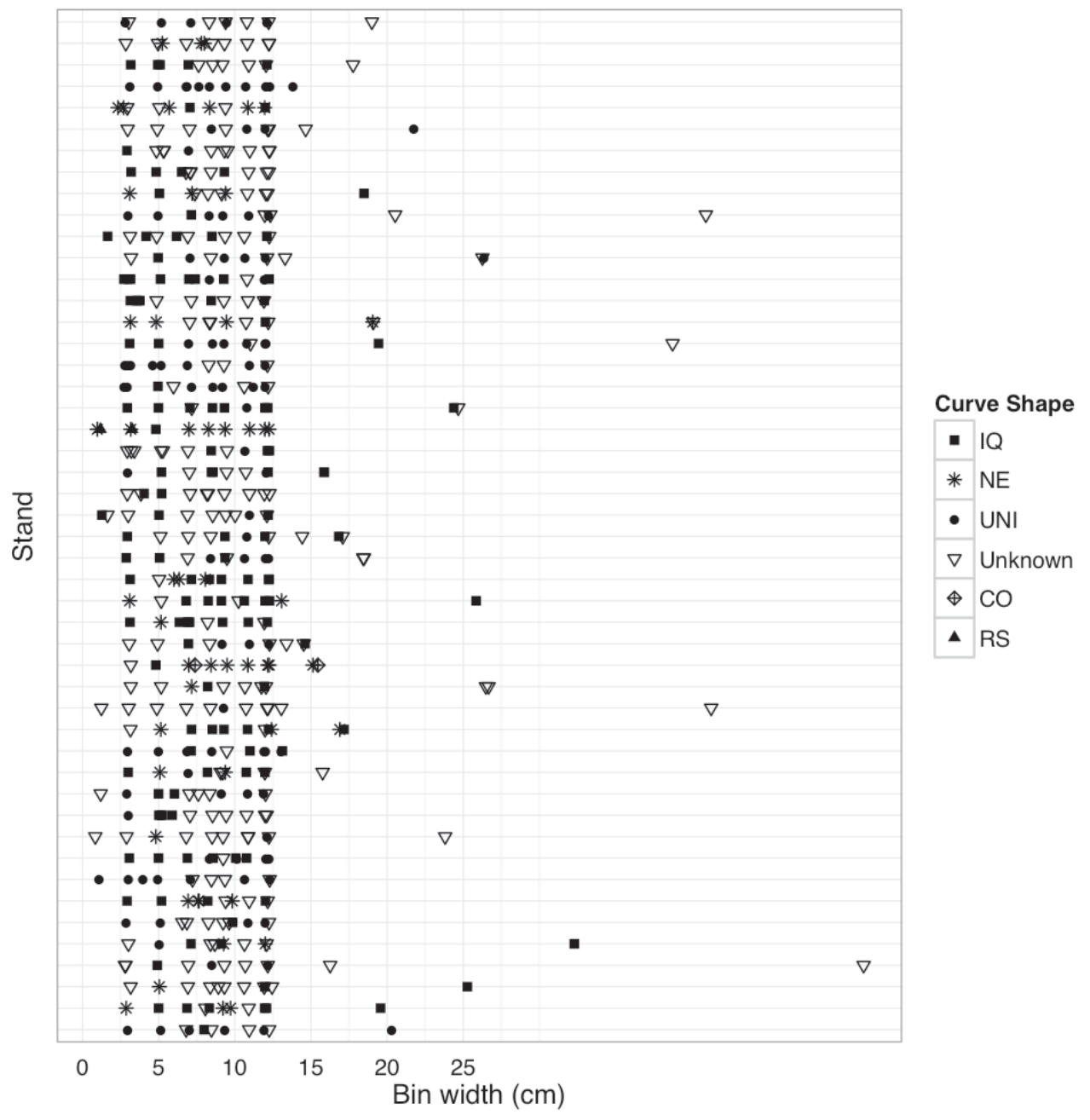

Relationship between bin widths and curve shapes using pre-harvest 2011 data, $100 \mathrm{~m}^{2}$ plots 


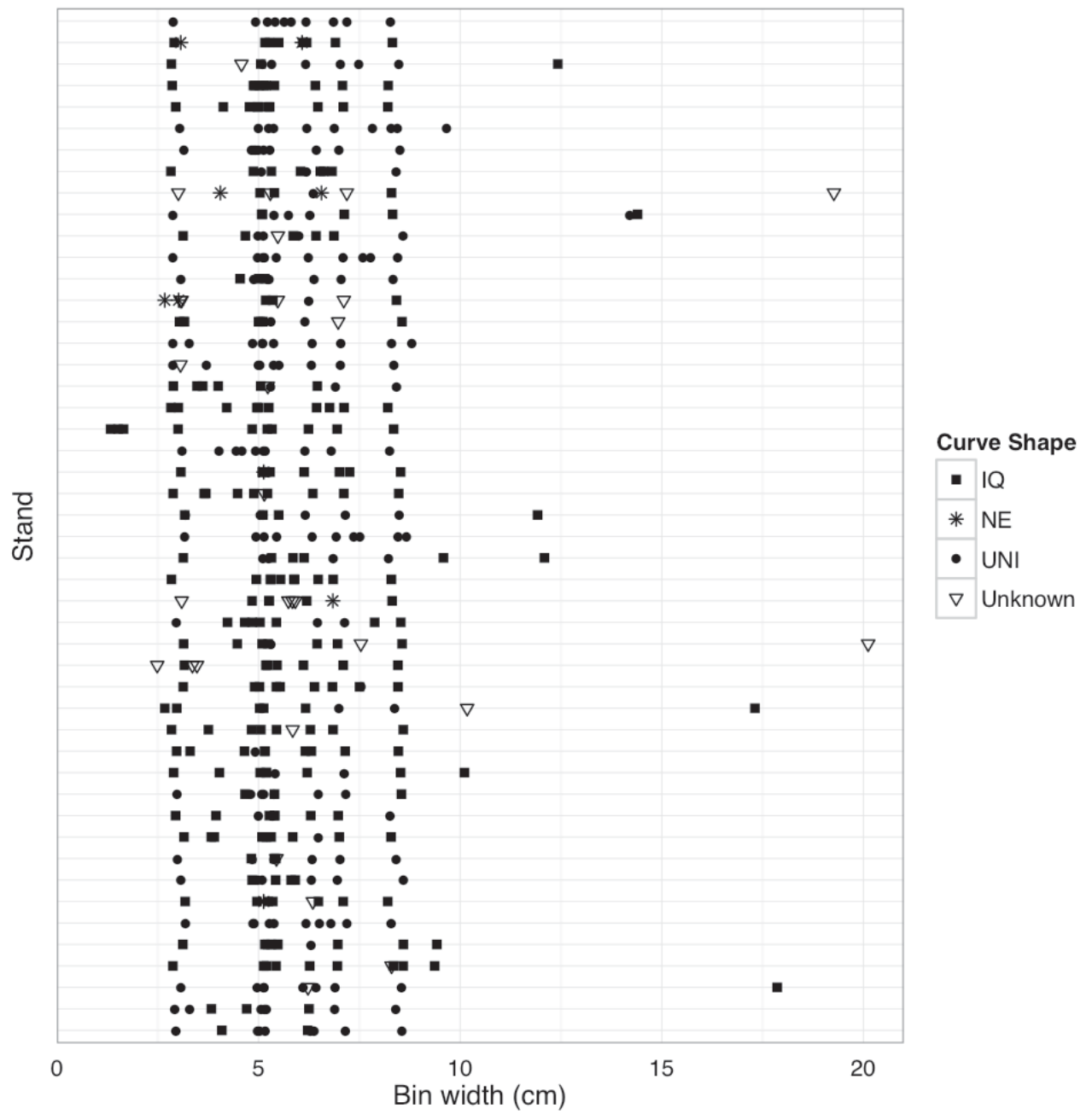

Relationship between bin widths and curve shapes using pre-harvest 2011 data, $400 \mathrm{~m}^{2}$ plots 


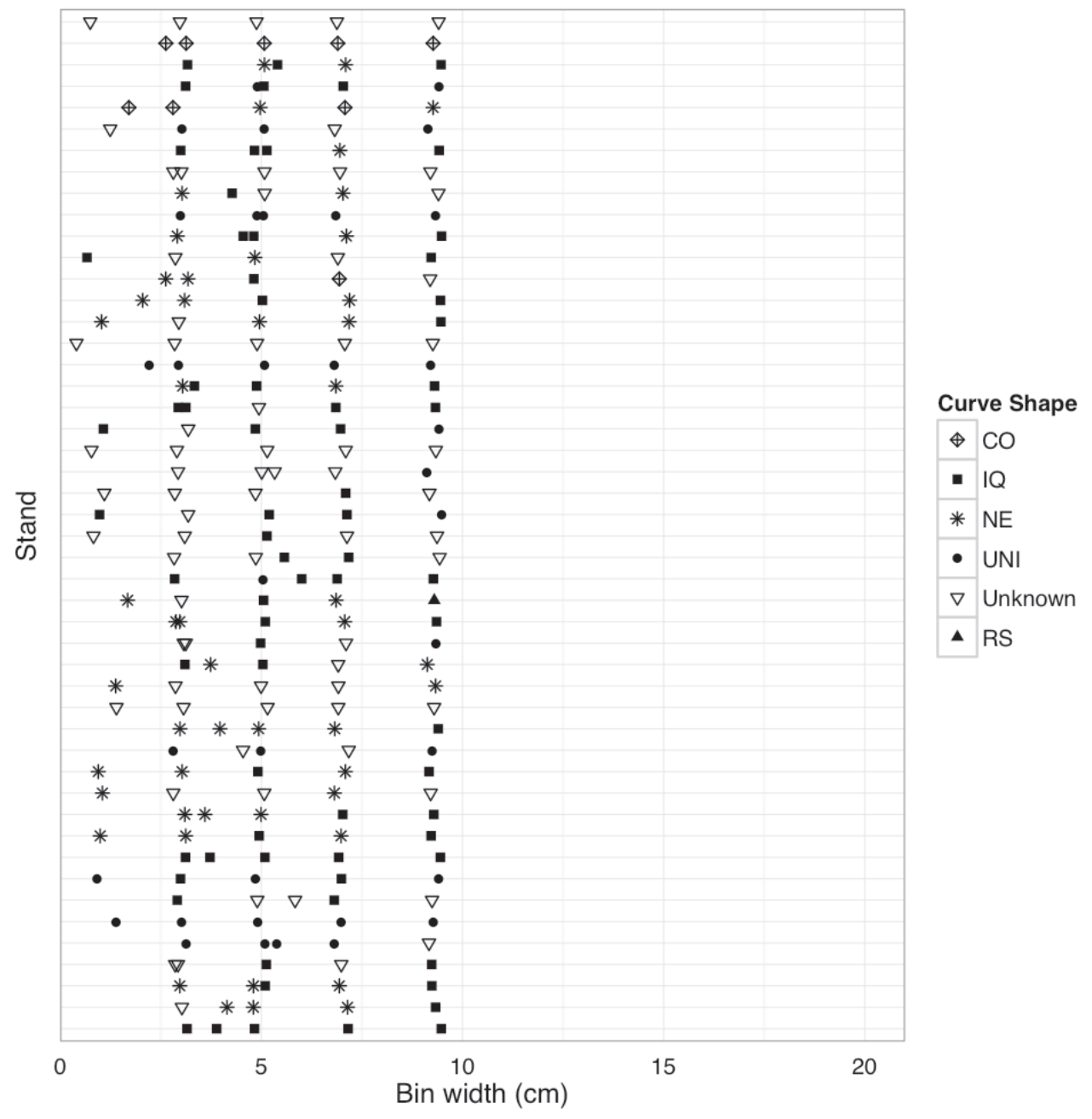

Relationship between bin widths and curve shapes using post harvest 2010 data, $100 \mathrm{~m}^{2}$ plots 


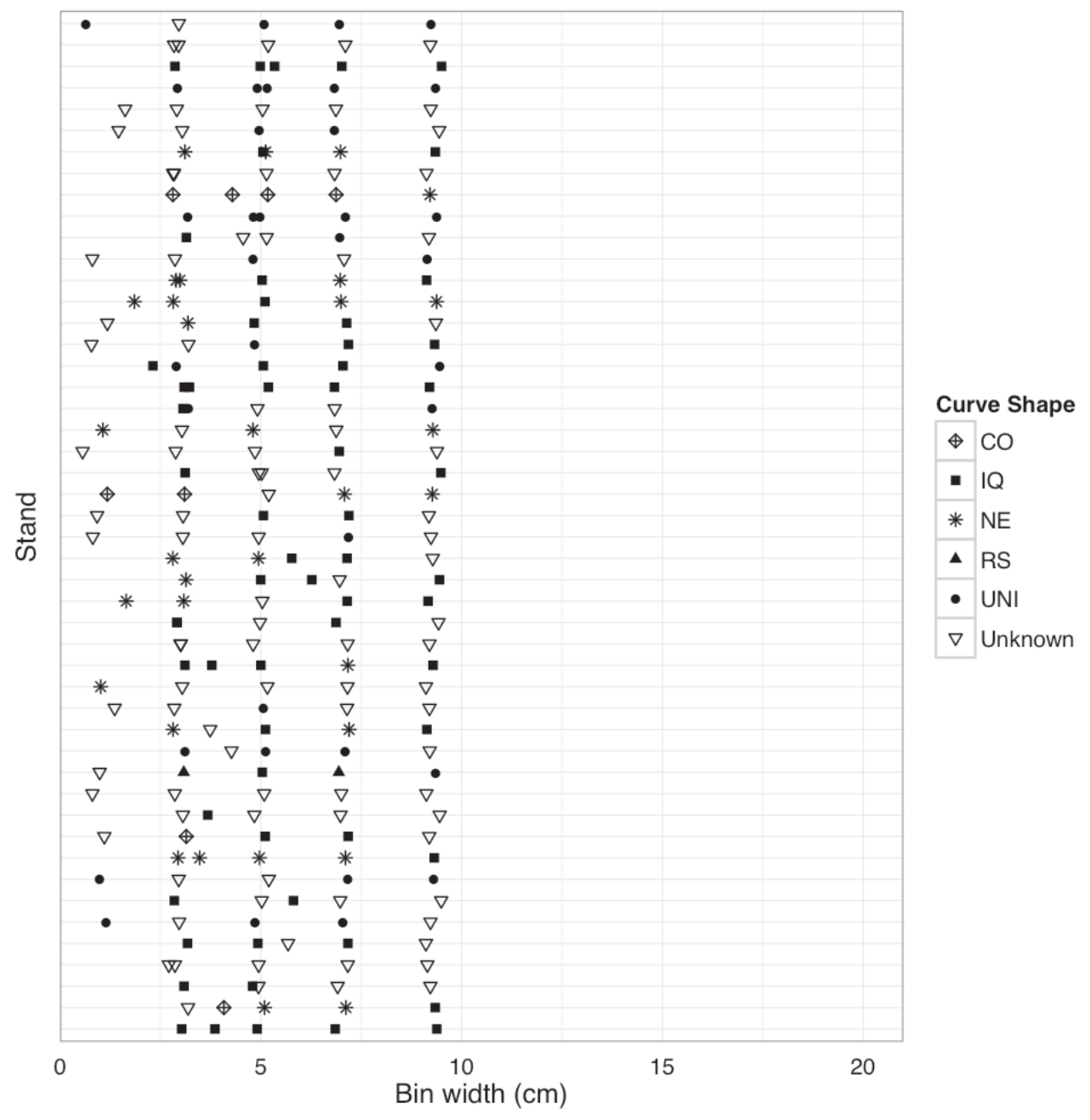

Relationship between bin widths and curve shapes using post harvest 2011 data, $100 \mathrm{~m}^{2}$ plots 


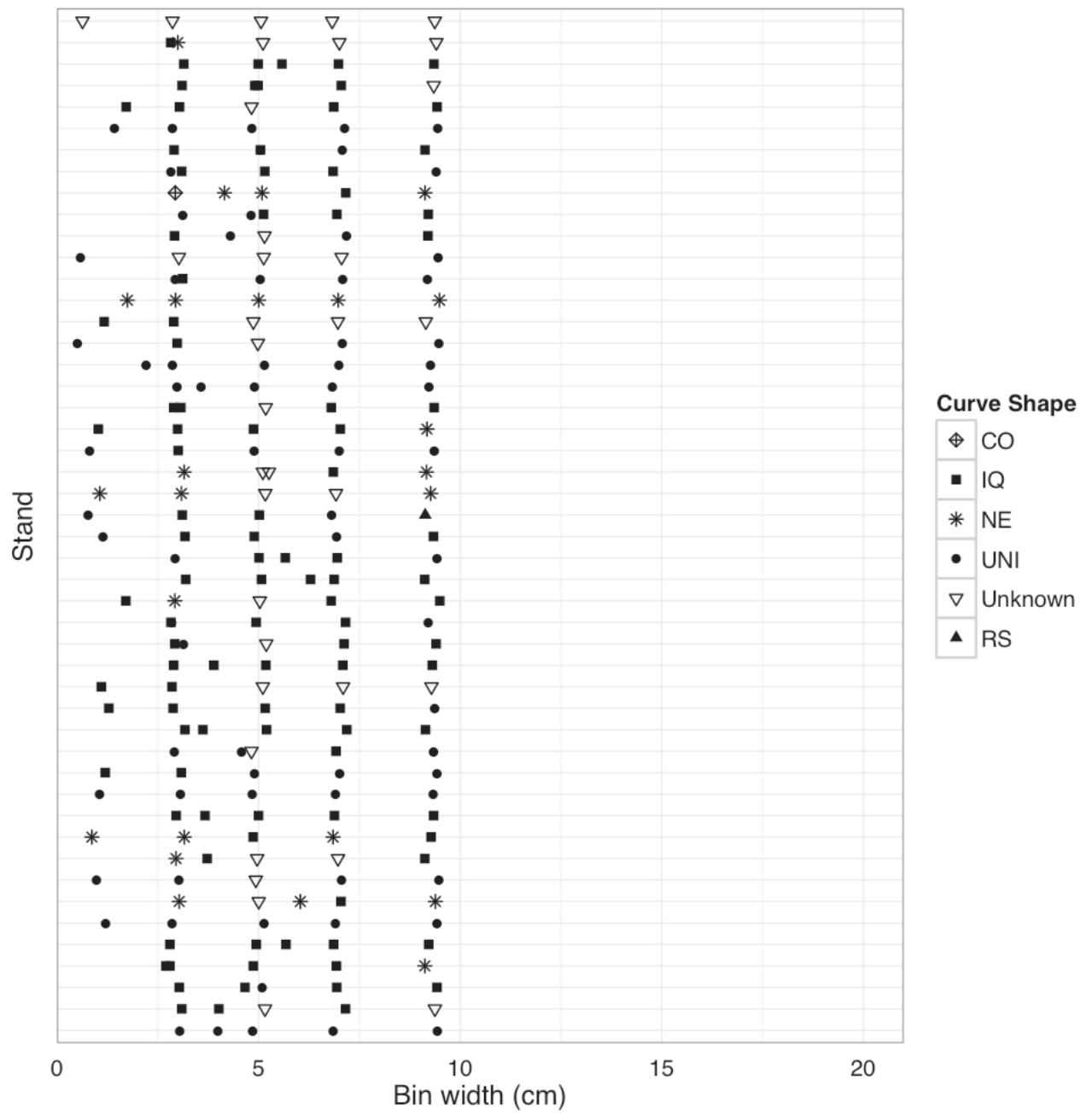

Relationship between bin widths and curve shapes using post-harvest 2011 data, $400 \mathrm{~m}^{2}$ plots 


\section{Appendix D}

\section{Letters of Permission}

The following represents permission from the publisher of Forest Science to reproduce Table 5.1, originally published in Janowiak et al. (2008). 


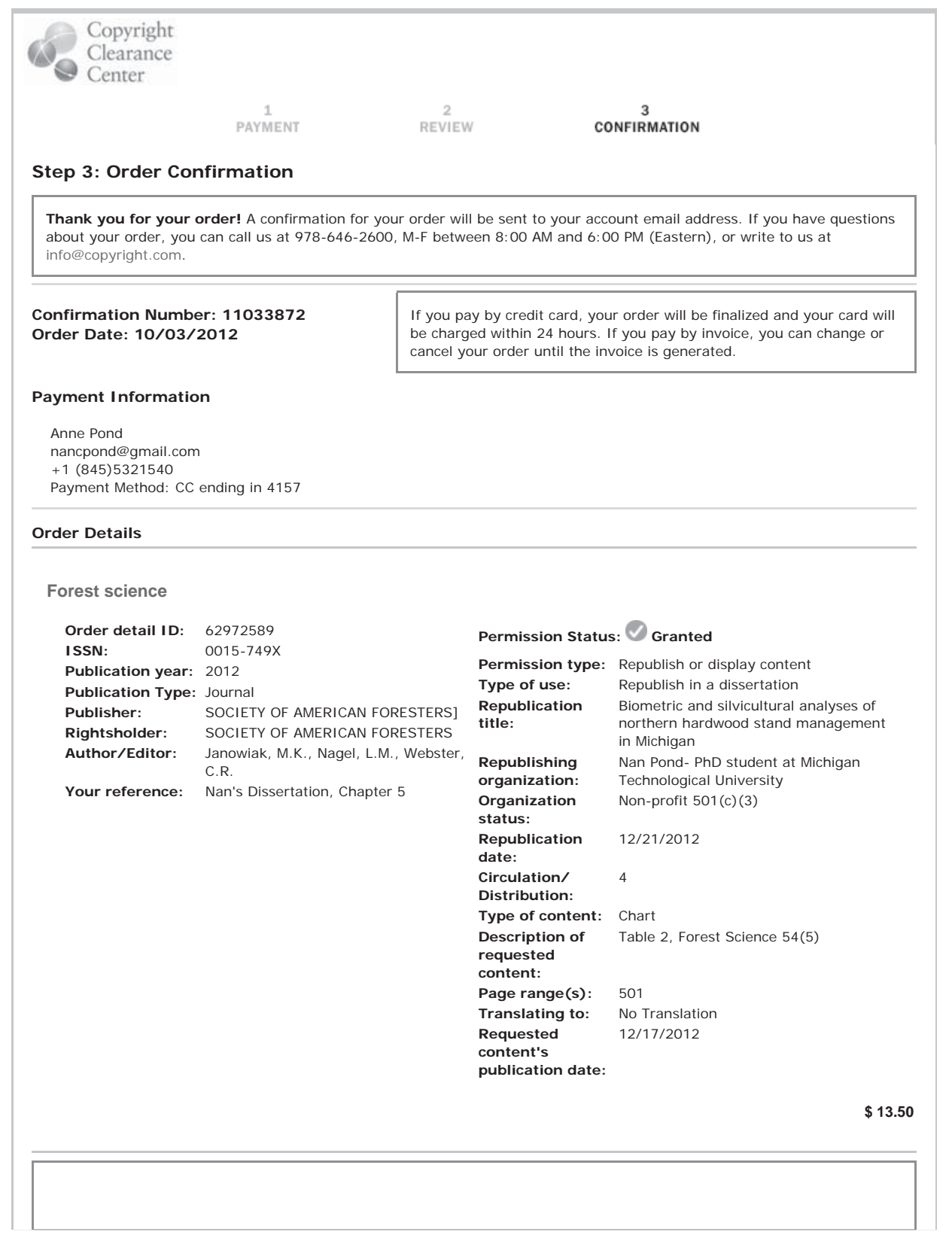




Copyright LICENSE YOUR CONTENT
Clearance
Center
Confirmation Number: $\mathbf{1 1 0 3 3 8 7 2}$
Special Rightsholder Terms \& Conditions
The following terms \& conditions apply to the specific publication under which they are listed
\begin{tabular}{l} 
There are no special terms. \\
\hline
\end{tabular}

Forest science

Permission type: Republish or display content

Type of use: Republish in a dissertation

\section{Terms and Conditions for Permission Category: "Republish Content"}

1. Description of Service.

Defined Terms. This Republication License enables the User to obtain licenses for republication of one or more copyrighted works as described in detail on the relevant Order Confirmation (the "Work(s)"). Copyright Clearance Center, Inc. ("CCC") grants licenses through the Service on behalf of the rightsholder identified on the Order Confirmation (the "Rightsholder"). grants licenses through the Service on behalf of the rightsholder identified on the Order Confirmation (the "Rightsholder").
"Republication", as used herein, generally means the inclusion of a Work, in whole or in part, in a new work or works, also as described on the Order Confirmation. "User", as used herein, means the person or entity making such republication.

2. User.

The terms set forth in the relevant Order Confirmation, and any terms set by the Rightsholder with respect to a particular Work, govern the terms of use of Works in connection with the Service. By using the Service, the person transacting for a republication license on behalf of the User represents and warrants that he/she/it (a) has been duly authorized by the User to accept, and hereby does accept, all such terms and conditions on behalf of User, and (b) shall inform User of all such terms and conditions. In the event such person is a "freelancer" or other third party independent of User and CCC, such party shall be deemed jointly a "User" for purposes of these terms and conditions. In any event, User shall be deemed to have accepted and agreed to all such terms and conditions if User republishes the Work in any fashion.

3. Scope of License; Limitations and Obligations.

3.1 Rights Granted: All Works and all rights therein, including copyright rights, remain the sole and exclusive property of the Rightsholder. The license created by the exchange of an Order Confirmation (and/or any invoice) and payment by User of the full amount set forth on that document includes only those rights expressly set forth in the Order Confirmation and in these terms and conditions, and conveys no other rights in the Work(s) to User. All rights not expressly granted are hereby reserved.

3.2 General Payment Terms: You may pay by credit card or through an account with us payable at the end of the month. If you and we agree that you may establish a standing account with CCC, then the following terms apply: Remit Payment to: Copyright Clearance Center, Dept 001, P.O. Box 843006, Boston, MA 02284-3006. Payments Due: Invoices are payable upon their delivery to you (or upon our notice to you that they are available to you for downloading). After 30 days, outstanding amounts will be subject to a service charge of $1-1 / 2 \%$ per month or, if less, the maximum rate allowed by applicable law. Unless otherwise specifically set forth in the Order Confirmation or in a separate written agreement by applicable law. Unless otherwise specifically set forth in the Order Confirmation or in a separate written agreement
signed by CCC, invoices are due and payable on "net 30" terms. While User may exercise the rights licensed immediately upon issuance of the Order Confirmation, the license is automatically revoked and is null and void, as if it had never been issued, if complete payment for the license is not received on a timely basis either from User directly or through a payment agent, such as a credit card company.

3.3 Term: Unless otherwise provided in the Order Confirmation, any grant of rights to User (i) is "one-time" (including the editions and product family specified in the license), (ii) is non-exclusive and non-transferable and (iii) is subject to any and all limitations and restrictions (such as, but not limited to, limitations on duration of use or circulation) included in the Order Confirmation or invoice and/or in these terms and conditions. Upon completion of the licensed use, User shall either secure a new permission for further use of the Work(s) or immediately cease any new use of the Work(s) and shall render inaccessible (such as by deleting or by removing or severing links or other locators) any further copies of the Work (except for copies printed on paper in accordance with this license and still in User's stock at the end of such period). 
3.4: Third Party Material: In the event that the material for which a republication license is sought includes third party materials (such as photographs, illustrations, graphs, inserts and similar materials) which are identified in such material as having been used by permission, User is responsible for identifying, and seeking separate licenses (under this Service or otherwise) for, any of such third party materials; without a separate license, such third party materials may not be used.

3.5: Copyright. Use of proper copyright notice for a Work is required as a condition of any license granted under the Service. Unless otherwise provided in the Order Confirmation, a proper copyright notice will read substantially as follows: "Republished with permission of [Rightsholder's name], from [Work's title, author, volume, edition number and year of copyright]; permission conveyed through Copyright Clearance Center, Inc. " Such notice must be provided in a reasonably legible font size and must be placed either immediately adjacent to the Work as used (for example, as part of a by-line or footnote but not as a separate electronic link) or in the place where substantially all other credits or notices for the new work containing the republished Work are located. Failure to include the required notice results in loss to the Rightsholder and CCC, and the User shall be liable to pay liquidated damages for each such failure equal to twice the use fee specified in the Order Confirmation, in addition to the use fee itself and any other fees and charges specified.

3.6: Limitation on Use: User may only make alterations to the Work if and as expressly set forth in the Order Confirmation; provided, however, that a Work consisting of photographs or other still images not embedded in text may, if necessary, be resized, reformatted or have its resolution modified without additional express permission, and a Work consisting of audiovisual content may, if necessary, be "clipped" or reformatted for purposes of time or content management or ease of delivery (provided that any such resizing, reformatting, resolution modification or clipping does management or ease of delivery (provided that any such resizing, reformatting, resolution modification or clipping do
not alter the underlying editorial content or meaning of the Work used and that the resulting resized, reformatted or clipped material is used solely within the scope of, and in a manner consistent with, the particular authorization described in the Order Confirmation and these terms and conditions). No Work may be used in any way that is defamatory, violates the rights of third parties (including such third parties' rights of copyright, privacy, publicity, or other tangible or intangible property), or is otherwise illegal, sexually explicit or obscene. In addition, User may not conjoin a Work with any other material that may result in damage to the reputation of the Rightsholder. User agrees to inform CCC if it becomes aware of any infringement of any rights in a Work and to cooperate with any reasonable request of CCC or the Rightsholder in connection therewith.

4. Indemnity.

User hereby indemnifies and agrees to defend the Rightsholder and CCC, and their respective employees and directors, against all claims, liability, damages, costs and expenses, including legal fees and expenses, arising out of any use of a Work beyond the scope of the rights granted herein, or any use of a Work which has been altered in any unauthorized way by User, including claims of defamation or infringement of rights of copyright, publicity, privacy or other tangible or intangible property.

5. LIMITATION OF LIABILITY.

(a) UNDER NO CIRCUMSTANCES WILL CCC OR THE RIGHTSHOLDER BE LIABLE FOR ANY DIRECT, INDIRECT, CONSEQUENTIAL OR INCIDENTAL DAMAGES (INCLUDING WITHOUT LIMITATION DAMAGES FOR LOSS OF BUSINESS PROFITS OR INFORMATION, OR FOR BUSINESS INTERRUPTION) ARISING OUT OF THE USE OR INABILITY TO USE A WORK, EVEN IF ONE OF THEM HAS BEEN ADVISED OF THE POSSIBILITY OF SUCH DAMAGES.

(b) IN ANY EVENT, THE TOTAL LIABILITY OF THE RIGHTSHOLDER AND CCC (INCLUDING THEIR RESPECTIVE EMPLOYEES AND DIRECTORS) SHALL NOT EXCEED THE TOTAL AMOUNT ACTUALLY PAID BY USER FOR THIS LICENSE. USER ASSUMES FULL LIABILITY FOR THE ACTIONS AND OMISSIONS OF ITS PRINCIPALS, EMPLOYEES, AGENTS, AFFILIATES, SUCCESSORS AND ASSIGNS.

6. Limited Warranties; Disclaimers.

(a) THE WORK(S) AND RIGHT(S) ARE PROVIDED "AS IS". THE RIGHTSHOLDER(S) HAS GRANTED CCC THE RIGHT TO GRANT PERMISSION UNDER THESE PAY-PER-USE SERVICES, AND HAS WARRANTED THAT IT HAS ALL RIGHTS NECESSARY TO AUTHORIZE CCC TO ACT ON ITS BEHALF. CCC AND THE RIGHTSHOLDER DISCLAIM ALL OTHER WARRANTIES RELATING TO THE WORK(S) AND RIGHT(S), EITHER EXPRESS OR IMPLIED, INCLUDING WITHOUT LIMITATION IMPLIED WARRANTIES OF MERCHANTABILITY OR FITNESS FOR A PARTICULAR PURPOSE. ADDITIONAL RIGHTS MAY BE REQUIRED TO USE ILLUSTRATIONS, GRAPHS, PHOTOGRAPHS, ABSTRACTS, INSERTS OR OTHER PORTIONS OF THE WORK (AS OPPOSED TO THE ENTIRE WORK) IN A MANNER CONTEMPLATED BY USER; USER UNDERSTANDS AND AGREES THAT NEITHER CCC NOR THE RIGHTSHOLDER MAY HAVE SUCH ADDITIONAL RIGHTS TO GRANT.

(b) USER ACKNOWLEDGES THAT THE RIGHTS GRANTED HEREUNDER OR UNDER ANY ORDER CONFIRMATION DO NOT INCLUDE ANY MODEL, PROPERTY OR OTHER RELEASES WHICH MAY BE NECESSARY FOR CERTAIN USES OF WORKS CONSISTING OF OR CONTAINING PHOTOGRAPHS, OTHER STILL IMAGES OR AUDIOVISUAL CONTENT. USER ACKNOWLEDGES THAT ADDITIONAL RIGHTS OR RELEASES MAY BE NECESSARY FOR CERTAIN USES OF MATERIALS ACKNOWLEDGES THAT ADDITIONAL RIGHTS OR RELEASES MAY BE NECESSARY FOR CERTAIN USES OF MATERIALS
WHICH INCLUDE DEPICTIONS OF PERSONS, PROPERTY OR TRADEMARKS AND THAT USER (AND NOT CCC OR ANY RIGHTSHOLDER) IS SOLELY RESPONSIBLE FOR OBTAINING ANY SUCH REQUIRED RIGHT OR RELEASE.

7. Effect of Breach.

Any failure by User to pay any amount when due, or any use by User of a Work beyond the scope of the license set forth 
in the Order Confirmation and/or these terms and conditions, shall be a material breach of the license created by the Order Confirmation and these terms and conditions. Any breach not cured within 30 days of written notice thereof shall result in immediate termination of such license without further notice. Any unauthorized (but licensable) use of a Work that is terminated immediately upon notice thereof may be liquidated by payment of the Rightsholder's ordinary license price therefor; any unauthorized (and unlicensable) use that is not terminated immediately for any reason (including, for example, because materials containing the Work cannot reasonably be recalled) will be subject to all remedies available at law or in equity, but in no event to a payment of less than three times the Rightsholder's ordinary license price for the most closely analogous licensable use plus Rightsholder's and/or CCC's costs and expenses incurred in collecting such payment.

8. Miscellaneous.

8.1: Changes to Service. User acknowledges that CCC may, from time to time, make changes or additions to the Service or to these terms and conditions, and CCC reserves the right to send notice to the User by electronic mail or otherwise for the purposes of notifying User of such changes or additions; provided that any such changes or additions shall not apply to permissions already secured and paid for.

8.2: Privacy Policy. Use of User-related information collected through the Service is governed by CCC's privacy policy, available online here : http://www.copyright.com/content/cc3/en/tools/footer/privacypolicy.html

8.3: License is Non-Transferable. The licensing transaction described in the Order Confirmation is personal to User. Therefore, User may not assign or transfer to any other person (whether a natural person or an organization of any kind) the license created by the Order Confirmation and these terms and conditions or any rights granted hereunder; provided, however, that User may assign such license in its entirety on written notice to CCC in the event of a transfer of all or substantially all of User's rights in the new material which includes the Work(s) licensed under this Service.

8.4: Amendment or Waiver, Objection to Contrary Terms. No amendment or waiver of any terms is binding unless set forth in writing and signed by the parties. The Rightsholder and CCC hereby object to any terms contained in any writing prepared by the User or its principals, employees, agents or affiliates and purporting to govern or otherwise relate to the licensing transaction described in the Order Confirmation, which terms are in any way inconsistent with any terms set
forth in the Order Confirmation and/or in these terms and conditions or CCC's standard operating procedures, whether forth in the Order Confirmation and/or in these terms and conditions or CCC's standard operating procedures, whether
such writing is prepared prior to, simultaneously with or subsequent to the Order Confirmation, and whether such writing appears on a copy of the Order Confirmation or in a separate instrument.

8.5: Governing Law and Jurisdiction. The licensing transaction described in the Order Confirmation document shall be governed by and construed under the law of the State of New York, USA, without regard to the principles thereof of conflicts of law. Any case, controversy, suit, action, or proceeding arising out of, in connection with, or related to such licensing transaction shall be brought, at CCC's sole discretion, in any federal or state court located in the County of New York, State of New York, USA, or in any federal or state court whose geographical jurisdiction covers the location of the Rightsholder set forth in the Order Confirmation. The parties expressly submit to the personal jurisdiction and venue of each such federal or state court.

If you have any comments or questions about the Service or Copyright Clearance Center, please contact us at 978-750-8400 or send an e-mail to info@copyright.com 